\title{
Extracellular Vesicles in Organ Fibrosis: Mechanisms, Therapies, and Diagnostics
}

\author{
David R. Brigstock ${ }^{1,2}$ (D) \\ 1 Center for Clinical and Translational Research, The Research Institute at Nationwide Children's Hospital, \\ Columbus, OH 43205, USA; David.Brigstock@NationwideChildrens.org \\ 2 Department of Surgery, Division of Pediatric Surgery, The Ohio State University Wexner Medical Center, \\ Columbus, OH 43212, USA
}

\begin{abstract}
Fibrosis is the unrelenting deposition of excessively large amounts of insoluble interstitial collagen due to profound matrigenic activities of wound-associated myofibroblasts during chronic injury in diverse tissues and organs. It is a highly debilitating pathology that affects millions of people globally and leads to decreased function of vital organs and increased risk of cancer and endstage organ disease. Extracellular vesicles (EVs) produced within the chronic wound environment have emerged as important vehicles for conveying pro-fibrotic signals between many of the cell types involved in driving the fibrotic response. On the other hand, EVs from sources such as stem cells, uninjured parenchymal cells, and circulation have in vitro and in vivo anti-fibrotic activities that have provided novel and much-needed therapeutic options. Finally, EVs in body fluids of fibrotic individuals contain cargo components that may have utility as fibrosis biomarkers, which could circumvent current obstacles to fibrosis measurement in the clinic, allowing fibrosis stage, progression, or regression to be determined in a manner that is accurate, safe, minimally-invasive, and conducive to repetitive testing. This review highlights the rapid and recent progress in our understanding of EV-mediated fibrotic pathogenesis, anti-fibrotic therapy, and fibrosis staging in the lung, kidney, heart, liver, pancreas, and skin.
\end{abstract}

Extracellular Vesicles in Organ

Fibrosis: Mechanisms, Therapies, and Diagnostics. Cells 2021, 10, 1596. https://doi.org/10.3390/ cells10071596

Academic Editors: Maurizio Onisto and Valentina Masola

Received: 26 May 2021

Accepted: 21 June 2021

Published: 25 June 2021

Publisher's Note: MDPI stays neutral with regard to jurisdictional claims in published maps and institutional affiliations.

Keywords: fibrosis; fibrogenic; extracellular vesicle; exosome; myofibroblast; collagen; extracellular matrix

\section{Introduction}

Fibrosis is the production and deposition of excessively large amounts of collagenous scar material in the interstitial spaces. This process, which can occur in virtually every tissue or organ of the body, usually develops over a protracted time period (frequently measured in years) and is most often a response to chronic injury and is thus manifest as a highly exaggerated wound healing response. Pathways of fibrosis involve multiple cell types which communicate in an orchestrated fashion via intercellular signaling networks that involve numerous cell-associated, matricellular, or soluble signaling molecules. In recent years, a new mode of cell-cell communication has been identified that involves the delivery of molecular information in extracellular vesicles (EVs) and this is now considered to be a significant signaling mechanism by which many homeostatic and pathological processes are regulated. Emerging evidence shows that specific populations of EVs are stimulatory for fibrosis or may possess intrinsic or engineered anti-fibrotic properties; these aspects of EV biology are the subject of this review.

\section{Fibrosis}

Fibrosis is a common feature of many varied chronic organ diseases in which it causes impairment of cell-cell communication, aberrant tissue remodeling, alterations in blood flow, reduced tissue or organ function, and increases the probability that more severe conditions such as end-stage organ disease or cancer will develop [1-3]. Fibrosis is the 
cause of considerable morbidity and mortality and has been estimated to contribute to $45 \%$ of all deaths in the USA [2,3]. While the etiology of fibrosis is multi-factorial and varies widely by organ, the molecular mechanisms that drive fibrosis often have many aspects in common [1-3]. The first event in the process is a typical wound healing response in which cell damage or death triggers a local inflammatory response, activation of tissue macrophages, and infiltration of immune cells from the circulation (Figure 1) [4]. In turn, cytokines and chemokines released by these cells are cues for the production of extracellular matrix (ECM) molecules by mesenchymal cells or myofibroblastic cells, the latter of which may be ordinarily resident in the tissue or arise by phenotypic transition from other cell types such as fibroblasts, epithelial cells, or endothelial cells [3]. This transition involves a process termed activation in which the cells become contractile, proliferative, migratory, and matrigenic and characteristically express high levels of alpha smooth muscle actin ( $\alpha \mathrm{SMA})$, growth factors, integrins, chemokines, cytokines, and ECM components such as collagens (Figure 1). In acute injury, activation is relatively short-lived and the myofibroblastic cell population wanes as a provisional ECM is established for parenchymal repopulation and growth. In contrast, in chronic injury the population of activated cells persists unabated, resulting in an unrelenting production of insoluble collagens and other ECM molecules that become deposited in the intercellular spaces at high concentrations and over time are manifested as fibrotic scar (Figure 1) [1-3]. Many pro-fibrotic changes are driven by similar molecular pathways including activation of transforming growth factor beta (TGF- $\beta$ ) (and its small mothers against decapentaplegic (Smad) regulatory axis) [5-14], reactivation of developmental pathways such as wingless/integrated (Wnt), Notch, and Hedgehog (Hh) [15-22], and production of a similar slate of chemokines and growth factors [23]. Collectively, these signaling events conspire to drive fibroblast/myofibroblast differentiation and production of ECM molecules. As fibrosis progresses, it impedes normal cellular functions and may accelerate the underlying disease by exacerbating other pathological responses in the affected organ. Emerging evidence from in vitro studies, animal models, and some clinical studies have revealed that fibrosis is amenable to therapy, either by targeting the underlying disease or by targeting downstream pathways that drive fibrosis $[24,25]$. Importantly, the elucidation of fibrogenic mechanisms at the molecular level has resulted in the identification of many rational therapeutic targets [24-26]. 


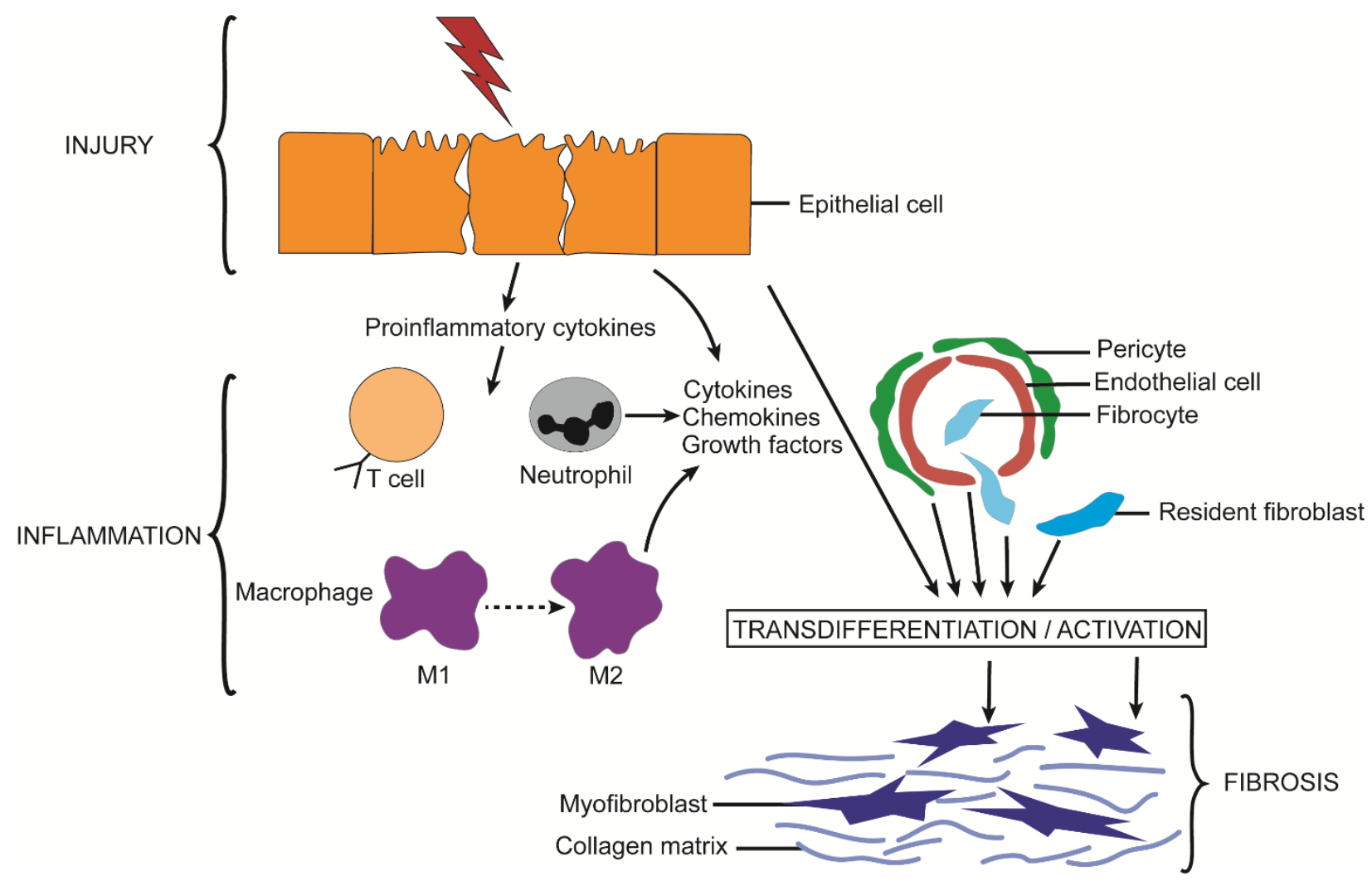

Figure 1. Principal cellular events leading to fibrosis. Injury to epithelial cells results in their release of pro-inflammatory cytokines, which is a stimulus for infiltration of macrophages and immune cells to the injury site. This results in an inflammatory environment in which cytokines, chemokines, and growth factors are produced that drive the production and action of contractile $\alpha$ SMA-producing myofibroblasts. Myofibroblasts arise by activation of resident fibroblasts or circulating fibrocytes or are the result of transdifferentiation from other cell types such as epithelial cells, endothelial cells, or pericytes. In acute injury, myofibroblasts transiently produce ECM components such as collagen, laminin, and FN which are necessary for normal wound healing, and parenchymal repopulation. During persistent or recurrent episodic injury, the inflammatory phase is protracted leading to unrelenting myofibroblastic activity, which is manifested as excessive production of ECM components that are deposited in the interstitial space as scar material, or fibrosis.

\section{Extracellular Vesicles}

\subsection{EV Definition}

EVs are a heterogenous group of microscopic $(<4-5 \mu \mathrm{m}$ diameter $)$ membrane-limited sacs that are released by many cell types and are found in interstitial spaces and body fluids. EVs are classified according to their mechanisms of biogenesis and currently comprise exosomes, microvesicles (microparticles), and apoptotic bodies. Exosome biogenesis is initiated by involution and fission of the endosomal membrane resulting in the production of intraluminal vesicles (ILV) within multivesicular bodies (MVBs), the latter of which then traverse to and fuse with the cell surface causing their internal vesicles to be released extracellularly as exosomes (Figure 2). Microvesicles are formed when the plasma membrane is "pinched off" by budding and fission and the resultant vesicles are shed extracellularly (Figure 2). Apoptotic bodies are also formed by outward budding of the plasma membrane, but the process is induced by self-destructive actions of the cytoskeleton during cell apoptosis (Figure 2). Apoptotic bodies, which are generally larger $(1-5 \mu \mathrm{m})$ than other EVs, contain debris from dying cells and undergo phagocytosis by macrophages. In contrast, exosomes and microvesicles are smaller in size (50-100 nm and 50-1000 nm respectively) and carry a complex molecular cargo comprising proteins, mRNA, microRNA (miR), lipids, and metabolites, some or all of which can be delivered to other cells which may respond to 
some of the molecular information received. Since apoptotic bodies are not discussed in this review, the term " $\mathrm{EV}$ " is used herein to describe exosomes or microvesicles.

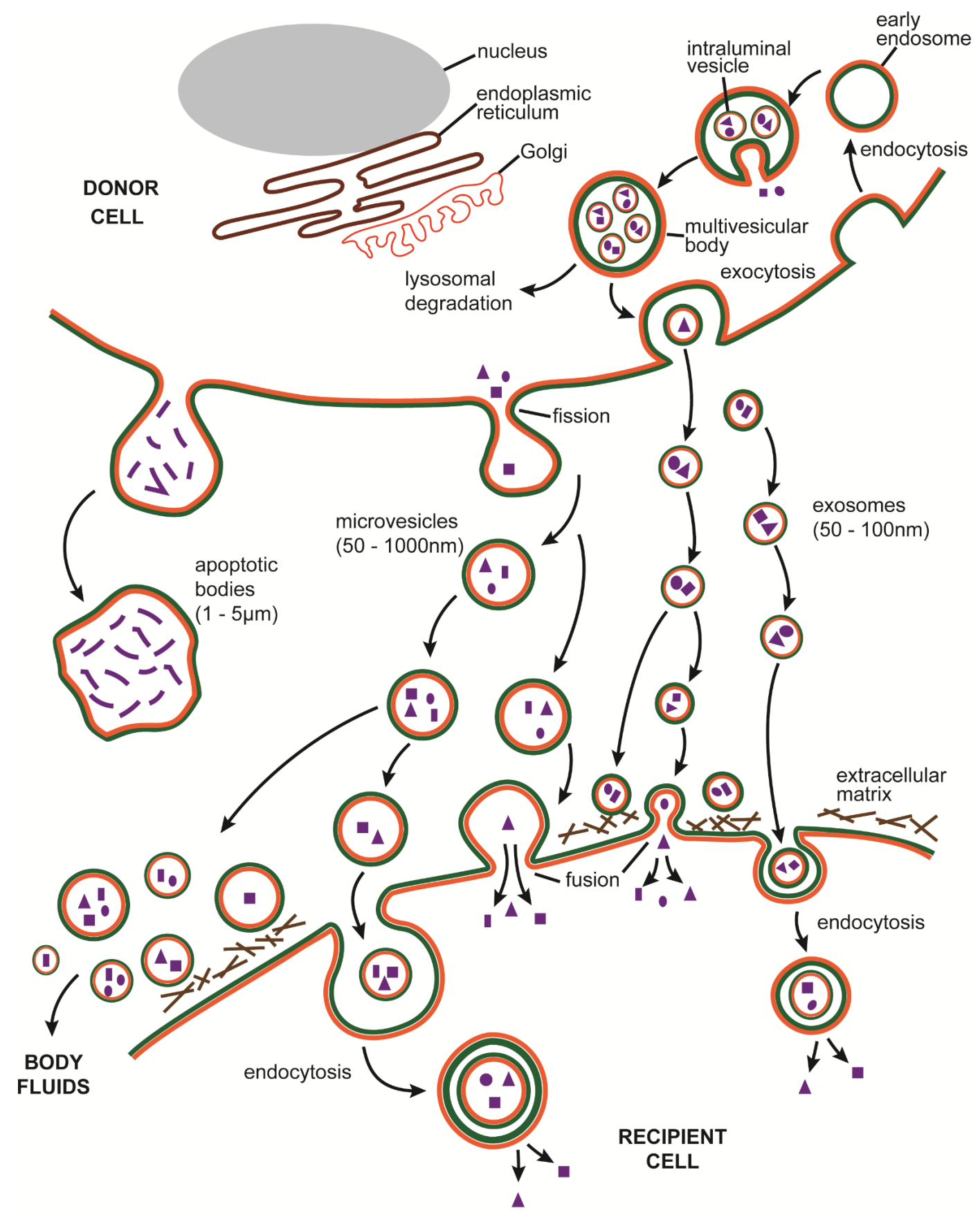

Figure 2. Pathways of EV biogenesis and action. Three type of EVs are produced by most cells. Exosome biogenesis is initiated by the involution and pinching off of the endosomal membrane resulting in the production of an ILV that contains cytoplasmic constituents. As ILVs accumulate, MVBs are generated, which are then either degraded via the lysosomal pathway or trafficked to the cell surface whereupon they fuse with plasma membrane and liberate their contents, now becoming exosomes, into the extracellular space. Mircovesicles also contain similar cytoplasmic constituents but are generated by fission of the plasma membrane. Apoptotic bodies contain components of cell degradation and form by cytoplasmic bulging and separation from the cell as a result of cytosketetal breakdown during cell disassembly. Microvesicles and exosomes may bind to ECM components in the interstitial space or may be internalized by target cells, either by fusion with the plasma membrane or by endocytosis, both of which result in delivery of their respective molecular payloads into the recipient cell. Once released into the extracellular space, EVs may alternatively be carried in interstitial fluids into the main body fluids allowing them to target cells at distant sites or to be cleared. 


\subsection{EV Biogenesis}

Exosomes are, in part, generated by a pathway that is dependent on endosomal sorting complex required for transport (ESCRT) machinery. This involves the coordinated assimilation of ESCRT-0, -I, -II, and -III complexes from many individual proteins and these complexes then interact with accessory proteins to cause invagination and scission of endosomal membranes resulting in formation of MVBs [27-30]. The involvement of ESCRT proteins may result in them becoming actual exosome constituents and this is used experimentally (e.g., by Western blot) to invoke the involvement of the ESCRT pathway in their formation and hence their identity as exosomes: such proteins include tumor susceptibility gene 101 (TSG101), which is a component of ESCRT-1 or apoptosis-linked gene-2 interacting protein X, which is an ESCRT accessory protein [31]. An ESCRT-independent means of exosome production also exists, which involves uptake of ceramide into the endosomal membrane thereby increasing the lipid raft content and promoting inward membrane budding [28-30,32]. This process is dependent on neutral sphingomyelinase 2 (nSmase2), which catalyzes the production of ceramide from sphingomyelin and which can be blocked using nSMase2 inhibitors such as GW4869 or small interfering RNA [33-38]. Exosome biogenesis is also regulated by tetrapanins (e.g., CD9, CD63, CD81), which are involved in cargo selection and exosome release as well as by small Rab guanosine triphosphate hydrolases (GTPases), which control endosomal trafficking, fusion with the plasma membrane, and release from the cell [28-30,39,40]; tetraspanins and Rabs are often present in exosomes and are frequently used for EV characterization [31]. Importantly, ESCRT components and tetraspanins are also involved in the production of microvesicles even though the biogenic mechanism is quite distinct. Micovesicles are formed as a result of numerous changes in membrane protein composition and lipid reorganization, as well as the activation of flippases, floppases, scramblases, and cytoskeleton regulators (Rho GTPases, Rho-associated protein kinase (ROCK), ADPribosylation factor 1 and 6 (ARF1, ARF 6)) [30,41-45]. This results in membrane instability and bending, with microvesicles then being liberated from the cell surface by fission.

Discrimination between exosomes and microvesicles is experimentally challenging because they have overlapping sizes and discernment of the biogenic pathways involved is very difficult, especially after they have left their cells of origin. However, whereas certain proteins are common to all EVs (e.g., actin, ezrin, moesin, heat shock protein (HSP)-70, flotillin-1, MHC I and II), the presence or absence of specific tetraspanins (CD9, CD63, CD81), especially in combination with proteins associated with ILV/MVB (TSG101, syntenin-1) or plasma membranes, can help to discriminate exosomes from microvesicles $[31,46,47]$. Nonetheless, biological samples invariably contain a mixture of such EVs and unless extremely rigorous steps are adopted, the precise EV subpopulations in a given sample are extremely challenging to definitively ascertain.

\subsection{EVs in the Biology of Fibrosis}

Following their release from producer cells, EVs may influence the behavior and function of the same or other cells in the local vicinity. For example, EVs may either function as dynamic structural and functional components of the ECM and contextually regulate ECM structure, signaling, and cell behavior [48] or may fuse with or be endocytosed by target cells, which may then respond according to the molecular information received in the EV payload (Figure 2). EVs from disease sites often contain altered cargo components as compared to their heathy counterparts and these can elicit disease-related or pro-pathogenic responses in target cells; fibrosis is an example of a pathological process that is driven directly or indirectly by altered populations of EVs that are produced by damaged, invading, or activated cells during chronic injury. On the other hand, it has been possible to capitalize on the intrinsic cellular homing and reprogramming functions of EVs, coupled with the fact that they are immunologically inert, to develop EV-based therapeutics for a wide range of pathophysiological conditions, including fibrosis for which therapeutic options are very limited. EVs may be particularly suited to fibrosis therapy 
because their aquaporin-1-regulated hydration confers unique structural flexibility for potential penetration of fibrotic scar [49].

EVs are present in numerous body fluids (e.g., saliva, sputum, serum, plasma, uterine secretions, urine, bronchoalveolar lavage fluid (BALF)), which may either result in their removal from the body or allow them to exert their biological effects at locations distant from their site of production (Figure 2). EVs can be readily harvested from body fluids and in light of their diverse molecular cargo, they are a valuable component of "liquid biopsies" whereby quantitative or qualitative features of their constituent EV payloads may be used to aid disease diagnosis or prognosis and thus facilitate decisions regarding patient management and treatment [50]. In most chronic diseases, the severity of organ fibrosis is an important prognostic indicator, but it often can only be directly measured by biopsy which is invasive, risky, and not conducive to the multiple sequential determinations needed to establish fibrosis progression or regression. Harnessing the molecular information from EVs in body fluids is a non- or minimally-invasive option that favors repetitive sampling and builds upon a broad platform of potential biomarkers for assessment of fibrosis severity during disease advancement or treatment.

\section{Pulmonary Fibrosis}

\subsection{Causes and Pathological Features of Pulmonary Fibrosis}

In pulmonary fibrosis, lung parenchyma becomes replaced with scar resulting in hampered alveolar function, compromised gas exchange and decreased compliance resulting in hypoxia, shortness of breath, cough, wheezing, and fatigue [51,52]. Pulmonary fibrosis is caused by infections (e.g., tuberculosis), inhalation of particulates, scleroderma, or radiation therapy or may be idiopathic with unknown etiology. Idiopathic pulmonary fibrosis (IPF) is a chronic progressive inflammatory interstitial lung disease in which pulmonary function becomes irreversibly lost due to deposition of scar and thickening of the pleural lining, eventually leading to death [51-54]. One of the earliest events in IPF is reprograming or dysfunctioning of alveolar epithelial cells due to mutations, environmental factors, aging, senescence, death, depletion, or expression of genes that predispose to develop fibrosis. This is followed by inflammatory cell activation and infiltration and the local production of chemokines and cytokines (e.g., TGF- $\beta$ ) that drive epithelial-to mesenchymal transition (EMT), fibroblast differentiation and fibrocyte recruitment. This process culminates in the production and deposition of excess ECM proteins, increased matrix stiffness, and epigenetic reprogramming that drives profibrotic changes in fibroblasts and epithelial cells [55]. The anti-fibrotic drugs nintedanib and pirfenidone are indicated for slowing fibrosis progression in IPF but neither drug is curative and they are often used palliatively while awaiting lung transplantation [56].

Chronic occupational exposure of the lung to airborne particulates can cause severe inflammation and fibrosis resulting in shortness of breath, cough, fatigue, chest tightness, and cyanosis. For example, silicosis is caused by inhalation of crystalline silica particles which become deposited in the alveoli and surrounded by collagen resulting in diffuse nodular fibrosis [57,58]. In asbestosis, inhaled asbestos fibers become embedded deep in the lungs and trigger inflammation and interstitial fibrosis around the alveoli, restricting elasticity and gas exchange and predisposing to develop mesothelioma and lung cancer [58,59]. In these examples, macrophages are recruited to remove particulates or damaged airway epithelial cells but the ensuing inflammatory response is a trigger for fibrosis [58]. Exposure to cigarette smoke or other airborne pollutants can cause chronic obstructive pulmonary disease (COPD) which is typified by chronic bronchitis and/or emphysema and involves ECM remodeling due to altered interactions between polymorphonuclear leukocyte i.e., neutrophil (PMN)-secreted proteases and the antiprotease barrier [60,61]. PMN involvement is also a hallmark of bronchopulmonary dysplasia (BPD), which occurs in low birth weight premature infants receiving prolonged supplemental oxygen to treat respiratory distress syndrome [62,63]. Pathological features of BPD include necrotizing bronchiolitis, alveolar 
septal injury, inflammation, and fibrosis, although the necrotic and fibrotic components are usually avoided with surfactant therapy and high frequency ventilation [63].

The best characterized murine model of pulmonary fibrosis involves administration of the antibiotic bleomycin and this has been employed in most EV studies to date. Other pulmonary fibrosis models are based on administration of particulates or irradiation. In each case, there are certain clinical correlates, with the extent and timing of fibrosis being variable and influenced by the strain and species used [64,65].

\subsection{Mechanistic Aspects of EVs in Pulmonary Fibrosis}

4.2.1. Production and Action of EVs from Lung Tissues or Pulmonary Fibroblasts

BALF from mice with bleomycin-induced pulmonary fibrosis or from IPF patients contained up to three times more EVs than BALF from controls [66]. EVs from both sources as well as EVs from human fibrotic lung explants or human lung fibroblasts contained increased levels of Wnt5A, a $\beta$-catenin-independent protein that was enhanced in EVs by TGF- $\beta$ treatment of the EV producer fibroblasts. EVs from lung fibroblasts or BALF from IPF patients stimulated proliferation of fibroblasts in vitro and this was mediated at least partly by EV Wnt5A [66]. BALF-derived EVs from mouse bleomycin pulmonary fibrosis contained reduced concentrations of let- $7 \mathrm{~d}$ and this was associated with stimulation of pericyte transdifferentiation and fibrogenesis via enhanced action of its direct TGF- $\beta$ receptor 1 (TGF- $\beta$ R1) target and downstream FoxM1/Smad/- $\beta$-catenin signaling [67]. Further, EVs from fibrotic mouse or human lungs exacerbated experimental lung fibrosis in mice and caused transcriptomic changes or signaling in lung epithelial cells in vitro that were associated with fibroproliferation and fibrogenesis (e.g., TGF- $\beta$, Wnt/catenin etc.) [68]. Syndecan-1, which is required for fibroproliferative gene expression in alveolar type II cells, reduced levels of EV miRs that target components of TGF- $\beta$ or Wnt/catenin signaling, thereby driving lung fibrosis in vivo [68]. In addition, EVs were proposed as a component of the senescent-associated secretory phenotype of senescent pulmonary cells that occurs in aging and heightens the chance of developing chronic lung diseases such as IPF and COPD [69]. Epithelial cell mitochondrial damage and senescence in lung epithelial cells was stimulated by EVs from IPF lung fibroblasts and attributed to suppression of SIRnotch3 by EV miR-23b-3p and miR-494-3p, the levels of which were correlated with IPF disease severity [70]. Finally, EVs from TGF- $\beta$-stimulated MRC5 human lung fibroblasts contained enhanced levels of programmed death-ligand 1 (PD-L1) that contributed to the ability of the EVs to decrease T cell proliferation and increase MRC5 cell migration and which suggest a role for EV immune checkpoint proteins in pulmonary immunosuppression and fibrosis [71].

\subsubsection{Production and Action of EVs from Lung Epithelial Cells or Macrophages}

Exosomes from cultured M2 macrophages or macrophages from rat bleomycin pulmonary fibrosis caused increased proliferation and expression of collagen $1 A / 3 A$ or $\alpha S M A$ in cultured pulmonary interstitial fibroblasts and this was attributed to targeting of FAM13A by miR-328 [72]. In bleomycin pulmonary fibrosis, collagen 1 and $\alpha S M A$ levels were attenuated by administration of either miR-328-depleted M2 macrophages or their exosomes [72]. Lipopolysaccharide (LPS)-induced acute lung injury in mice resulted in the presence of macrophage-derived exosomes in BALF that were enriched in pro-inflammatory tumor necrosis factor- $\alpha$ (TNF- $\alpha$ ), which was proposed to activate neutrophils from which 1L10-enriched exosomes were then released causing polarization of macrophages to the M2 phenotype and downstream fibrotic sequala [73]. The proteomic content of exosomes from lung epithelial or macrophage cell lines was qualitatively and quantitatively changed when the cells were exposed to asbestos and these exosomes caused expression of mesenchymeand cancer-related genes in mesothelial cells, which were consistent with a transition to a mesothelioma-related phenotype [74,75]. Exosomes from silica-exposed RAW264.7 macrophages stimulated $\alpha$ SMA production in fibroblasts and contained differentially expressed miRs that had predicted effects on cell differentiation, proliferation, and collagen 
production, and which targeted the TGF- $\beta$ pathway [76]. MiR-125a-5p was one such component since it was up-regulated in EVs from silica-treated macrophages and it induced TGF- $\beta$-mediated fibroblast transdifferentiation by downregulating Smurf1. Levels of serum exosomal miR-125a-5p were higher in patients with silicosis as compared to healthy controls [76]. Bleomycin-induced pulmonary fibrosis was associated with increased serum levels of exosomal miR-22 and fibrotic pathology was ameliorated with a miR-22 mimic due to its ability to inhibit TGF- $\beta 1$-induced expression of $\alpha S M A$ or profibrotic cell communication network factor 2 (CCN2; also known as connective tissue growth factor) in lung fibroblasts in vitro [77].

\subsubsection{Production and Action of EVs from Endothelial Cells}

Exosomes from pulmonary microvascular endothelial cells contained miR-107, which inhibited hypoxia inducible factor- $1 \alpha(H I F-1 \alpha)$ in pericytes, resulting in suppression of a Notch1/PDGFR $\beta$ /yes associated protein 1 (YAP1)/Twist1 axis and downstream inhibition of $\alpha S M A$ and collagen 1 $\alpha 1$ expression [78]. During pulmonary fibrosis, endothelial cell EV miR-107 levels were downregulated, resulting in enhanced HIF-1 $\alpha$ expression and stimulation of pericyte transdifferentiation and fibrogenesis [78].

Some of the pathways of EV-regulated pulmonary fibrosis discussed above are shown in Figure 3.

\subsection{Therapeutic Actions of EVs in Pulmonary Fibrosis \\ 4.3.1. EVs from Adult Stem Cells}

Exosomes from human bone marrow mesenchymal stem cells (BM-MSC) prevented or reversed bleomycin-induced pulmonary fibrosis in mice by improving pulmonary morphology and decreasing collagen deposition [79]. Therapy was associated with a switch from pro-inflammatory lung monocytes and macrophages to homeostatic populations (e.g., non-classical monocytes) present in control animals. Concomitant changes occurred in the bone marrow myeloid cell population that were consistent with proteomic changes induced by exosome treatment of monocytes in vitro and, further, i.v. administration of bone-marrow-derived monocytes that had been pre-treated with BM-MSC exosomes in vitro prevented bleomycin pulmonary fibrosis [79]. Administration of EVs from BMMSC or umbilical cord Wharton's jelly MSC (WJ-MSC) to a mouse BPD model normalized the expression of hyperoxia-sensitive genes involved in immunity and inflammation and suppressed proinflammatory M1 macrophages while enhancing anti-inflammatory M2 macrophages [80]. This was accompanied by EV-mediated improvement of lung architecture and function, reduced pulmonary inflammation and fibrosis, and rescue of peripheral vascular deficits [80] as well as reversal of long-term pulmonary complications (e.g., pulmonary hypertension, exercise capacity etc.) [81]. EVs from WJ-MSC were also protective in a rat model of monocrotaline-induced pulmonary hypertension, resulting in restored cardiac function and attenuation of pulmonary fibrosis and vascular remodelling, the latter being attributed to EV-regulated Wnt5a/bone morphogenic protein (BMP) signaling in vascular smooth muscle cells and endothelial cells [82].

In vitro, activation of LL29 pulmonary fibroblasts was suppressed by BM-MSC EVs and this was due to targeting of frizzled class receptor 6 (FZD6) by EV miR-29b-3p, which was also shown to be required for the inhibition by BM-MSC EVs of bleomycin-induced pulmonary fibrosis in mice [83]. Exposure of LPS-treated MLE-12 type II alveolar epithelial cells to BM-MSC exosomes resulted in inactivation of the nuclear factor kappa-light-chainenhancer of activated B cells (NF- $\mathrm{KB}$ ) pathway, reversal of EMT due to targeting of $I k b k b$ by exosomal miR-182-5b, and ubiquitinylation of Ikbkb due to targeting of Usp 5 by exosomal miR-23a-3p [84]. In a mouse model of silicosis, lung dysfunction and fibrosis were reduced by exosomes from human umbilical cord MSC (UMSC), which were also effective in decreasing collagen deposition in silica-exposed fibroblasts in vitro [85]. In radiationinduced lung injury in mice, the senescence-associated secretory phenotype, endothelial damage, inflammation, and fibrosis were reduced by placenta-derived MSC EVs, with 
therapy being attributed partly to EV miR-214-3p, which targeted ataxia telangiectasia mutated (ATM) to reduce ATM/P53/P21 signaling and DNA damage [86].

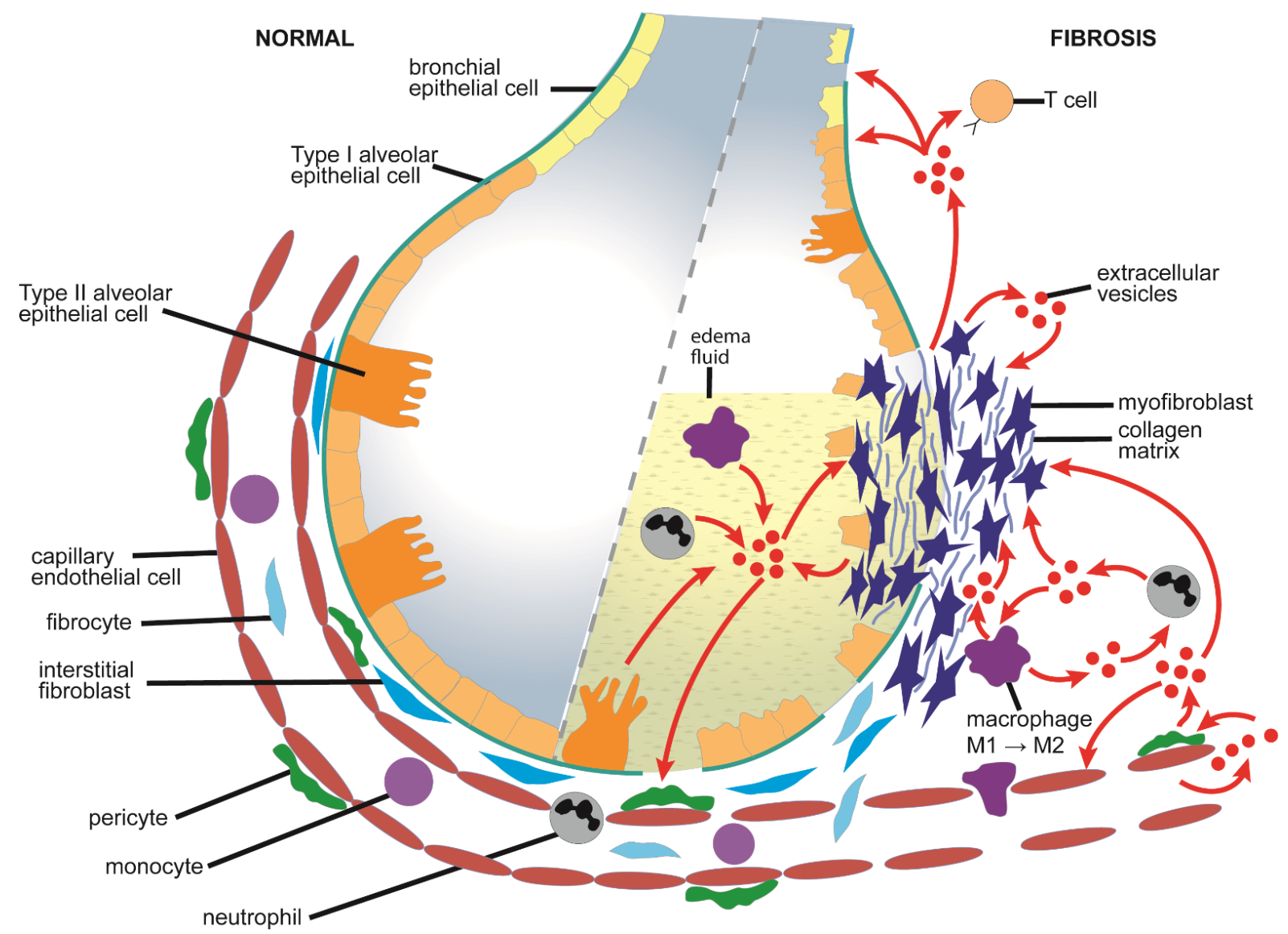

Figure 3. Proposed EV pathways in the pathogenesis of pulmonary fibrosis. Prolonged alveolar injury results in the production and interstitial deposition of type I collagen by $\alpha$ SMA-positive myofibroblasts and the resulting increased edema and expansion of fibrotic ECM impinges on alveolar air space, structure and function, severely limiting gaseous exchange and decreasing lung performance. Myofibroblast expansion is the result of transdifferentiation/activation of resident interstitial fibroblasts, bone marrow-derived fibrocytes, endothelial cells, epithelial cells, or pericytes. Altered EV components such as Wnt5a and let-7d from these cell types are proposed to promote the transition into myofibroblasts and/or to enhance activation and fibrogenesis in the accumulating myofibroblast population through the regulation of TGF- $\beta$, Smad and $\beta$-catenin pathways, while increased EV PD-L1 dampens T cell responses and promotes fibroblast migration. Further, miR-23b-3p and miR-494-3p in EVs from activated fibroblasts suppress notch signaling and drives cell senescence in epithelial cells. EVs from infiltrating or activated M2 macrophages contain altered levels of miRs-328 and $-125 a-5 p$ which drive fibroblast transdifferentiation and collagen production in fibroblasts, and this process is exacerbated by the effect of 1L-10-enriched EVs from TNF- $\alpha$-primed neutrophils. Pro-fibrogenic EVs in BALF originate from damaged, infiltrating, and activated cells in lung tissue and edema fluid but in most studies the precise cellular sources of BALF EVs have not been definitively determined. Transdifferentiation of pericytes is triggered as a response to EVs from BALF or capillary endothelial cells which contain, respectively, suppressed let-7d or miR-107. Only cells with a demonstrated role in EV production or response are shown; some of the depicted EV pathways are surmised from in vitro observations and have not been demonstrated in vivo. See text for details.

In a rat model of lung injury and fibrosis caused by intratracheal instillation of $\leq 2 \mu \mathrm{m}$ particulates, administration of adipose-derived MSC (AD-MSC) EVs resulted in restoration of lung architecture, reduced apoptosis and necrosis in type II alveolar cells, and suppression of reactive oxygen species (ROS), inflammation and fibrosis, the latter of which was associated with targeting of TGF- $\beta R 1$ by EV let-7d-5p [87]. 
Amnion epithelial cells (AECs) have a high capability for multipotent differentiation and can be induced to exhibit lung lineage-specific markers and to develop into differentiated lung cells such as type II alveolar pneumocytes. In models of ovalbumin/napthaleneinduced allergic airways disease or bleomycin-induced pulmonary fibrosis, intranasal administration of AEC exosomes resulted in reduced inflammation, epithelial damage, ECM, myofibroblast frequency, collagen content, fibrosis, and/or TGF- $\beta$ expression $[88,89]$. These outcomes were associated with normalized airway reactivity and dynamic lung compliance and were augmented by co-administration of serelaxin (recombinant human relaxin-2) [88]. AEC exosomes contained proteins related to apoptosis, development, mitogen-activated protein kinase (MAPK), inflammation, and growth factor signaling and miRs predicted to impact pathways of fibrosis, cancer and stem cell pluripotency [89]. In vitro, AEC exosomes lowered neutrophil survival and myeloperoxidase activity, suppressed $\mathrm{T}$ cell proliferation and stimulated macrophage phagocytosis and their anti-inflammatory M2 phenotype [89].

Cultured lung tissue gives rise to self-aggregating three-dimensional spheroids comprising progenitor cells and supporting stromal cells. In rodent models of silica- or bleomycin-induced pulmonary fibrosis, administration of a nebulized lung spheroid cell secretome or its constituent exosomes decreased alveolar epithelial damage, reduced collagen deposition, decreased vascular injury, and improved pulmonary function, with miR-30a and the let-7 and mirR-99 families being implicated in the therapeutic effects [90].

Administration of EVs from menstrual blood-derived stems cells MenSC to mouse bleomycin pulmonary fibrosis models resulted in reduced alveolar epithelial cell injury, reduced pulmonary fibrosis, and restoration of hyroxyproline, malondialdehye, and glutathione peroxidase to baseline values [91]. The therapeutic activity was associated with EV-mediated delivery into alveolar epithelial cells of let-7, which suppressed production of lectin-like oxidized low-density lipoprotein scavenger receptor-1 (LOX1) and downstream NLR family pyrin domain containing 3 (NLRP3)-mediated apoptosis [91].

\subsubsection{EVs from Lung Fibroblasts or Macrophages}

EVs produced by lung fibroblasts from IPF patients induced senescence in lung epithelial cells via EV-stimulated mitochondrial ROS and DNA damage response activation, and these effects were due to the targeting of surtuin-3 (SIRT-3) by elevated EV levels of miR$23 b-3 p$ and miR-494-3p [70]. Expression of TGF- $\beta R 1$ and fibrotic genes in alveolar epithelial cells or lung fibroblasts was suppressed by miR-142-3p in EVs from THP1 macrophages, supporting a potential anti-fibrotic role for this miR, which was enriched in in EVs from IPF sputum macrophages [92].

\subsubsection{EVs from Serum}

Acute respiratory distress syndrome (ARDS) is characterized by rapid-onset pulmonary inflammation and edema that results in death of 33\% of affected individuals and a high incidence of interstitial and alveolar fibrosis in survivors. Exosomes from the serum of patients with ARDS contained reduced levels of miR-425, which targets the lysine demethylase 6A-TGF- $\beta$-Smad axis in lung fibroblasts [93]. Suppression of miR-425 expression in lung fibroblasts led to their enhanced proliferation and production of collagens, suggesting that fibrotic pathways in ARDS are regulated by cellular or exosomal miR-425 [93]. EVs from serum of mice with bleomycin-induced pulmonary fibrosis contained increased levels of several miRs including miR-22 [77] and miR-16 [94]. Bleomycin-induced pulmonary fibrosis was attenuated by mimics of either miR-22 or miR-16 which, when tested on TGF$\beta$-treated lung fibroblasts in vitro, caused suppressed expression of, respectively, $\alpha S M A$ and CCN2 [77] or rapamycin-insensitive companion of mechanistic target of rapamycin (mTOR) (Rictor) and secreted protein acidic and rich in cysteine (Sparc) [94].

\subsection{EVs as Biomarkers for Pulmonary Fibrosis}

Serum EV miR-21-5p was significantly elevated in the acute inflammatory phase and chronic fibrotic phase in mouse bleomycin lung fibrosis and was correlated with decreased 
vital capacity and survival in IPF patients [95]. In IPF patients, sputum exosomal miR$142-3 p$ and miR-33a-5p were increased while let-7d-5p was decreased, with miR-142-3p and let-7d-5p being respectively, inversely or positively associated with severity of lung dysfunction [96]. Some differentially expressed sputum exosomal miRs were predicted to have targets related to inflammation, ECM/collagen production and EMT [96]. IPF disease severity was positively corelated with levels of EV miR-23b-3p and miR-494-3p from the patients' lung fibroblasts [70]. MiR-142-3p was significantly upregulated in EVs of IPF sputum and plasma and was strongly associated with macrophage frequency [92].

\section{Renal Fibrosis}

\subsection{Causes and Pathological Features of Renal Fibrosis}

Renal fibrosis is a hallmark of numerous chronic kidney diseases (CKD), which affect millions of people globally [97]. CKD patients have an irreversible deterioration of renal function, which results in end-stage renal failure for which the only treatments are kidney transplantation or hemodialysis. Glomerulosclerosis and tubulointerstitial fibrosis are triggered by sustained injury or stress to cells of the glomerulus or collecting tubule due to insults that are metabolic, immunological, toxic, or mechanical $[98,99]$. Scarring impedes the critical interactions between cells of the tubules, glomerulus, and capillaries resulting in compromised filtration and resorption, and a progressive loss of renal function [100-102]. The severity of renal fibrosis is highly correlated with progression of CKD and is a major contributor to CKD pathophysiology.

The most common cause of end-stage CKD is diabetic nephropathy ( $\mathrm{DN})$, a microvascular complication of diabetes mellitus involving hemodynamic changes and oxidative stress caused by hypergycemia [103]. This results in the production of ROS, cell damage, release of pro-inflammatory cytokines, recruitment of inflammatory cells, mesangial cell expansion, glomerulosclerosis, and fibrosis [104]. Glomerular injury is a hallmark of early $\mathrm{DN}$ and involves macrophage infiltration, thickening of basement membranes, mesangial expansion, and loss of glomerular cells leading to breakdown of the glomerular filtration barrier, which is manifested clinically as proteinuria. Tubular hypertrophy and interstitial inflammation occur in the early phases of $\mathrm{DN}$ and is followed by tubular atrophy and interstitial fibrosis as the disease progresses [105]. Progression of DN is slowed using medications to control hypergycemia or hypertension but there is an urgent need for therapies that act directly on renal fibrosis itself. CKD is also caused by acute kidney injury (AKI), such as that due to hypoxia or ischemia/reperfusion (I/R) [106]. AKI is associated with a high morbidity and mortality and involves sudden kidney damage that occurs over hours or days. While AKI is self-limiting in some individuals, there is no treatment and it is a major risk factor for CKD because the acute insult leaves the kidneys permanently injured or exacerbates chronic renal failure [107].

Several in vivo EV studies have utilized the unilateral ureteral obstruction (UUO) model in mice or rats, which reliably results in rapid and severe tubulo-interstitial renal fibrosis. Other EV investigations have been undertaken in injury or disease models in which renal fibrosis is a common pathological feature such as I/R, 5/6 nephrectomy, streptozotocin (stz)-induced diabetes mellitus, and aristolochic acid nephropathy (AAN) [100].

\subsection{Mechanistic Aspects of EVs in Renal Fibrosis}

\subsubsection{Production and Action of EVs from Epithelial Cells}

Renal fibrosis in vivo was shown to be EV-dependent by treating mice with the exosome inhibitors GW4869 or dimethyl amiloride (DMA) which resulted in decreased fibrosis and decreased expression of fibronectin (FN), $\alpha \mathrm{SMA}$, collagen I, and /or fibroblast-specific protein in I/R or UUO models $[108,109]$. EVs produced by the I/R kidney were enriched in miR-150, which was directly fibrogenic in its mimic form, while EVs from NRK-52E proximal tubular epithelial cells (TEC) were stimulatory or inhibitory for I/R kidney fibrosis when they were respectively, enriched or depleted of miR-150 [108]. In vitro, cellular and EV levels of miR-150 were enhanced in NRK-52E cells under hypoxic conditions and its 
EV-mediated delivery to NRK-49F fibroblasts resulted in their enhanced proliferation and suppressed apoptosis [108]. Similar pathways, in which TEC exposed to stress, injury, or pro-fibrogenic molecules (e.g., TGF- $\beta$ ) produce EVs that are functionally delivered to other TECs or fibroblasts, have been documented in several other studies. For example, EVs from TGF- $\beta$-stimulated NRK-52E cells stimulated mesenchymal transition in recipient TECs and this was mediated by EV miR-21, which targeted phosphatase and tensin homolog $(P T E N)$ and enhanced protein kinase B (AKT) signaling in the recipient cells [110]. EVs from high glucose treated mouse proximal TEC cells induced proliferation and production of $F N, \alpha S M A$, and collagen I in NRK-49F rat kidney interstitial fibroblasts [111]. Human proximal TEC exposed to high glucose became senescent and liberated miR-21-containing EVs that promoted subsequent EMT in the cells through its suppression of peroxisome proliferator-activated receptor $\alpha$ (PPAR $\alpha$ ) and enhanced HIF-1 signaling supporting a role for miR-21 in age-related fibrosis [112]. Exposure of TEC to hypoxia in vitro caused their exosome production to increase and these exosomes (unlike their normoxic counterparts) promoted proliferation and enhanced levels of TGF- $\beta 1, \alpha S M A, F$-actin, and collagen $\alpha 1$ in renal tubulointerstitial fibroblasts [113]. The activation-inducing property was dependent on exosomal TGF- $\beta$ mRNA, the level of which was also elevated in exosomes produced during hypoxic fibrosis in the UUO model in mice [113]. Similar data were reported in the UUO model, while renal exosome production in vivo was enhanced after I/R injury or 5/6 nephrectomy [109]. Expression of sonic hedgehog (Shh) was associated with exosome production in vivo and was also required for exosome production by TGF- $\beta$-treated HKC-9 kidney proximal TEC in vitro. Moreover, exosomes from TGF- $\beta$-treated HKC-9 cells activated fibroblasts in vitro and exacerbated kidney injury and fibrosis in vivo, the latter of which was Shh-dependent [109]. Further, cellular export by TEC of transglutaminase 2 (which stimulates ECM cross-linking and functions during fibrosis progression) occurred through its incorporation into TEC EVs, production of which was stimulated by TGF- $\beta$ [114]. Upon EVs being released from their producer TEC, transglutaminase 2 promoted fibrogenic pathways via direct binding interactions with ECM proteins and stimulation of myofibroblast functions [114]. Aldosterone-induced renal fibrosis in $d b / d b$ mice involved export of EV miR-196b-5p from TEC and its delivery into fibroblasts resulting in downregulation of suppressor of cytokine signaling 2 (SOCS2) expression and enhanced expression of signal transducer and activator of transcription 3 (STAT3), FN, $\alpha S M A$, or collagen $1 \alpha 1[115]$.

5.2.2. Production and Action of EVs from Podocytes, Endothelial Cells, Mesangial Cells, or Macrophages

Podocytes are terminally differentiated epithelial cells that interact with TEC or glomerular cells to maintain renal function but which become functionally compromised and depleted in DN resulting in proteinuria and glomerulosclerosis. Podocyte exosomes are present in human urine [116] and may target TEC since in vitro addition of EVs from human differentiated podocytes to human proximal TEC caused p38-MPAK-dependent Smad3 phosphorylation and activation of TGF- $\beta R 1$, resulting in enhanced expression of FN and collagen IV [117]. Podocytes undergo EMT during DN, which further compromises glomerular function. Podocytes were injured by EVs from glomerular endothelial cells (GEC) that had undergone endothelial-to-mesenchymal transition after exposure to high glucose as occurs in DN [118]. In vitro, EVs were produced at higher frequency by glucose-treated GEC and the EVs both promoted mesenchymal transition in podocytes by a process involving $W n t / \beta$-catenin signaling [118] and stimulated activation of glomerular mesangial cells (GMC) by mechanisms that involve EV TGF- $\beta$ levels [119] and EV delivery of PI3K/AKT- and MAPK-associated circular RNAs [120]. High glucose-treatment of GMC caused EVs to be produced at higher frequency and they caused injury in podocytes (increased apoptosis and TGF- $\beta 1 /$ PI3-AKT signaling; reduced cell adhesion and expression of nephrin, podocin, and WT-1 [121] while stimulating fibrosis-related changes in control GMC (increased production of FN, angiotensin II (Ang II), renin, $\mathrm{AT}_{1} / \mathrm{AT}_{2}$ ) [122]. Finally, high glucose-treated RAW264.7 macrophages stimulated activation of mouse GMC via 
TGF- $\beta 1 /$ Smad signaling [123] and promoted activation, proliferation, and inflammatory cytokine production in control RAW264.7 macrophages [124].

Some of the pathways of EV-regulated renal fibrosis discussed above are shown in Figure 4.

NORMAL

FIBROSIS

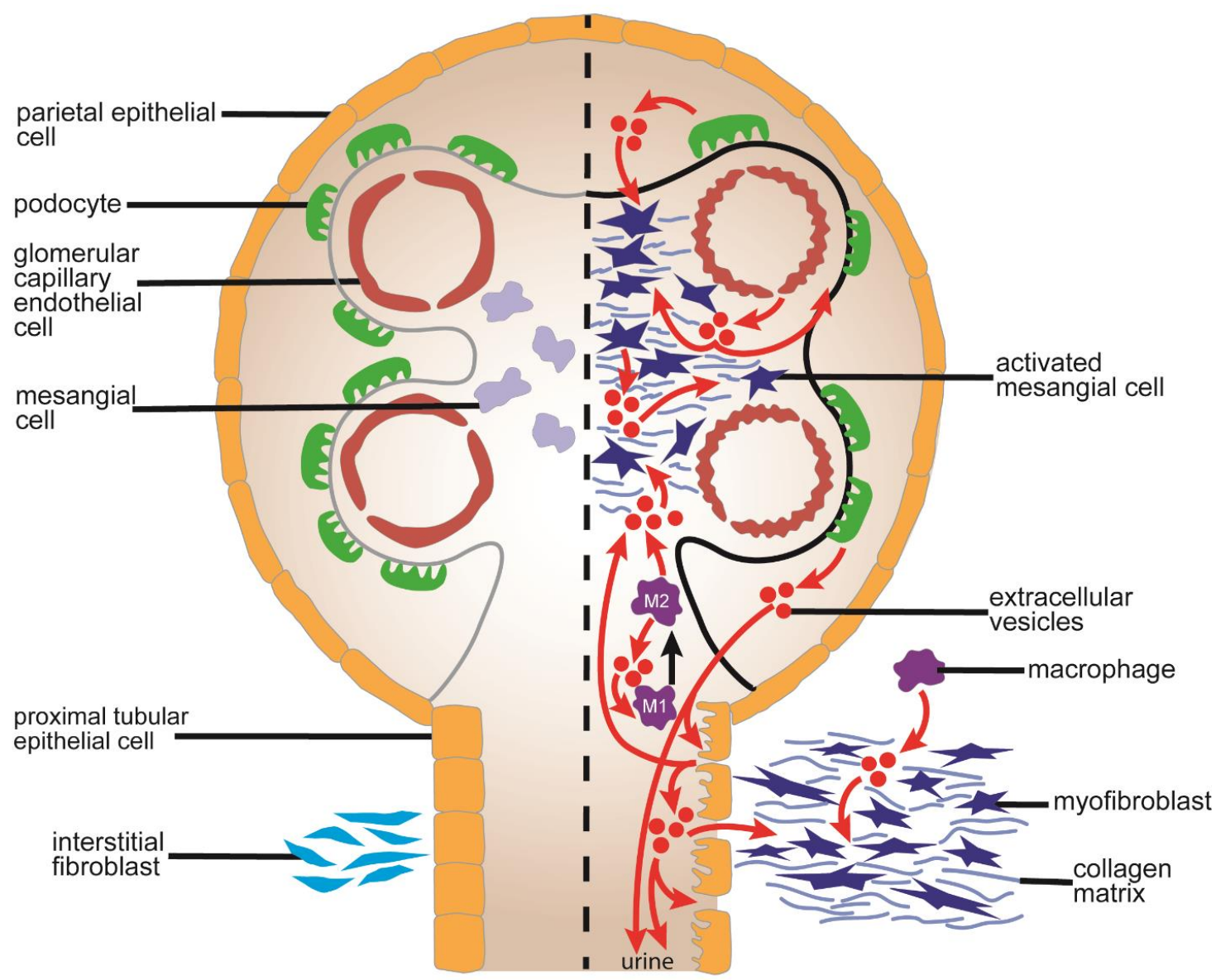

Figure 4. Proposed EV pathways in the pathogenesis of renal fibrosis. EVs are produced in enhanced numbers by stressed or injured TEC downstream of Shh and they cause proliferation and fibrogenesis in fibroblasts, in part by downregulation of SOCS2 by EV miR-196b-5p. TEC EVs also drive EMT and activation in TEC themselves via processes that are dependent on the action of EV TGF- $\beta$, transglutaminase 2, or miR-21, the latter of which is associated with regulation of PTEN/AKT or PPAR/HIF in recipient cells. Podocyte injury and drop-out is a feature of DN and EVs from these cells are present in urine and, when produced in the context of DN-like high glucose conditions, drive ECM production via a TGF- $\beta / \mathrm{p} 38 / \mathrm{Smad}$ axis in TEC and mesangial cells. High glucose levels also result in the production of EVs by GEC that drive Wnt/ $\beta$ catenin-mediated EMT in podocytes or circular RNA-mediated EMT in mesangial cells. Macrophages exposed to high glucose produce pro-inflammatory EVs that are themselves macrophage-activating and further stimulate TGF- $\beta$-dependent activation of mesangial cells. Production by mesangial cells of pro-fibrogenic and pro-pathogenic molecules such as FN and Ang II is stimulated by EVs that are produced by mesangial cells exposed to high glucose concentrations. Only cells with a demonstrated role in EV production or response are shown; some of the depicted EV pathways are deduced from in vitro observations and have not been demonstrated in vivo. See text for details.

\subsection{Therapeutic Actions of EVs in Renal Fibrosis}

\subsubsection{EVs from Adult Stem Cells}

In a rat model of stz-induced diabetes mellitus, administration of BM-MSC exosomes reversed renal tubule expansion, inflammation, interstitial fibrosis, cellular atrophy, and expression of TGF- $\beta$ in TEC [125]. Furthermore, primary TEC cultures derived from stz- 
induced diabetic rats exhibited reduced degeneration and atrophy when treated with BM-MSC exosomes [125] while BM-MSC exosomes reduced stz-induced DN with improved renal function and structure and decreased expression of mTOR and fibrosis-related gene expression. The therapeutic mechanism appeared to involve autophagy (degradation/recycling of proteins/organelles to maintain homeostasis) as exosomes were less effective in the presence of autophagy inhibitors [126]. Likewise, in DN mice, human BM-MSC exosomes corrected kidney dysfunction and inhibited onset and progression of glomerular and interstitial fibrosis, with the anti-fibrotic effects being attributed in part to anti-fibrotic EV miRs [127]. BM-MSC EVs also attenuated renal fibrosis, inflammation, oxidative stress, and apoptosis in TGF- $\beta$-stimulated HK-2 proximal TECs or a UUO rat model, with the therapeutic effects being attributed to inhibition of Rho/ROCK by EVmediated delivery of milk fat globule-epidermal growth factor-factor 8 (MFG-E8) [128]. BM-MSC EVs from older donors showed reduced therapeutic efficacy and was associated with reduced EV levels of miR-133 and -294 [129].

Administration of let-7c-enriched exosomes in the UUO model caused enhanced renal let7c expression, decreased kidney injury, and suppressed expression of collagen IV, matrix metalloprotease-9 (MMP-9), TGF- $\beta 1$, or TGF- $\beta$ R1 [130]. Further, let7c-enriched MSC exosomes reduced TGF- $\beta$-mediated expression of fibrotic genes in NRK cells in vitro and this was associated with down-regulation of TGF- $\beta$ R1 [130]. Similarly, in TGF- $\beta$-treated HK-2 TEC, the inhibited expression of TJP1 or E-cadherin and stimulated expression of $\alpha S M A, F N$, Notch-1 or Jagged-1 were restored to control levels by miR-34a-enriched BMMSC EVs suggesting that the inhibition by of EMT by EV miR-34a was due to targeting of the Jagged-1/Notch-1 pathway [131].

AD-MSC exosomes were therapeutic in a pig model of metabolic syndrome and renal artery stenosis in which improved kidney effects included reduced inflammation and fibrosis and appeared to be dependent on exosomal interleukin (IL)-10 [132]. Moreover, as compared to AD-MSC EVs from pigs with metabolic syndrome, those from lean pigs were more effective in improving renal function and decreasing inflammation and fibrosis in the stenotic kidney $[133,134]$. The therapeutic effects were associated with an enhanced M2:M1 ratio and frequency of CD8+ T cells possibly driven by anti-inflammatory actions of EV TGF- $\beta$ as well as decreased oxidative stress due to EV mitochondria-regulating miRs $[133,134]$. In a deoxycorticosterone acetate (DOCA)-salt hypertensive model, ADMSC EVs were therapeutic both in the kidney, in which filtration rate, fibrosis inflammatory reactions were attenuated, and in the cardiovascular system, as shown by attenuation of cardiac fibrosis and normalization of blood pressure [135]. The kidney effects were attributed to EV-mediated regulation of a miR200-TGF- $\beta$ axis, which damped EMT [135]. EVs isolated from human AD-MSC that had been transfected with glial cell line-derived neurotrophic factor reduced peritubular capillary loss and fibrosis in the mouse UUO model and enhanced migration and angiogenesis and reduced apoptosis in HEVECS in vitro [108]. The endothelial benefit was due to EV-enhancement of SIRT-1 signaling and levels of phosphorylated endothelial nitric oxide synthase, which was proposed to result in post-injury angiogenesis and to contribute to reduced renal fibrosis [108].

In the UUO model in rats, EVs from human UMSC attenuated renal injury and interstitial fibrosis while promoting proliferation but suppressing oxidative stress and apoptosis in renal TEC, the latter of which was attributed to inhibition of ROS-mediated activation of p38MAPK/extracellular signal-regulated kinase (ERK) signaling [136]. It was further shown that the anti-fibrotic effect in this model involved EV-mediated delivery of casein kinase $1 \delta$ and E3 ubiquitin ligase $\beta$-TRCP resulting in ubiquitinylation and degradation of YAP, thereby attenuating YAP activation and collagen production [137]. Human UMSC EVs were therapeutic for kidney injury and fibrosis in models of renal ischemia and this outcome was augmented by EV Oct-4, which reduced EMT by inhibiting expression of Snail $[138,139]$. Finally, EV-mediated mechanisms for the inhibition by UMSC of inflammation and fibrosis in stz-induced DN in rodents was supported by the findings that the production of TGF- $\beta, I L-6, I L-1 \beta$, and TNF- $\alpha$ in high glucose-injured HK2 human 
proximal TEC was inhibited by conditioned medium or EVs from UMSC [140] and that the removal of EVs from UMSC conditioned medium impaired its ability promote promoting proliferation or expression of $F N, M M P s$, or collagen 1 in high glucose-cultured mesangial cells [141].

In a model of AAN, EVs from BM-MSC or human liver stem cells attenuated tubular necrosis, interstitial fibrosis and cellular infiltration and involved EV-mediated changes in fibrosis-, inflammation- and/or apoptosis-related mRNA and miR levels in the diseased kidneys $[138,139,142,143]$. Administration of placental MSC (PMSC) EVs in the UUO model resulted in decreased $\alpha \mathrm{SMA}$ and collagen-I staining and increased infiltration of Foxp3+/IL$17+\mathrm{CD} 4+\mathrm{T}$ cells, mimicking some of the anti-fibrotic and anti-inflammatory properties directly exhibited by PMSC in the same model [144]. Further, in an in vivo model of Ang II -induced cardiac hypertension and concomitant chronic kidney injury, renal function, inflammation, and fibrosis were attenuated by administration of cardiosphere-derived cells (CDC)-exosomes, the effect of which was attributed to exosomal Y RNA fragment, EV-YF1, which modulated IL-10 levels [145].

\subsubsection{EVs from Differentiated Cells or Urine}

In AKI rat models employing renal ischemia/hypoxia, i.v. injection of exosomes from normoxic rat TEC resulted in improved renal function and reversed tubular damage, neutrophil fibrosis, vascular alterations, and transcriptomic changes [146]. Similar results occurred in a nude rat model of hypoxic renal injury after administration of exosomes from human TEC [147]. Interestingly, EVs from hypoxia-conditioned TEC were also therapeutic, sometimes even more so than their normoxic counterparts [146] which is enigmatic considering that EVs from damaged or injured TECs are pro-pathogenic [109,110,113,114]. In HEK 293 epithelial cells, a micellized form of BMP-7 was endosomally internalized (rather than binding its cell surface receptors), resulting in antagonism of TGF- $\beta$-induced EMT and the production of EVs containing active BMP-7 and these combined effects were proposed to contribute to the anti-fibrotic effect of micellized BMP-7 in a pig UUO model [148].

Several lines of evidence suggest that miR-29a is an important antifibrotic agent in the kidney. Expression of miR-29a was reduced in the kidney in rodent UUO models [149] and in urinary exosomes from CKD patients [150-152], while renal fibrosis was suppressed after administration of AAV-miR-29 in mice with UUO or DN [153]. Muscle satellite cell exosomes engineered to contain enriched levels of miR-29a and to elaborate a surface RVG-moiety that targeted acetylcholine receptors in the kidney were therapeutic after intramuscular injection in the UUO model [154]. These exosomes reversed muscle wasting and partially suppressed renal fibrosis and fibrosis-related gene expression, with the therapeutic effects of miR-29a in muscle or kidney being attributed to direct inhibition of, respectively $Y Y 1$ or TGF- $\beta 3$ [154]. Similar results were obtained for HEK293 exosomes enriched in miR-26a, which suppressed renal fibrosis in UUO kidneys by targeting profibrotic CCN2 [155].

\subsection{EVs as Biomarkers in Renal Fibrosis}

EVs in urine are particularly attractive as a source of molecular information that can be harvested non-invasively and assessed for renal fibrosis-related biomarkers. Several studies have shown that the amount of miR-29c in urinary exosomes from patients with CKD and renal interstitial fibrosis is markedly reduced and correlated with renal function and degree of histological fibrosis [150-152]. Similarly, in lupus nephritis, declining urinary exosomal miR-29c levels were negatively correlated with early renal fibrosis, degree of histological chronicity and exosomal Smad3 and MMP2 mRNA levels [156], urinary EV miR-146a was related to disease activity and was associated with TRAF6 suppression in driving inflammation and fibrosis [157], while urinary EV miR-31, -107 and -135-b are predictive of renal recovery and collectively target fibrosis-related HIF-1 $\alpha$ [158]. Other studies of CKD showed that levels in urinary exosomal CD2AP mRNA (a podocyte molecule), miR-21, miR$181 \mathrm{a}, \mathrm{E}$-cadherin, or vimentin were correlated with severity of tubulointerstitial fibrosis 
and glomerulosclerosis $[150-152,156,159,160]$. Levels of vitronectin in urine and urinary EVs [161] or of miR-21 in plasma EVs [162] were proposed as biomarkers for post-kidney transplantation patients with a high incidence of tubulointerstitial fibrosis. Finally, miR-29a was elevated in serum EVs from mice with UUO [153] and plasma-derived exosomal miRs in rats that had undergone 5/6th partial nephrectomy or two-kidney-one-clip were associated with pathways of fibrosis and injury and could be discriminated from free plasma miRs [163].

\section{Cardiac Fibrosis}

\subsection{Causes and Pathological Features of Cardiac Fibrosis}

Although therapies for heart disease have improved significantly, a huge medical and financial burden remains and additional treatment strategies are needed. One promising approach is to target cardiac fibrosis because this pathological feature is widespread, but it is especially prevalent after myocardial infarction (MI) or during heart disease [164]. In MI, blockage of the coronary artery leads to cardiomyocyte death and damage and functional muscle mass is replaced with proliferative collagen-producing myofibroblasts that arise from transdifferentiation of cardiac fibroblasts, which comprise $\sim 75 \%$ of all cardiac cells [164-166]. As myocytes are lost and fibrotic scar is deposited, the ventricle undergoes remodeling (myocyte hypertrophy and elongation, increased wall mass, chamber enlargement) to maintain cardiac output but ventricular structure and performance continue to decline and heart failure is inevitable. In the systolic form of heart failure, the replacement of cardiomyocytes by fibrotic scar results in ventricular stiffness that causes reduced ejection fraction (reduced cardiac output and systemic perfusion capacity), while in the diastolic form of heart failure, the ejection fraction is unchanged but the presence of fibrosis causes blood filling during diastole to be reduced [167].

There are several well-characterized animal models of heart failure and associated inflammation and fibrosis $[168,169]$ but EV studies of cardiac fibrosis have principally used animal models of MI, with or without perfusion.

\subsection{Mechanistic Aspects of EVs in Cardiac Fibrosis \\ 6.2.1. Production and Action of EVs from Cardiomyocytes}

Primary cardiomyocyte cultures exposed to hypoxia or angiotensin II (Ang II) produced miR-208-enriched exosomes that promoted miR-208a-dependent myofibroblastic transition in cardiac fibroblasts [170]. Exosomes from hypoxic cardiomyocytes exacerbated cardiac dysfunction, cardiac fibrosis, and myofibroblast differentiation in post-MI rats and caused cardiac miR-208a levels to be increased, with post-MI cardiac dysfunction and fibrosis being driven by miR-208-mediated targeting of the differentiation-regulating factor Dyrk2 [170]. Cardiomyocytes exposed to ischemia and reoxygenation in vitro produced EVs that elicited profibrotic gene expression in fibroblasts and were enriched in long noncoding (lnc) RNAs [171]. Neat 1, a lncRNA which predominates in large EVs, was required for in vitro cardiomyocyte or fibroblast survival and also reduced migration, cell cycle progression, and fibrotic gene expression in fibroblasts. In vivo, Neat 1 was induced shortly after onset of MI in mouse models and present in large EVs isolated from damaged hearts. Knockout of Neat 1 in mice led to impaired cardiac function, increased fibrosis, and increased fibrotic gene expression as compared to wild-type mice [171]. Hypoxia/reoxygenation of neonatal rat cardiomyocytes in vitro resulted in release of EVs that were enriched for miR-100-5p, -30d-5p, -21-5p, and -29b-3p [172].

TGF- $\beta$-treated rat cardiomyocytes in vitro released miR-21-enriched EVs that stimulated AKT-mediated fibrogenesis in target cardiac fibroblasts by inhibiting PTEN expression [173]. The cholesterol-lowering drug, simvastatin, protected against Ang II-induced cardiac fibrosis by blocking the interaction of EVs from Ang II-treated cardiomyocytes with target cardiac fibroblasts, by preventing EV-mediated differentiation of fibroblasts into myofibroblasts, and by modulating vesicular fibrosis-associated proteins that are required for fibroblast collagen production [174]. In addition, treatment of induced pluripo- 
tent stem cell-derived cardiomyocytes with sacubitril (neprilysin inhibitor) and valsartan (angiotensin receptor blocker) resulted in increased exosome production but decreased exosomal miR-181a levels [175]. In a chronic rat MI model, these drugs resulted in decreased miR-181a levels in plasma EVs and improved cardiac function, reduced fibrosis and hypertrophy, with these outcomes also being achieved by downregulation of miR181a. Thus, miR-181 is a driver of cardiac dysfunction and fibrosis and its suppression in exosomes by sacubitril/valsartan underlies the pharmacological action of these drugs in cardiac repair [175].

\subsubsection{Production and Action of EVs by Fibroblasts}

Elevated levels of miR-27a, $-28-3 p$, and $-34 a$, which are predicted to target nuclear factor erythroid 2-related factor $2(\mathrm{Nrf} 2)$ were present in the infarcted heart and these miRs were enriched in TNF- $\alpha$-stimulated EVs that mediated cross-talk between cultured cardiomyocytes and fibroblasts [176]. In the post-MI heart, EV delivery of Nrf-targeting miRs from fibroblasts to cardiomyocytes were proposed to disrupt Nrf-regulated antioxidant enzymes [176]. When added to cardiac fibroblasts, exosomes from Wnt3a-producing mouse fibroblast $L$ cells activated canonical $\beta$-catenin-dependent signaling and exacerbated TGF- $\beta$-mediated fibrogenic signaling, while Wnt5a-enriched exosomes partially activated non-canonical Wnt pathways [177].

\subsubsection{Production and Action of EVs from T Cells}

Infiltrating CD4+ T cells are important drivers of inflammation and fibrosis after MI [178] and exosomes from activated CD4+ T cells promoted cardiac fibroblast activation in vitro and exacerbated fibrosis and heart dysfunction in mouse MI [179]. This effect was attributed to exosomal 142-3p, which promoted Wnt signaling and cardiac fibroblast activation by attenuating expression of the Wnt suppressor molecule, adenomatous polyposis coli [179].

\subsubsection{Production and Action of EVs from Macrophages}

Levels of the mRNA-stabilizing human antigen $\mathrm{R}(\mathrm{HuR})$ protein were increased in myocardium from diabetic ischemic human hearts and in cardiac or bone marrow-derived macrophages from $d b / d b$ mice [180]. Exosomes from cultured macrophages exposed to high glucose induced expression of inflammatory or fibrogenic genes in fibroblasts in vitro but this effect was abrogated when EVs were rendered HuR-deficient. Moreover, cardiac fibrosis and left ventricle dysfunction in Ang II-induced diabetes in mice was attenuated by administration of HuR-deficient macrophage exosomes [180]. Also, miR-155 in macrophage EVs has shown to favor a profibrotic cardiac environment in several studies. For example, following MI in mice, miR-155 was upregulated in cardiac macrophages from which it was released in EVs that mediated its transfer into cardiac fibroblasts where it inhibited proliferation and promoted inflammation by suppressing expression of, respectively, Son of Sevenless 1 and SOCS1 [181] while, in a model of uremic cardiomyopathy in mice, miR-155 in macrophage EVs targeted Foxo3a in cardiomyocytes, resulting in pyroptosis (pro-inflammatory programmed cell death) and downstream cardiac hypertrophy and fibrosis [182].

\subsubsection{Production and Action of EVs from the Circulation}

Serum exosomes from older rats were more effective than those from younger rats in promoting cardiac fibroblast proliferation and transdifferentation and this was correlated with an age-dependent decrease in exosomal HSP70 levels [183]. The proliferative and fibrogenic actions of serum exosomes could be "tuned" by experimentally manipulating the amount of exosomal HSP70 present [183].

Some of the pathways of EV-regulated cardiac fibrosis discussed above are shown in Figure 5 . 


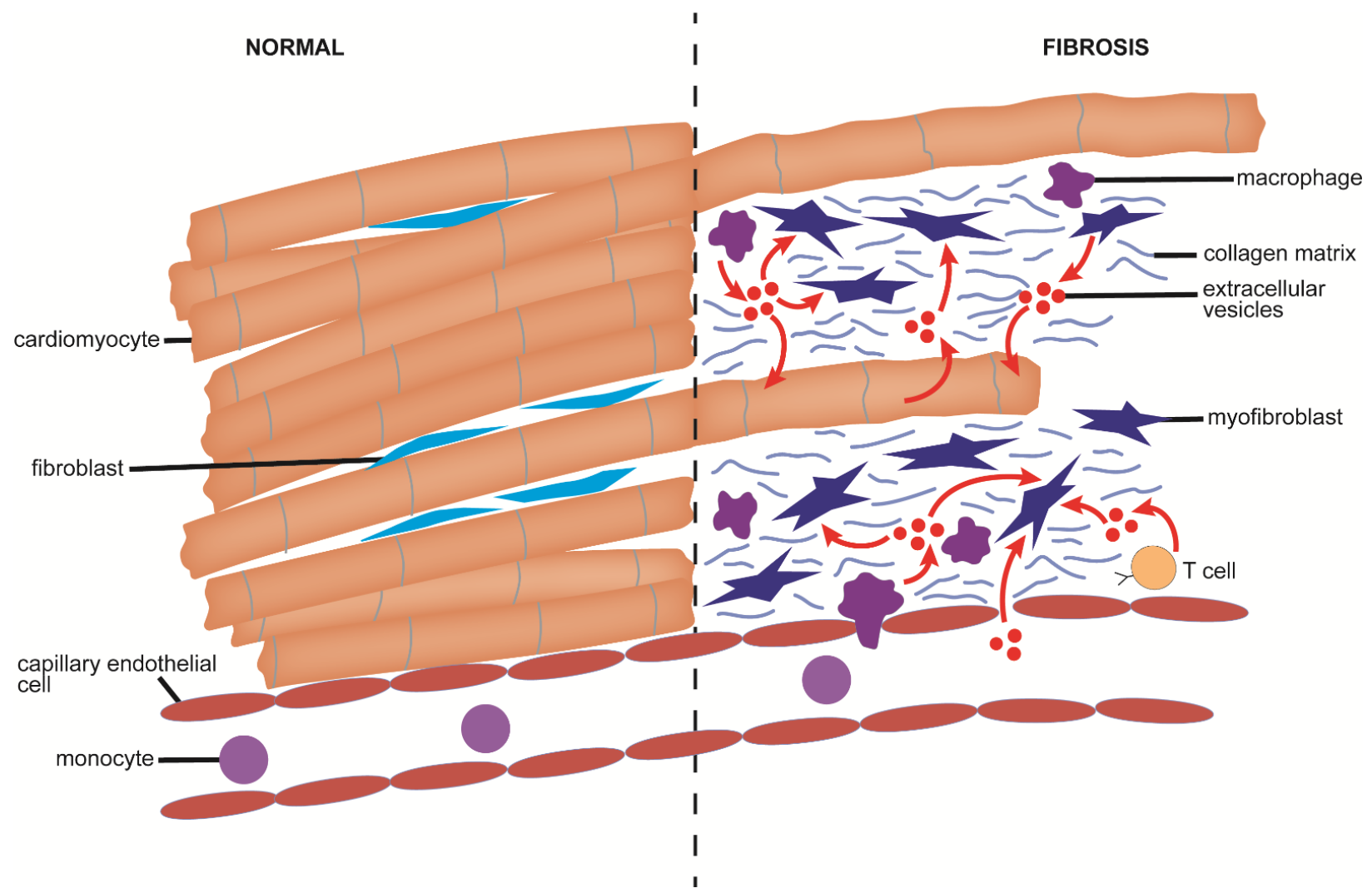

Figure 5. Proposed EV pathways in the pathogenesis of cardiac fibrosis. Cardiomyocytes exposed to stress such as hypoxia produce EVs that promote mesenchymal transition, survival, and fibrogenesis in cardiac fibroblasts/myofibroblasts in part due to delivery of enriched EV cargo components that include Neat 1, miR-29b-3p, miR-30d-5p, miR-100-5p, miR181a, miR-21 and miR-208a, the latter two of which target, respectively, AKT-PTEN and Dyrk2. TNF- $\alpha$-stimulated cardiomyocytes and cardiac fibroblasts produce EVs that are exchanged between them and which can promote increased oxidative stress by delivery of Nrf2-tartgeting miR-27a, -28-3p, or -34a, while profibrotic pathways in cardiac fibroblasts are promoted by delivery of fibroblast EVs enriched with Wnt3a or Wnt5a. High glucose-stimulated macrophages produce EVs that are enriched in HuR which is required for EV-stimulated expression of inflammatory or fibrogenic genes in cardiac fibroblasts. Macrophage EVs are also enriched in miR-155 which exerts, firstly, anti-proliferative and pro-inflammatory effects in cardiac fibroblasts by targeting Son of Sevenless 1/SOCS1 and, secondly, pyroptosis, hypertrophy and fibrosis in cardiomyocytes by its targeting of Foxo3a. Finally, age-related declines in HSP70 levels in serum EVs are associated with increased cardiac fibroblast proliferation. Only cells with a demonstrated role in EV production or response are shown; some of the depicted EV pathways are deduced from in vitro observations and have not been demonstrated in vivo. See text for details.

\subsection{Therapeutic Actions of EVs in Cardiac Fibrosis \\ 6.3.1. EVs from Adult Stem Cells}

EVs from human BM-MSC protected cardiomyocytes from oxidative stress-induced apoptosis stress, stimulated cardiomyocyte proliferation, and inhibited TGF- $\beta$-induced $\alpha S M A$ production in BJ fibroblasts [184]. These EVs improved cardiac function and increased angiogenesis, and decreased inflammation and fibrosis in rats MI models and were enriched in miRs that were predicted to target PI3-AKT and mTOR [184]. Administration of miR-101a-enriched BM-MSC EVs in post-MI mice resulted in improved heart function and anti-inflammatory and anti-fibrotic effects and were due to EV-mediated polarization of macrophages to the anti-inflammatory phenotype, dampening of TGF- $\beta$ expression, and inhibition of autophagy [185]. BM-MSC exosomes that contained elevated levels of HIF- $1 \alpha$ promoted in vitro endothelial cell angiogenesis, migration, proliferation and expression of angiogenic factors while preserving cardiac function, promoting angiogenesis, and reducing fibrosis in a rat MI model [186]. The therapeutic effect of EVs from human BM-MSC on endothelial function, myocyte survival, and fibrosis in rat MI models was reduced in 
older versus younger BM-MSC donors and attributed to the age-related loss of miR-221-3p which otherwise suppressed apoptosis through its inhibition of PTEN and stimulation of AKT activity [187]. BM-MSC exosomes engineered to contain the membrane Lamp2b fused to ischemic myocardium-targeting peptide were more efficiently internalized by hypoxic cardiomyocytes in vitro and showed enhanced accumulation in the post-MI heart in mice, resulting in improved effects in vivo including reduced myocardial inflammation, apoptosis, and fibrosis while improving vascularization and cardiac function [188]. Post-MI therapy by BM-MSC EVs was not improved using cell-free hydrogel formulations used to facilitate effectiveness of other cardiac therapies [189]. Aortic constriction in mice resulted in pressure overload-induced cardiac hypertrophy, myocardial apoptosis, and fibrosis that was attenuated by administration of mouse BM-MSC exosomes which, in vitro, prevented myocyte hypertrophy and apoptosis while promoting senescence of cardiac myofibroblasts [190].

Ischemia of BM-MSC also results in production of therapeutic EVs, which may be more potent than their normoxic counterparts. Thus, exposure of BM-MSC to ischemia resulted in the production of miR-22-enriched exosomes that reduced apoptosis in ischemic cardiomyocytes by miR-22 targeting of methyl CpG binding protein 2 [191]. These EVs reduced collagen deposition and infarct size in mouse MI models, and the anti-fibrotic effect was abrogated by inhibiting miR-22 production in the exosome donor BM-MSC [191]. EV therapy was enhanced by exposure of the donor BM-MSC to hypoxia, which resulted in elevated cellular and EV miR-210 and nSMase2 activity [192].

The therapeutic efficacy of cardiac stem cells in a post-MI model in rats was substantially improved by their pre-exposure to BM-MSC exosomes, as evidenced by improved cardiac stem cell survival, cardiac vascularization and function, and reduced fibrosis [193]. Exosome treatment resulted in modulation of multiple miRs that were predicted to impact genes involved in cardiac repair and regeneration [193].

Muscle satellite cells engineered to produce miR-26a-enriched muscle-targeted exosomes dampened fibrotic responses in the cardiac and skeletal muscle of CKD mice, reduced muscle wasting, and improved cardiac function [194].

In vitro, EVs from UMSC increased the Bcl2: Bax ratio in hypoxic myocardial cells and stimulated endothelial cell migration and tube formation [195]. In acute MI in rats, UMSC EVs improved lung function, reduced fibrosis and apoptosis, and stimulated cardiomyocyte proliferation [195] and in vivo therapeutic effects were enhanced by encapsulation of the EVs in cardioprotective peptide hydrogel [196]. The therapeutic effect of UMSC EVs also involved targeting of the Bim apoptosis gene by exosomal miR-24 while immune rejection of BM-MSC used for cell-based therapy was prevented and cardiac repair was enhanced by knockout of human leucocyte antigen light chain $\beta 2$ microglobulin to modulate exosome imprinting [184]. In a mouse MI model, the therapeutic properties of BM-MSC from elderly human donors was improved by pretreating the cells with EVs from UMSC, which resulted in the loss of senescence and apoptosis from the BM-MSC and their prolonged survival in vivo resulting in improved cardiac function, increased cardiac vessel density, and decreased scar [197]. This improved outcome was attributed to the effect of EV miR-136, which inhibited expression of apoptotic peptidase activating factor [197]. In type 2 diabetes mellitus stroke mice, administration of exosomes from human umbilical cord blood derived stem cells improved cardiac function, increased myocardial vascularization, and decreased cardiomyocyte hypertrophy, oxidative stress, interstitial fibrosis and expression of TGF$\beta$ [198]. These exosomes were enriched in miR-126 and caused cardiac expression of its targets (MCP1, VCAM1, Spred-1) to be attenuated [198].

EVs from AD-MSCs were therapeutic for post-MI heart damage by attenuating inflammation, apoptosis, and fibrosis and promoting macrophage M2 polarization and angiogenesis [199-201]. EVs targeted the S1P/SK1/S1PR1 axis [199] and their therapeutic effects were augmented with either miR-126 to target angiogenic and cardiac repair pathways [200] or miR-146a to targeted early growth response factor 1 [201]. In a pig model of co-exisiting metabolic syndrome and renal stenosis, intra-renal administration of AD-MSC 
EVs resulted in attenuation of cardiac injury and dysfunction, including improved myocyte and capillary density and reduced inflammatory cytokine expression and fibrosis [202].

Cardiac mesenchymal stem cells CMSC are a subpopulation of predominantly Sca-1+ MSC that arise from cardiac tissue and play a role in cardiac regeneration. Exposure of ischemic Sca-1+ CMSC to heat shock resulted in enhanced cell survival due to regulation of a heat shock factor $1 / \mathrm{miR}-34 \mathrm{a} / \mathrm{HSP70}$ axis [203]. CMSC exosomes promoted the same pro-survival pathway in oxygen/glucose deprived cardiomyocytes suggesting that they contribute to CMSC-mediated reduced cell death and fibrosis in ischemic heart in vivo [203]. EVs from Notch-overexpressing CMSC were therapeutic in post-MI mouse heart, resulting in neovascularization of the infarct area, decreased cardiac fibrosis, and improved cardiac function [204].

EVs from cardiac-resident mesenchymal progenitor cells (CPC) blocked oxidative stress in cardiomyocytes exposed to doxorubicin and trastuzumab, which have off-target cardiac toxicity when used clinically to treat breast cancer [205]. CPC EVs were therapeutic in a rat model of doxorubicin/trastuzumab-induced myocardial fibrosis, inflammation, inducible nitric oxide synthase (iNOS), and left ventricular dysfunction and this was due to suppression of genes involved in inflammation, innate immunity, and death by EV miR-146a-5p [205]. The therapeutic actions of subcutaneously implanted CPCs in rat MI involved transit to the hearts of CPC EVs carrying cardiac repair proteins [206].

Treatment in vitro of dermal fibroblasts with EVs from rat cardiosphere cells (CDCs), which are obtained from CPCs via cardiosphere formation resulted in a phenotypic and functional reprogramming whereby "therapeutic" apoptotic and angiogenic cells were produced that contained cardioprotective miRs typical of the EV producer CDC [207]. Moreover, these EV-primed fibroblasts, or the EVs themselves, were therapeutic in rat chronic MI, resulting in improved left ventricular ejection fraction, reduced scarring, and increased microvessel density [207]. Similar results were obtained after administration of human CDC EVs in porcine models of acute or chronic MI [208] or pediatric dilated cardiomyopathy [209]. Wnt/ $\beta$-catenin signaling in the CDC was critical for the potency of CDC and proposed to enhance an antifibrotic EV miR-92-BMP pathway [210]. Overexpression of $\beta$-catenin and Gata4 in fibroblasts imparted therapeutic properties on the cells or their EVs as shown by, respectively, improved survival and heart function in mouse MI models or functional improvement and anti-fibrotic effects in the skeletal muscle of the $m d x$ mouse model of Duchenne muscular dystrophy [210]. In the dilated cardiomyopathy model, the improvement in cardiac function and reduced fibrosis was attributed to the enrichment in CDC EVs of proangiogenic and cardioprotective miRs including miR-146a-5p which attenuated fibrosis by reducing inflammation and apoptosis through its targeting of TRAF6/Smad4/FOS [209]. CPC-derived exosomes also resulted in improvement of heart function and reduced apoptosis and fibrosis when administered to a mouse model of doxorubicin-induced dilated cardiomyopathy [211] and the therapeutic outcome was improved by conjugation of the exosomes with cardiac homing peptide which targets ischemic myocardium [212]. Human trophoblast-derived exosomes had similar therapeutic outcomes in the same injury model, with the effects attributed to EV-mediated suppression of a mir-200b-Zeb1 axis in cardiomyocytes [213].

Endothelial progenitor cells that were exposed to hypoxia/reoxygenation produced exosomes that promoted mesenchymal to endothelial transition in cultured cardiac fibroblasts [214]. This pro-angiogenic and anti-fibrotic activity was attributed to the action of exosomal miR-133 [215]. Exosomes from endothelial colony-forming cells (ECFCs) attenuated activation of cardiac fibroblasts in vitro when the EV donor ECFC were grown under normoxic but not hypoxic conditions [216]. The therapeutic effect was attributed to exosomal miR-10b-5p, which was suppressed during hypoxia but which, in normoxic conditions, attenuated expression of the fibrosis-related genes Smurd 1 and HDAC4 [216].

Telocytes are interstitial cells that occur in multiple organs and which, in the heart, play a supportive role in the stem cell niche and function in post-MI regeneration. Exosomes from cardiac telocytes promoted a pro-angiogenic phenotype when added to cultured 
endothelial cells and caused improved cardiac function and angiogenesis and decreased fibrosis when administered in a rat MI model [217]. Delivery of exosomes from myogenic progenitor cells into the hearts of MDX Duchenne muscular dystrophy mice caused cardiac levels of dystrophin to be restored and improved myocardial function [218].

\subsubsection{EVs from Induced Pluripotent Stem Cells (iPSC)}

Exosomes from iPSC-derived cardiomyocytes (iCM) stimulated cardiomyocyte survival under hypoxic conditions and enhanced cardiac function and decreased apoptosis and fibrosis in mouse MI [219]. iCM exosomes targeted mTOR signaling and autophagy and elicited therapeutic and transcriptomic changes in the ischemic heart that were comparable to iCM themselves [219]. CPCs induced from human iPSCs produced EVs that inhibited TGF- $\beta$-induced fibrotic gene expression in cultured fibroblasts in vitro and attenuated cardiac dysfunction and fibrosis in mouse MI in vivo [220]. The EVs were enriched in miRs associated with promoting angiogenesis and cardiomyocyte proliferation or inhibiting fibrosis, the latter involving targeting of growth differentiation factor-11 (GDF-11) or ROCK-2 by miR-373 [220].

\subsubsection{EVs from Embryonic stem Cells (ESC)}

In MI models, myocardial administration of ESC exosomes enhanced left ventricular function, neovascularization, cardiomyocyte survival, expansion of CPC and reduced fibrosis [221]. Moreover, in vitro pre-treatment of CPCs with ESC exosomes resulted in augmentation of the ability of CPCs themselves to improve cardiac function and reduce fibrosis post-MI and this was attributed to the effect of exosomal miR-294, which promoted CPC survival, cell cycle progression, and proliferation [221]. In mouse MI models, EVs from cardiac-committed ESCs were as effective as the cells themselves in improving heart function, decreasing infarct size and modulating cardiac gene expression [222]. On the other hand, whereas in a porcine MI model intravenous injection of EVs from the E1MYC 16.3 ESC-derived MSC line resulted in a 30\% decreased infarct size and somewhat improved regional and global LV functions, fibrosis was accelerated rather than diminished and likely accounted for sub-optimal EV therapeutic effects on heart function [223].

\subsubsection{EVs from Cardiomyocytes or Skeletal Muscle}

In diabetic mice, levels of cardiomyocyte exosomal miR-29b and -455 were increased during exercise and were associated with exercise-mediated improvements in cardiac remodeling through their ability to inhibit MMP9 activity [224]. MiR-378 in cardiomyocyte EVs was implicated in inhibiting fibrogenic gene expression in cardiac fibroblasts by targeting mitogen-activated protein kinase kinase 6 and downstream p38 MAPK signaling, consistent with a role for miR-378 in cardiac dysfunction, hypertrophy, and fibrosis in a mouse pressure overload model [225]. In rat MI, remote ischemic conditioning by repeated bilateral hindlimb ischemia/reperfusion resulted in improvement of cardiac function, reduced interstitial fibrosis and reduced oxidant stress and this outcome was suggested to involve systemic delivery from skeletal muscle to cardiomyocytes of exosomes enriched in anti-fibrotic miR-29a and cardioprotective insulin-like growth factor-1 receptor (IGF1R) [226].

\subsubsection{EVs from Vascular Endothelial or Smooth Muscle Cells}

Increased numbers of exosomes were released from cultured human umbilical vein endothelial cells exposed to shock waves and these EVs were angiogenic due in part to the presence of pro-angiogenic miR-19a-3p. When administered in vivo to a mouse MI model, these EVs preserved ventricular function and angiogenesis and decreased the degree of fibrosis in the infarct area [227]. In a study of vascular inflammatory mediators, EVs from LPS-treated endothelial cells stimulated endothelial dysfunction as shown by increased production of ICAM protein, ROS, and onset of cellular senescence but decreased levels 
of phospho-endothelial nitric oxide synthase and pAKT, while EVs from vascular smooth muscle cells produced increased levels of anti-fibrotic MMP-9 [228].

\subsubsection{EVs from the Circulation}

Hypertension is a progressive chronic disease that can lead to coronary artery disease, stroke and CKD, with fibrotic manifestations in the heart and kidney. Plasma exosomes from normotensive rats caused decreased blood pressure and prevented perivascular cardiac fibrosis when transferred into hypertensive rats and, conversely, plasma exosomes from hypertensive rats caused increased blood pressure and increased perivascular fibrosis when transferred into normotensive rats [229]. In another study, administration of miR21-loaded human blood exosomes to hypoxic cardiomyocytes in vitro resulted in downregulation of Smad7 and PTEN and upregulation of MMP2 while cardiac dysfunction and fibrosis in mouse MI were exacerbated or blocked by exosomes enriched with, respectively, miR-21 or miR-21 inhibitor [230].

\subsection{EVs as Biomarkers in Cardiac Fibrosis}

Exosomes from the serum of patients with persistent atrial fibrillation contained levels of miRs $-103 a,-107,-320 d,-486$, and let-7b that were elevated at least 4.5 -fold as compared to control patients [231]. These miRNAs targeted pathways related to atrial function and structure, oxidative stress, and fibrosis [231]. Similarly, EVs from pericardial fluid of atrial fibrillation patients contained 31 downregulated miRs and 24 upregulated miRs, the latter of which included miR-382-3p, -2136-5p, and 450a-2-3p which are predicted to target multiple fibrosis-related genes [232]. Plasma exosomes from heart failure patients contained elevated levels of miR-21 and reduced levels of miR-425 and miR-744 and these miRs regulated fibrogenic pathways in cardiomyocytes [173,233].

\section{Hepatic Fibrosis}

\subsection{Causes and Pathological Features of Hepatic Fibrosis}

Chronic liver injuries affect millions of people world-wide and are characterized by prolonged hepatic injury, inflammation, and fibrosis, the latter increasing the risk of lifethreatening complications such as cirrhosis, portal hypertension, hepatocarcinoma, and organ failure [234]. The principal fibrosis-producing cells of the liver are hepatic stellate cells (HSC) which undergo activation and play a transient self-limiting role in would repair in acute injury but which unrelentingly produce large amounts of collagenous scar during chronic liver injury [235]. Portal fibroblasts in the periportal mesenchyme surrounding the bile ducts may also produce fibrotic scar, especially after cholestatic liver injury [236].

Alcoholic liver disease (ALD) describes a spectrum of hepatic pathologies that are caused by chronic alcohol consumption [237]. Hepatocytes are the principal site of ethanol metabolism but the action of alcohol dehydrogenase or cytochrome P450 2E1 (CYP2E1) yields highly toxic acetaldehyde as an intermediate metabolite. Alcohol exerts additional direct toxic effects by its stimulation first, of ROS via CYP2E1-mediated mitochondrial influx of reduced NADPH or TNF- $\alpha$ mediated interaction of $N$-acetyl-sphingosine with mitochondria and second, of reactive nitrogen species by inducible nitric oxide synthase. Chronic alcohol consumption also induces alcoholic steatosis due to inhibition of fatty acid oxidation, upregulation of lipogenic genes, and altered lipid transport. In some cases, the disease advances to inflammation (alcoholic steatohepatitis) in which infiltration of macrophages and neutrophils is driven by gut-derived pathogen-associated molecular patterns (e.g., LPS), damage associated molecular patterns from dying hepatocytes, and inflammatory cytokines from hepatocytes or Kupffer cells (KC). With continued alcohol consumption, HSC may become activated by the combined effects of alcohol, acetaldehyde, ROS, KC activity, and inhibition of intrinsic anti-fibrotic pathways, resulting in progression to fibrosis and cirrhosis in some individuals [237]. Likewise, non-alcoholic fatty liver disease (NAFLD) encompasses a spectrum of diseases of increasing severity from simple fatty liver (steatosis) to non-alcoholic steatohepatitis (NASH) and cirrhosis [238]. About 
$20 \%$ of NAFLD patients progress to NASH, a subset of whom will progress to fibrosis and cirrhosis [239]. NASH is initiated by multiple hits to the liver (insulin resistance, obesity, diabetes, gut endotoxin, hyperlipidemia) causing lipotoxicity-induced oxidative or endoplasmic reticulum stress in hepatocytes, which triggers similar pathogenic pathways as in ALD [240,241].

Chronic infection with hepatitis B or C virus (HBV, $\mathrm{HBC}$ ) results in severe parenchymal injury leading to fibrosis, cirrhosis, and hepatocarcinoma. The use of sofosbuvir (which inhibits HCV NS5B protein) as a first line treatment for all HCV genotypes has virtually eradicated $\mathrm{HCV}$ while the $\mathrm{HBV}$ vaccine (which targets $\mathrm{HBsAg}$ viral envelope protein) is highly efficacious. However, not all individuals are effectively treated (due to drug cost, accessibility, non-compliance, etc.) and even when the primary disease is successfully treated, hepatic fibrosis may still persist. Hepatic fibrosis, cirrhosis, and hepatocarcinoma thus remain significant complications of $\mathrm{HBV}$ or $\mathrm{HCV}$ infection for millions of people worldwide.

The role of EVs in hepatic fibrosis has been determined using several in vivo liver injury models, including administration of chemicals, consumption of special diets to cause NASH-like pathology, surgery, or parasitic infections [242].

\subsection{Mechanistic Aspects of EVs in Hepatic Fibrosis}

\subsubsection{Production and Action of EVs from Hepatocytes}

Hepatocytes produce increased numbers of EVs when cultured in the presence of free fatty acids such as palmitic acid to mimic the lipotoxicity seen in NAFLD and this is due activation of ROCK-1 via a C/EBP homologous protein/DR5/caspase8/caspase 3 proapoptotic axis [243-245]. EVs from lipotoxic hepatocytes stimulated migration, proliferation, activation, and fibrogenesis in human or mouse HSC in vitro $[245,246]$. HSC activation was dependent on the presence of vannin on the EV surface, while fibrogenesis was stimulated by EV miR-128-3p, -27b, or -130b, which targeted PPAR $\gamma$ [246]. EVs from lipotoxic hepatocytes contained enhanced levels of NASH-related miRs including miR-24, $-19 b,-34 a,-122$, and -192 , the latter two of which were also enhanced in serum exosomes from patients with advanced NAFLD (S2-3 steatosis, F2-F4 fibrosis) [245]. These EVs, or those from the serum of experimental NASH in mice or of human NASH patients, induced expression and release of proinflammatory cytokines (IL-1 $\beta$, IL-6) in macrophages and this was dependent on the presence of TNF-related apoptosis-inducing ligand, a DR5 ligand, in the EV payload [244]. Internalization of EVs from fat-laden hepatocytes caused NF- $\mathrm{kB}$-mediated activation of NLRP3 inflammasome in hepatocytes and macrophages resulting in increased IL-1 $\beta$ release [247].

Mice fed choline-deficient L-amino acid defined diet or high fat diet had increased numbers of circulating EVs that were correlated with progression of NAFLD [248]. Some circulating EVs in NAFLD animals were likely of hepatocyte origin because they contained liver carboxylesterase, asialoglycoprotein-receptor, mir-122 and miR-192 which are principally hepatocyte-associated [248]. In mice fed trans-fatty acids, fructose, and cholesterol (HTF-C) diet, hepatic fibrosis and expression of HSC markers was blocked and reversed by the thiazolidinedione, MSDC-0602 [249]. When added to HSC in vitro, plasma EVs from HTF-C-fed mice stimulated expression of fibrotic markers whereas those from mice receiving MSCD-0602 or that were null for mitochondrial pyruvate carrier 2 (MPC2; a thiazolidinedione-binding moiety) did not. These data show that plasma EVs, possibly of hepatocyte origin, stimulate HSC activation in NASH/NAFLD [249]. In HTF-C-fed mice, the frequency of circulating hepatocyte-derived EVs was increased and this was reduced using fausidil, a ROCK inhibitor which also reduced serum alanine transaminase (ALT), hepatic expression of mac1, IL-1 $\beta$, and $\alpha S M A$, and collagen deposition [244]. EVs from lipotoxic hepatocytes were enriched with activated integrin $\beta 1$ and enhanced integrin $\beta 1$-mediated monocyte adhesion to liver sinusoidal endothelial cells under conditions of shear stress [243]. Lipotoxic hepatocytes released increased numbers of EVs into the circulation of NASH mice and, further, serum EVs from NASH patients with Stage 1-2 
hepatic fibrosis contained significantly more integrin $\beta 1$ than EVs from patients with simple steatosis. In mouse NASH, proinflammatory monocyte infiltration, hepatocyte apoptosis and injury, and expression of fibrotic markers collagen $1 \alpha 1$ and osteopontin were decreased by anti-integrin $\beta 1$ antibody supporting a role for circulating hepatocyte EV integrin- $\beta 1$ in these processes [243].

As compared to EVs from control hepatocytes, those produced by hepatocytes isolated from a mouse model of alcoholic hepatitis were increased 10-fold in frequency and stimulated $\alpha S M A$ and collagen $1 \alpha 1$ expression in HSC or Toll-like receptor 9 (TLR9)-dependent IL-1 $\beta$ and IL-17 production in hepatic macrophages [250]. The EVs contained firstly, 4 downregulated and 20 upregulated miRs, the latter including miR-27a and miR-181 which were predicted to target Smad7 and the Nrld2 quiescence marker and secondly, a 10-fold enrichment of organelle proteins and mitochondrial DNA. This elegant study suggested that in the context of alcoholic hepatitis, hepatocyte EVs drive fibrosis by direct miR-mediated regulation in HSC and by production of profibrogenic cytokines by macrophages [250]. In mouse models of acute liver injury and early fibrosis, hepatocyte exosomes increased TLR3 expression in HSC [251]. This resulted in HSC activation and increased their production of IL-17A, IL-1 $\beta$, and IL-23 which acted locally to amplify ll-17A production in nearby $\delta \mathrm{T}$ cells. Self-coding TLR3 ligands and exosomes produced by damaged hepatocytes were propose to act in concert to drive expression and activation of TLR3 in HSC, resulting in a positive feedback mechanism between HSC and $\delta \mathrm{T}$ cells that drives 11-17A production and exacerbates hepatic fibrosis [251]. In hepatocytes, the stress protein tribbles pseudokinase 3 (TRIB3) mediated profibrotic effects by suppressing autophagic degradation of late endosomes and increasing the production of EVs that are enriched in inhibin beta A/activin A and which stimulated migration, proliferation and activation of HSCs [252]. Metastasis-associated lung adenocarcinoma transcript 1 (MALAT1), a lncRNA that is upregulated in hepatic fibrosis and activated HSC, was present in exosomes released by L-02 human fetal hepatocytes exposed to fibrosis-causing arsenite [253]. Incubation of these EVs with cultured human LX2 HSCs resulted in the delivery of MALAT1 to the cells which contributed to their activation by suppressing miRNA-26b, a negative regulator of collagen $1 \alpha 2$ [253]. Exposure of rats to high concentrations of heavy metals resulted in liver injury that included hepatocyte damage, inflammation, and fibrosis and this was accompanied by an increased frequency of EV shedding [254].

Exosomes from HCV-infected hepatocytes were enriched in miR-19a, -20a, and -195 and stimulated expression of profibrotic markers in HSC [255]. MiR-19a was correlated with advanced hepatic fibrosis in serum exosomes from HCV patients and, in HSC, directly stimulated fibrotic gene expression and inhibited SOCS3 expression via downstream activation of the STAT3/TGF- $\beta 1 / \mathrm{Smad} 3$ axis, the latter also occurring in response to exosomes from HCV-infected hepatocytes [255]. HCV-replicating human hepatocytes delivered EV miR-192 into co-cultured human HSC, HSC resulting in upregulation of its TGF- $\beta$ target and downstream stimulation of fibrogenic gene expression and transdifferentiation [256].

\subsubsection{Production and Action of EVs from Cholangiocytes}

Cholangiopathies such as primary sclerosing cholangitis involve epithelial damage and inflammation in the bile duct, resulting in blockage of the duct and fibrosis. Cultured mouse large cholangiocytes (MLE) produced more EVs when they were treated with cholestatic estrogen or taurocholate acid and these EVs contained increased levels of H19, a lncRNA that is preferentially expressed in cholangiocytes and associated with cholestatic injury [257]. In mouse fibrotic or cholangiopathic models, delivery of exosomal H19 from cholangiocytes to hepatocytes, macrophages, or HSC drove cholestatic injury, inflammation, and fibrosis [257-259]. In addition, plasma EVs from the $M d r 2^{-/-}$primary sclerosing cholangitis mouse model stimulated macrophage activation in vitro and localized to hepatic monocytes in vivo, consistent with the identification of an EGFR-mediated pathway of macrophage activation triggered by EVs from senescent cholangiocytes [260]. 


\subsubsection{Production and Action of EVs from HSC or Fibroblasts}

Treatment of human HSC in vitro with platelet-derived growth factor (PDGF) resulted in a $>50 \%$ increase in EV release and a $>2$-fold increase in the concentration of $440 \mathrm{EV}$ proteins [261]. One such protein was PDGF receptor alpha (PDGFR $\alpha$ ) and its enrichment in EVs was dependent on Src homology region 2 domain-containing phosphatase-2 (SHP2) which binds to Tyr720, and resulted in the ability of the EVs to stimulate HSC migration in vitro and collagen deposition and/or fibrotic gene expression under basal conditions or in carbon tetrachloride $\left(\mathrm{CCl}_{4}\right)$ or bile duct ligation (BDL) hepatic fibrosis models. PDGFR $\alpha$ levels were enhanced in serum EVs from ALD patients with hepatic fibrosis or mice with $\mathrm{CCl}_{4}$ or BDL hepatic fibrosis [261]. The release of pro-fibrotic EVs from activated HSC by PDGF or SHP2 occurred through the activation of the mTOR pathway, which caused increased exosome release via inhibition of autophagy and increased microvesicle release via activation of ROCK [262]. Exosome release and autophagy were also mechanistically linked by decreased levels of miR-30a in exosomes from activated HSC which was consistent with the downregulation of miR-30a in mouse models of hepatic fibrosis and its ability to suppresses HSC autophagy, activation, and fibrogenesis by attenuating of beclin1 expression [263]. Additionally, exosome release from activated HSC was HIF-1-dependent and the resultant exosomes contained HIF-1-dependent glucose transporter 1 (GLUT1) and pyruvate kinase M2 (PKM2) which were subsequently delivered to quiescent HSC, KCs, or luminal sinusoidal endothelial cells (LSECs) [264]. Furthermore, profibrotic CCN2 in activated HSC was packaged into their secreted EVs which, upon binding to target HSC via cell surface integrins and heparan sulfate proteoglycans, caused elevated intracellular CCN2 and $\alpha S M A$ levels [36,265], while stimulation by Ang II of HSC fibrogenesis and endoplasmic reticulum stress in vitro was mediated by apoptosis signaling regulating kinase 1 and resulted in the liberation of pro-fibrogenic EVs [266].

Autonomous HSC activation in vitro was associated with a 4.5 -fold increase in EV production and a switch in EV bioactivity such that EVs from quiescent HSC suppressed HSC fibrogenic gene expression whereas EVs from activated HSC stimulated HSC fibrogenesis and activation [267]. This switch was accompanied by a dramatic increase in EV proteomic complexity in which the number of EV proteins increased from 46 proteins during quiescence (with histones and keratins predominating) to 337 proteins after activation (with the principal proteins associated with extracellular spaces or ECM, proteasome, collagens, vesicular transport, metabolic enzymes, ribosomes and chaperones) [267].

EVs from portal myofibroblasts were proposed to function in hepatic vascular remodeling and the production of scar tissue because progression to cirrhosis involved the production of collagen 15A1-positive portal myofibroblasts, which localized to vessels in fibrotic septa and released vascular endothelial growth factor A (VEGFA)-rich microparticles that stimulate VEGF receptor 2 activation and tube formation in endothelial cells [268].

\subsubsection{Production and Action of EVs from Endothelial Cells or Macrophages}

EVs from immortalized liver sinusoidal endothelial cells activated AKT and migration in human LX2 HSC [269]. These effects were mediated by exosomal sphingosine kinase 1 (SK1) and sphingosine 1-phosphate (S1P), as well as exosomal FN which engaged integrin $\alpha 5 \beta 1$ on the HSC cell surface. Serum exosomes from human liver cirrhosis or alcoholic hepatitis or from mouse $\mathrm{CCl}_{4}$ or BDL hepatic fibrosis contained elevated SK1 or S1P [269]. Proliferation and activation of human LX2 HSC was stimulated by exosomes from LPSprimed THP-1 human monocytic leukemia macrophages to [270]. LPS treatment affected the concentrations of multiple exosomal miRs, including miR-103-3p, the levels of which were increased and caused suppression of its KLF4 target, thus enhancing expression of $\alpha S M A$ and collagen $1 \alpha 1$ [270].

\subsubsection{Action of EVs from the Circulation}

Differential cytokine and miR expression was reported in plasma EVs from patients with alpha-1 antitrypsin deficiency (in whom hepatic inflammation and fibrosis occur 
due to accumulated misfolded ZAAT protein in hepatocytes) and these EVs activated JAK/STAT, NF- $\mathrm{KB}$, and CXCR3/CXCL10 in human HSC in vitro [271]. In systemic mastocytosis (SM), a condition in which mast cells accumulate in excessive numbers in multiple organs and can result in hepatic fibrosis, serum EVs were enhanced and correlated with disease progression, contained common mast cell proteins and stimulated proliferation, fibrogenesis and activation in human LX2 HSC in vitro [272]. This interaction involved the delivery of phospho-KIT from EVs to HSC and its neutralization using blocking KIT antibody negated EV-mediated HSC proliferation and activation. Moreover, administration of SM-EVs in mice resulted in HSC activation and the delivery of EV-derived KIT into the HSC population [272].

Some of the pathways of EV-regulated hepatic fibrosis discussed above are shown in Figure 6.

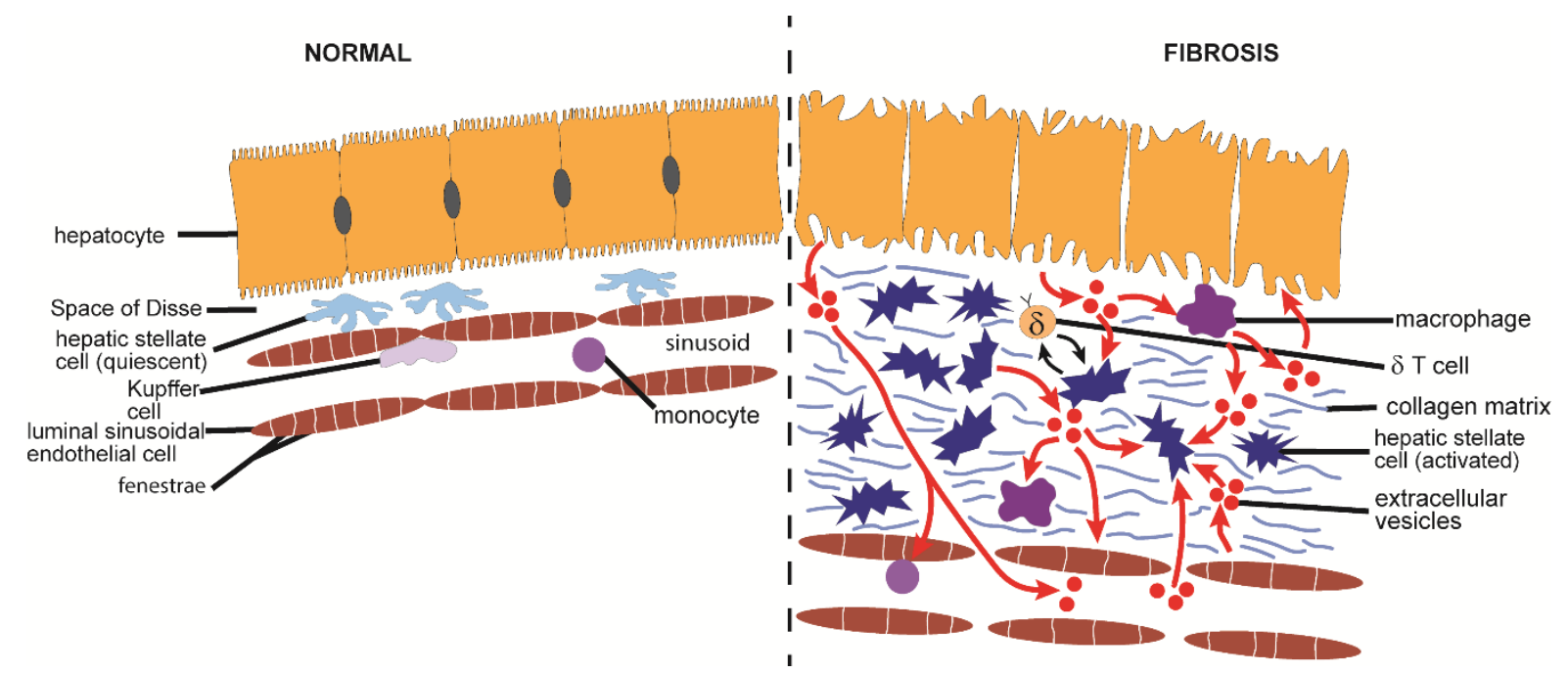

Figure 6. Proposed EV pathways in the pathogenesis of hepatic fibrosis. Hepatocytes that are injured by exposure to hepatitis viruses, alcohol, or free fatty acids produce increased numbers of EVs due to activation of EV biogenic components (e.g., ROCK-1) and suppression of autophagy-associated late endosomes. These EVs drive activation and function in macrophages or HSC, or alternatively are released into the circulation. Production by macrophages of pro-inflammatory cytokines (e.g., IL-1 $\beta$, IL-6) occurs upon interactions of hepatocyte EVs with TLR and DR5 as well as stimulation of NF- $\mathrm{kB}-$ activated NLRP3 inflammasomes. Hepatocyte EVs also stimulate TLR3 expression in HSC which causes HSC activation and drives an IL-17A positive feedback loop between HSC and $\delta \mathrm{T}$ cells that exacerbates inflammation and fibrosis. HSC activation and fibrogenesis is directly stimulated by hepatocyte EVs and involves various mechanisms such regulation of PPAR $\gamma$ by EV miR-128-3p, -27b, -130b, Smad 7 by EV miR-27a, Nrld2 by miR-181, SOCS3 by EV miR-19a, TGF- $\beta$ by miR-192, and miR-26b and its collagen $1 \alpha 2$ target by EV MALAT. HSC themselves release EVs that are enriched in PDGF $\alpha$, bind to HSC integrins and heparan sulfate proteoglycans, and stimulate HSC migration, activation, and fibrogenesis. EVs produced downstream of activation of apoptosis signaling regulating kinase 1 or HIF-1 during HSC activation deliver GLUT1 and PKM2 to quiescent HSC, KC or LSECs and are pro-fibrogenic in part due to suppressed EV miR-30a levels and a proteomic cargo that is enriched for ECM-, proteasome- and collagen-associated components. AKT activation and migration in HSC is stimulated by EVs from liver sinusoidal endothelial cells while vascular endothelial cells undergo tube formation in response to VEGF-enriched EVs from fibrotic myofibroblasts and demonstrate enhanced adhesion to monocytes in the presence of integrin- $\beta 1$-enriched EVs from lipotoxic hepatocytes. Activated macrophages produce miR-103-3p-eriched EVs that stimulate HSC activation and fibrogenesis via suppression of KLF4. EVs in serum or plasma from fibrotic patients activate HSC and are likely derived from injured hepatocytes (e.g., NAFLD, alpha-1 antitrypsin deficiency) or mast cells (e.g., systemic mastocytosis). Only cells with a demonstrated role in EV production or response are shown; some of the depicted EV pathways are deduced from in vitro observations and have not been demonstrated in vivo. See text for details. 


\subsection{Therapeutic Actions of EVs in Hepatic Fibrosis}

\subsubsection{EVs from Adult Stem Cells}

In rats, administration of human BM-MSC EVs reduced $\mathrm{CCl}_{4}$-induced liver injury, fibrosis, oxidative stress, and circulating inflammatory cytokines while increasing hepatocyte proliferation [273]. Mechanistically, the therapeutic effect was attributed to exosomemediated activation of $W n t / \beta$-catenin as shown by reduced hepatic production of PPAR $\gamma$, Wnt3a, Wnt10b, $\beta$-catenin, WISP1, cyclin D1, $\alpha S M A$, and collagen I [273]. In studies relating to BM-MSC-augmented post-liver transplant regeneration, LPS-stimulated macrophages produced enhanced levels of fibrolytic MMPs when the cells were co-cultured with BM-MSC; this was associated with the action of miR-6769b-5p, which inhibited ATF4 expression and was the most enriched miR in EVs from the co-culture supernatant, highlighting potential anti-fibrotic actions of EV miR-6769-5p [274].

EVs from AD-MSC engineered to over-produce miR-122 (a known inhibitor of fibrosis) suppressed proliferation and collagen production in activated human or mouse HSC with suppressed expression of P4HA1, IGF-1R and CCNG1 target genes [275]. Administration of miR-122-enriched AD-MSC EVs in $\mathrm{CCl}_{4}$-treated mice resulted in attenuation of hepatic fibrosis, suppression of hepatic TGF- $\beta 1$ and $\alpha S M A$ expression, and inhibition of serum ALT, hyaluronan, type III procollagen, aspartate transaminase and liver hydroxyproline [275] while mir-150-5p-enriched AD-MSC EVs were anti-fibrotic due to targeting of CXCL1 [276]. Similarly, EVs from miR-181-5p-over-expressing AD-MSCs were antifibrogenic in vitro and anti-fibrotic in vivo at least in part due to down regulation of STAT3 and Bcl2, stimulation of autophagy, and suppression of fibrogenic gene expression [277]. $\mathrm{CCl}_{4}$-induced liver fibrosis in mice resulted in downregulated levels of hepatic $m m u \_c i r c \_0000623$ and when mice were treated with EVs from AD-MSCs enriched in this circular RNA, liver fibrosis was suppressed due to promotion of miR-125/ATG4D-mediated autophagy of damaged cells, including hepatocytes [278].

In $\mathrm{CCl}_{4}$ mouse models, EVs from human UMSC caused a decrease in inflammation, acute liver injury, hepatic fibrosis, hepatic fibrotic gene expression, and hepatic tumor development $[279,280]$. These effects were accompanied by EV-mediated reduction in TGF- $\beta 1 /$ Smad signaling and myofibroblast frequency [280] as well as reduced apoptosis and oxidant stress [279]. The EVs elicited similar effects when added to TGF- $\beta 1$-treated HL7702 [280] or $\mathrm{CCl}_{4}$-treated L-02 hepatic cells in vitro [279]. EVs from human tonsilderived mesenchymal stromal cells reduced expression of $\alpha S M A, T G F-\beta, C C N 2$ and vimentin in human LX2 HSC in vitro and attenuated collagen deposition and profibrotic gene expression in $\mathrm{CCl}_{4}$-induced liver fibrosis in mice, with the therapeutic effect attributed to elevated levels of EV miR-486-5p which suppressed Smo Hh receptor expression and signaling in HSC [281]. EVs from human umbilical cord perivascular cells were antifibrotic and inhibited fibrosis-related gene expression in TAA-induced hepatic fibrosis in vivo but these effects were augmented upon prior loading of the EVs with IGF-1 by adenoviral transduction of the donor cells [282]. These EVs were also inhibitory for fibrogenesis in HSC in vitro as well as modulating inflammatory mediators (iNOS, arginase, IL-6, TNF- $\alpha$ ) in cultured macrophages [282].

In $\mathrm{CCl}_{4}$-treated mice or rats, hepatic fibrosis was suppressed by administration of EVs from human AECs $[283,284]$. The therapeutic effect in vivo was linked to the presence in EVs of MFGE8, HSP72, and superoxide dismutase 1 (SOD1) which attenuate TGF- $\beta$ regulated processes such as fibrosis and myofibroblast production as well as decreased macrophage infiltration and with increased macrophage polarization to the M2 phenotype, possibly by regulation of PI3K/Ak [283,284]. Similar outcomes occurred in rat high fat diet NASH models in which hepatic inflammation, inflammatory cytokines and KC activation were reduced by AEC EVs [284].

Administration of EVs from human liver stem cells to SCID mice with diet-induced NASH resulted in decreased serum ALT, hepatic fibrosis and expression of fibrosis- and inflammation-related genes [285]. $\mathrm{CCl}_{4}$-induced fibrosis in rats was also reduced by liver stem cell EVs and this effect was enhanced by co-administration with the tyrosine 
kinase inhibitor Nilotinib [286]. Liver stem cell-derived EVs reduced the ductular reaction, cholangiocyte growth, hepatic fibrosis, and HSC activation in $\mathrm{Mrd2} 2^{-/-}$mice and this was attributed to the action of let-7 in the EVs, which caused multiple targets of let-7 to be suppressed in vivo or in cultured cholangiocytes [287]. HSC were deactivated in culture when treated with supernatant from EV-treated cholangiocytes suggesting that liver stem cell EV therapy of cholangiopathic injuries is likely attributable to their direct effects on cholangiocytes and indirect effects on HSC [287].

\subsubsection{EVs from iPSCs}

Human iPSCs obtained by reprogramming primary skin fibroblasts released EVs that contained high levels of 22 miRs including miR-92a-3p, 302-3p, and 10b-5p which have potential antifibrotic properties [288]. In cultured TGF- $\beta$-treated human primary HSC, iPSC EVs suppressed fibrogenic gene expression, chemotaxis, and proliferation and resulted in significant up- or down-regulation of 295 genes. iPSC EVs suppressed hepatic fibrosis in mouse $\mathrm{CCl}_{4}$ and BDL injury models [288].

\subsubsection{EVs from ESC}

Administration of EVs from human ESC during thioacetamide (TAA) administration in rats resulted in less chronic liver injury as shown by reduced hepatic fibrosis, suppressed expression of fibrogenic, inflammatory and apoptotic genes, and increased expression of collagenases, anti-apoptotic genes, and anti-inflammatory molecules [289].

\subsubsection{EVs from Hepatocytes}

EVs produced by mouse hepatocytes bound to integrins $\alpha \mathrm{v} \beta 3$ and $\alpha 5 \beta 1$ on the surface of activated mouse HSC or ethanol-treated mouse hepatocytes in which, respectively, fibrogenesis and cell death were subsequently suppressed [265,290,291]. Similarly, human hepatocytes produced EVs that dampened activation and fibrogenesis in activated mouse HSC and which rescued human or mouse hepatocytes or $\mathrm{HSC}$ from $\mathrm{CCl}_{4}$-mediated damage or altered gene expression [291]. Hepatocyte EVs bound preferentially to hepatocytes and HSC in vivo [290] and blocked $\mathrm{CCl}_{4}$ hepatic fibrosis in mice through their attenuation of hepatocyte damage, pro-inflammatory pathways, $\mathrm{HSC}$ activation, and modulation of $\mathrm{CCl}_{4}$ regulated hepatic genes [291]. CRISPR/dCAs9/VP64 in EVs from transfected AML12 mouse hepatocytes was delivered in vitro to mouse HSC in which expression of $d$ Cas 9 , E-cadherin, and hepatocyte nuclear factor- $4 \alpha(H N F-4 \alpha)$ was increased and expression of $\alpha S M A$ and collagen 1 was decreased, while i.v. administration of the fluorescently-tagged EVs resulted in their localization to mouse liver and were proposed as a fibrosis therapy [292].

\subsubsection{EVs from HSC}

Quiescent HSC produce EVs that attenuate fibrogenic functions of activated HSCs $[37,293,294]$. This was attributed to the presence in EVs of miR-199a-5p or miR-214 (or their Twist-1 transcripton factor) which target CCN2 mRNA and caused suppressed expression of CCN2 and downstream targets collagen $1 \alpha 1$ and $\alpha S M A$ in activated HSC $[37,293,294]$.

\subsubsection{EVs from T Cells, Macrophages or Natural Killer Cells}

CD4+ or CD8+T cell microparticles were more abundant in the circulation of patients with chronic hepatitis $\mathrm{C}(\mathrm{CHC})$ while microparticles purified from Jurkat $\mathrm{T}$ cells utilized CD11a/CD18 to bind to HSC via cellular CD54 (ICAM-1) [295]. This binding resulted in increased expression of fibrolytic genes (MMP-1, -3, -9, -13) and this was partly dependent on CD147 (emmprin) and involved activation of ERK1/2 and NFKB pathways [295]. Recent data suggest that the well-characterized elevation of IL-6 levels in NAFLD actually limits the fibrotic response by stimulating macrophage production of miR-223-enriched EVs which are delivered to hepatocytes causing expression of the miR-223 pro-fibrotic target, transcriptional activator with PDZ-binding motif (TAZ), to be inhibited [296]. EVs from NK-92MI natural killer cells inhibited TGF- $\beta 1$-induced proliferation and expression of 
$\alpha S M A$ and collagen $1 \alpha 1$ in human LX2 HSC in vitro and, when administered to $\mathrm{CCl}_{4}$-treated mice, the EVs caused normalization of serum AST/ALT, reduced collagen deposition and attenuation of fibrotic markers [297]. These therapeutic effects were attributed to EV-mediated delivery of miR-223, which targeted ATG7 and suppressed autophagy in HSC [298].

\subsubsection{EVs from Serum}

In vitro, serum EVs from normal mice decreased HSC proliferation and fibrotic gene expression and reversed $\mathrm{CCl}_{4}$ - or ethanol-mediated inhibition of hepatocyte proliferation [299]. Administration of serum $\mathrm{EVs}$ to $\mathrm{CCl}_{4}$ - or TAA-treated mice resulted in reduced hepatic fibrosis, hepatocyte death, inflammatory infiltration, circulating AST/ALT levels and hepatic or circulating pro-inflammatory cytokines whereas serum EVs from fibrotic mice were not therapeutic. MiRs-34c, -151-3p, -483-5p, -532-5p and -687 were enhanced in serum EVs from normal mice as compared to their fibrotic counterparts and inhibited HSC fibrogenesis and hepatocyte injury [299]. Human LX-2 HSC activation was similarly attenuated by serum EVs from healthy human subjects and these EVs contained a similar enrichment of anti-fibrogenic miRs when compared to serum EVs from hepatic fibrosis patients [299].

\subsection{EVs as Biomarkers in Hepatic Fibrosis}

Circulating EVs in experimental or clinical NAFLD or NASH occur at higher frequency and may contain hepatocyte components or markers [243,244,248,249]. In experimental NAFLD, the number of EVs in serum or plasma was correlated with cell death, fibrosis and pathological angiogenesis [248] while F3/F4 patients with NAFLD had frequencies of EVs that were, respectively, increased from plasma platelets or CD31+ leukocytes and decreased from endothelial cells or other leukocyte populations [300]. The association between F3/F4 fibrosis and the liver fibrosis score (LFS) algorithm was improved by inclusion of the CD14+ or CD16+ leukocyte EV frequency, each of which also improved the risk prediction of F3/F4 fibrosis in NAFLD [300].

Serum exosomal miRs discriminated between chronic hepatitis B (CHB), chronic hepatitis $\mathrm{C}(\mathrm{CHC}), \mathrm{NASH}$ and normal individuals while also distinguishing between hepatic inflammation and fibrosis [301]. Progression of hepatic fibrosis in CHC was associated with diminished expression of let-7a and miR-106b, -1274a, -130a, -140-3p, -151-3p, -181a, -19b, $-21,-24,-375,-5481,-93$ and -941 and enhanced expression of miR-483-5p and -672-5p [301]. Plasma EVs from F0-F2 HBV or HCV patients showed significant decreases in miR-150, $-192,-200 b$, and $-92 a$ levels as compared to healthy controls and these miRs were also downregulated during activation of human HSC in vitro [302]. These miRs did not show the same discriminatory power when measured directly in plasma and were proposed as novel EV markers for early hepatic fibrosis [302]. In CHC, circulating let-7a-5p was correlated negatively with the severity of hepatic fibrosis but not inflammation and had similar efficacy as transient elastography in discriminating liver cirrhosis [303]. Whereas let-7a-5p in serum EVs was also correlated with hepatic fibrosis severity, it was a less powerful measurement than free let-7a-5p. In the same study, miR-122-5p in serum or EVs was correlated with liver damage but was not correlated with hepatic fibrosis or inflammation [303]. Serum exosomal miR-103-3p levels allowed discrimination between HBV patients with no, mild or severe hepatic fibrosis, consistent with the role of exosomal miR-103 in macrophage-mediated activation of HSC (see above) [270]. Plasma EVs from $\mathrm{CCl}_{4}$-treated rats contained upregulated mir-122, $-99 \mathrm{~b}$, and -192 and downregulated miR-100 and these were variably differentially expressed when the rats were treated with anti-fibrotic phosphodiesterase 5 inhibitor supporting their potential as biomarkers during fibrosis therapy [304]. Finally, in Schistosoma infection, levels of serum exosomal miR-92a-3p, 146a-5p and 532-5p discriminated patients with grades I-III hepatic fibrosis from those with no hepatic fibrosis, while exosomal miR-146a-5p also showed promise 
for discriminating grades 0-I (mild) hepatic fibrosis from grades II-III (severe) hepatic fibrosis [305].

\section{Pancreatic Fibrosis}

\subsection{Causes and Pathological Features of Pancreatic Fibrosis}

Pancreatic fibrosis is a major pathophysiological feature of chronic pancreatitis or desmoplastic stroma in pancreatic ductal adenocarcinoma (PDAC) [306,307]. Pancreatitis is often associated with chronic alcohol consumption and results in acinar cell injury and protease-driven autodigestion. The acute form of the disease involves episodic pancreatic inflammation which, if severe and continuous, can lead to chronic pancreatitis which is characterized by progressive acinar cell destruction, extensive perilobular and intralobular fibrosis, and reduced exocrine or endocrine function leading to, respectively, maldigestion or diabetes [307]. The fibrotic component reflects the unabated matrigenic actions of pancreatic stellate cells (PSC) which reside in peri-acinar and peri-ductular locations and are functionally similar to HSC in the liver [308,309]. PSC also play a central role in the development of desmoplasia in PDAC, an extremely aggressive disease in which most patients present with non-resectable tumors at the time of diagnosis [306,308]. A major histopathological feature of PDAC is an abundant interstitial stroma comprising fibroblasts, myofibroblasts, inflammatory cells and PSC and an extensive ECM that may constitute $80 \%$ of the tumor mass and which functions to sustain tumor growth and increase its invasive potential [310,311].

\subsection{Mechanistic Aspects of EVs in Pancreatic Fibrosis}

In chronic pancreatitis in mice, miR-21 expression was upregulated in PSC and participated with CCN2 in cellular or EV positive feedback loops to drive collagen expression [36]. When added to pancreatic cancer cells, exosomes from PSC or cancer-associated fibroblasts caused increased cancer cell aggressiveness, proliferation, migration, EMT, activation of ERK1/2, AKT, and expression of CXCL1/2, in part due to the actions of exosomal miR-21, -451a, and -5703. [312-315]. On the other hand, exosomes from pancreatic cancer cells promoted PSC proliferation, migration, fibrogenesis and recruitment, due to activation of a Lin28B/let-7/HMGA2/PDGFB axis in PSC by exosomal lin28 protein [316] and stimulation of PSC fibrogenesis by miR-1290 [317]. Thus PDAC progression and desmoplasia are driven by bi-directional EV transfer between cancer and stromal compartments.

\section{Skin Fibrosis}

\subsection{Causes and Pathological Features of Skin Fibrosis}

Healing of skin wounds involves coordinated interaction between multiple cell types (keratinocytes, fibroblasts, endothelial cells, immune cells). Epidermal re-epithelialization is generally achieved at high fidelity but macrophage recruitment into the dermis is a trigger for (usually limited) scarring due to activation and matrigenesis in wound fibroblasts and myofibroblasts [318]. This response is exaggerated and modified in hypertrophic scars and keloids which lack effective treatments and cause discomfort, functional disability, and psychological distress [319]. Hypertrophic scars are often a disfiguring result of surgery or trauma (e.g., burns) and contain an abundance of myofibroblasts, oriented collagen bundles, and regress partially, while keloids contain thick collagen bundles, few fibroblasts, extend beyond the wound margin, do not regress, have occluded blood vessels, and are more common in dark-skinned individuals [320-322].

Skin fibrosis can also occur in immune-related disease processes. For example, systemic sclerosis (SSc) or scleroderma is a rare life-threatening systemic autoimmune disease with a highly dysregulated immune response, endothelial damage, fibroproliferative vasculopathy, and progressive fibrosis in the skin and numerous internal organs [323]. Depending on the extent of skin involvement, SSs is clinically classified as a limited form associated with pulmonary arterial hypertension or a diffuse cutaneous form that is associated with pulmonary fibrosis [323]. As another example, inflammation and fibrosis 
of multiple organs (skin, mucosa, lungs) is a feature of chronic graft versus host disease (cGVHD) which typically occurs in long-term survivors of allogeneic hematopoietic stem cell transplantation to treat hematologic malignancy [324]. cGVDH patients face disablement due to fibrosis of the skin and joints as well as the life-threatening consequences of pulmonary fibrosis [324].

\subsection{Mechanistic Aspects of EVs in Skin Fibrosis}

In SSc patients with lung fibrosis, there was a marked increase in annexin $\mathrm{V}^{-}$endothelial cell-derived EVs in plasma which was associated with diffuse SSc [325]. In vitro, SSc fibroblasts expressed higher levels of EV-associated tetraspanins and produced more EVs than normal fibroblasts [326]. SSc fibroblast EVs stimulated collagen production in normal fibroblasts and contained higher levels of miR-142-3p and lower levels of miR-150a and -196a [326]. Serum EVs from SSc patients also contained higher tetraspanin levels than in control patients [327] but serum EV concentrations were reduced in SSc patients, possibly due to impaired EV transport from skin to bloodstream due to SSc-associated vasculopathy [326]. Vasculopathy and microvascular fibrosis were linked to inhibition of endothelial cells by serum- or neutrophil-derived EVs, possibly mediated by S100 calcium binding proteins [327]. As compared to control patients, serum EVs from patients with diffuse SSc were enriched with a profibrotic transcriptome, a subset of which was shared with serum EVs from limited SSc; these cargo differences were reflected in their relative in vitro fibrogenic actions [328]. Similarly, EVs purified from cultured peripheral blood neutrophils from diffuse SSc patients contained 22 differentially regulated miRs and 281 differentially regulated lncRNAs that were associated with fibrosis-related signaling by Wnt, AMPK, Il-23 and Notch, with concomitant changes in these pathways being induced in EV-treated endothelial cells or fibroblasts [329]. Finally, EVs from wound myofibroblasts contained FGF2 and VEGF and promoted proliferation of dermal fibroblasts, wound myofibroblasts, and endothelial cells [330]. In vitro, serum or plasma stimulated production of EVs by wound fibroblasts but not by dermal fibroblasts or fibroblasts from hypertrophic scar, suggesting that production of myofibroblast EVs is dynamically regulated by myofibroblast phenotype [330].

\subsection{Therapeutic Actions of EVs in Skin Fibrosis \\ EVs from Adult Stem Cells}

BM-MSC produced EVs that were therapeutic for systemic cGVHD in mice, including anti-fibrotic effects in the skin, lung, and liver [331]. Principal therapeutic effects included correction of cGVDH-associated alterations in T cell immune responses [331]. Umbilical cord-derived MSC EVs accelerated wound closure and reduced scar formation and myofibroblast frequency in full thickness skin wounds in nude mice and also reduced TGF$\beta$-induced $\alpha S M A$ and proliferation, migration and contraction in fibroblasts in vitro [332]. These actions were linked to exosomal miR-21, miR-23a, miR-100, miR-125b, and miR-145 which targeted components of the TGF- $\beta$-Smad 2 axis [332]. These EVs also attenuated skin fibrosis in a mouse model of cGVHD by reducing macrophage frequency and expression of TGF- $\beta / S \operatorname{mad} 2$ while also modulating B cell-mediated immune responses [333].

When added to fibroblasts in vitro, EVs from human AECs promoted proliferation, wound migration, and expression of MMP1 while decreasing expression of collagen I and III [334]. In vivo, AEC EVs reduced scar formation in full thickness skin wounds in rats by promoting more rapid would closure and improving collagen organization [334]. Similar accelerated healing occurred in full thickness wounds in mice that were treated with mouse serum exosomes, although collagen expression was not significantly altered [326].

\section{Perspective and Concluding Remarks}

Considerable evidence has accumulated over the last few years, which supports the notion that fibrosis is an EV-regulated pathology in multiple organs. Regarding the role of EVs that are instrinsically produced during fibrosis, the principal findings are that cellular trans- 
differentiation into myofibroblasts or the activation of myofibroblasts and their production of fibrosis-related signaling molecules or components (e.g., TGF- $\beta, C C N 2$, PDGF, $\alpha$ SMA, $\mathrm{FN}$, collagen, tissue inhibitors of MMPs), are stimulated by EVs that derive from cells (or fluids) in the vicinity of the fibrosing injury, or that are produced by these cells in vitro when they experience damage or stress or in response to environmental or molecular cues that promote migration, infiltration or activation. These direct pro-fibrogenic effects are elicited by EVs from many different cell types that play an orchestrated role in wound repair responses including epithelial cells, macrophages, neutrophils, T cells, B cells, interstitial fibroblasts, myofibroblasts and endothelial cells as well as by endothelium-associated cells such as pericytes, podocytes and HSC. Even so, many conclusions are based on in vitro observations in which either purified EVs from a presumptive EV donor cell type are investigated for their effects on fibrogenic readouts in cultured myofibroblasts or co-culture approaches are used to provide evidence of functional EV-mediated interactions between injured or damaged donor cells and recipient fibrogenic cells. Currently, there is a lack of compelling evidence that these intrinsic EV pathways exist in vivo as de facto drivers of fibrosis and proof for this will necessitate technically challenging approaches that involve cell-specific interruption of EV biogenesis, cargo loading, delivery or targeting in animal models of fibrosis. While definitive answers to this question will likely require the use of genetically modified animals in which EV production, trafficking or responses are altered, support for intrinsic EV-mediated regulation of fibrosis has come from studies demonstrating fibrosis progression by injury-related EVs in vivo [68,72,109,170,179,182,251,257-260] and by the suppression of experimental renal or cardiac fibrosis in vivo by chemical- or drug-induced attenuation of EV secretion or miR content. [108,109,174,185]. A further mechanistic complication is that fibrosis is preceded by tissue injury and inflammation and the involvement of EVs in any one of these processes may be permissive for downstream pro-fibrotic pathways. Indeed, EVs from damaged or effector cells can exacerbate parenchymal dysfunction as well as promote infiltration and/or activation of immune cells and macrophages and these are likely important mechanisms, albeit indirect, by which a fibrotic environment is favored or primed by injury-related EVs. That said, EVs drive fibrosis by regulating a broad variety of well-characterized fibrosis-associated signaling pathways and several of these such as Wnt/ $\beta$-catenin, Notch, YAP/TAZ, PTEN, AKT, PPAR, HIF, NF-kB, CXCR/CXCL, and MAPK/ERK are implicated in EV pro-fibrotic actions across multiple organ systems (Table 1 ).

Table 1. Representative examples of fibrosis-related signaling pathways or components that are affected by pathogenic or therapeutic EVs in different organ systems.

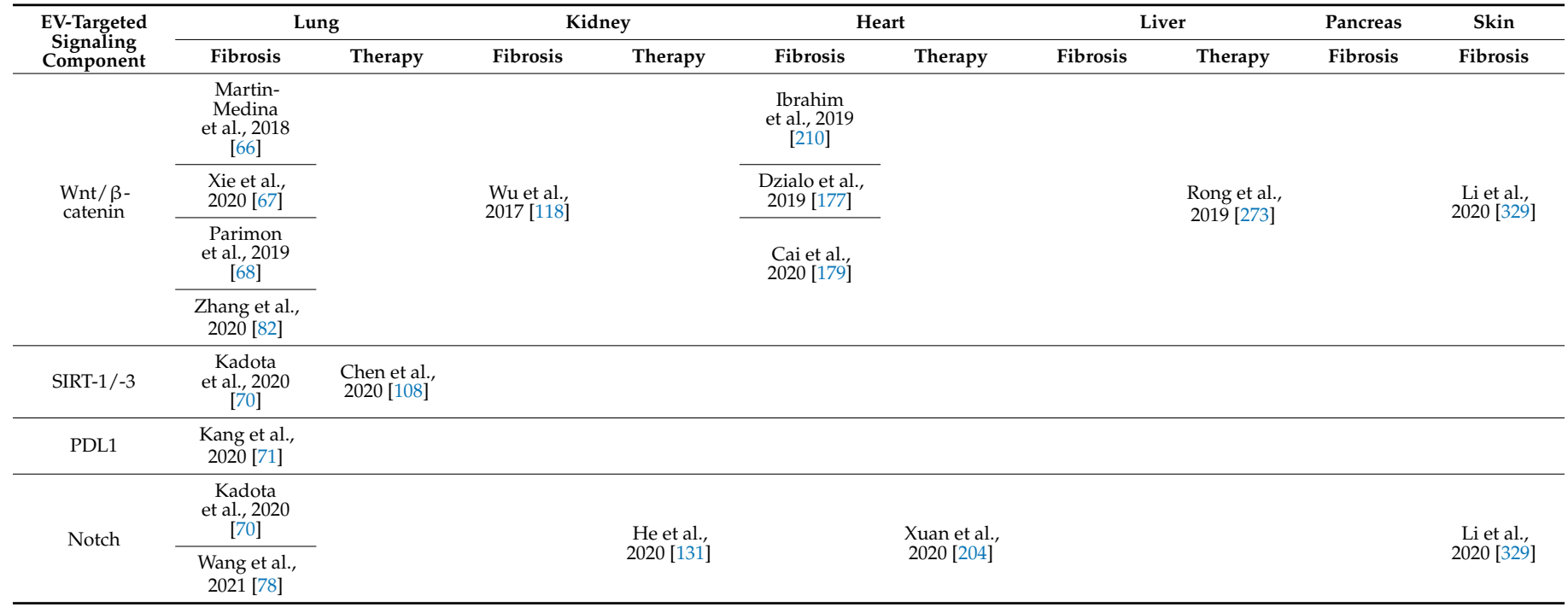


Table 1. Cont.

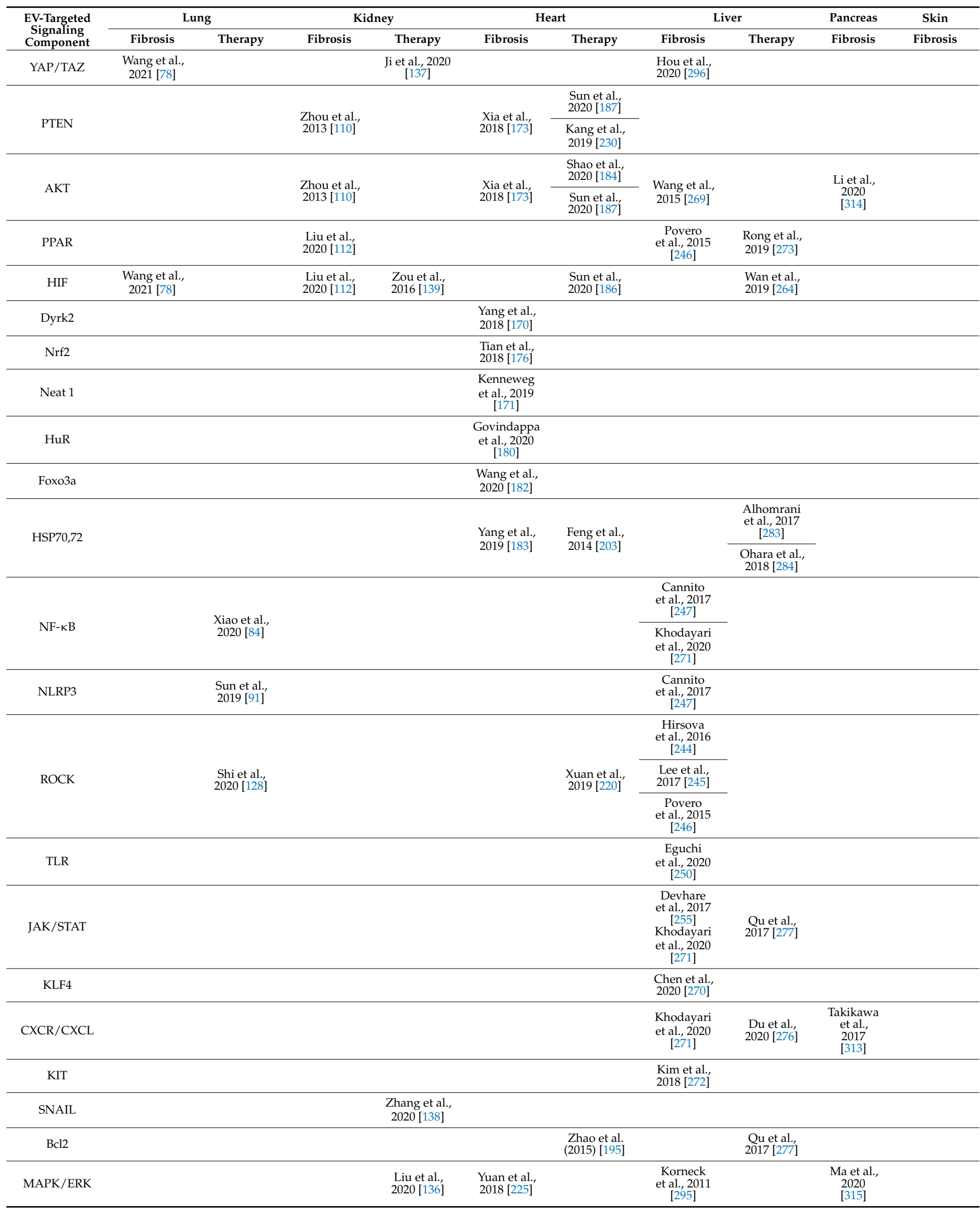


With respect to therapeutic aspects, there is abundant evidence that experimental fibrosis in many different organ systems is attenuated by EVs from numerous varied sources. As well as direct targeting of pro-fibrotic factors such as TGF- $\beta$, CCN2, PDGF, and TIMPs, the actions of therapeutic EVs in multiple organs arise due to their modulation of well-characterized fibrosis-associated signaling pathways (Table 1). Even so it is very apparent that in vivo anti-fibrogenic effects in myofibroblasts by therapeutic EVs frequently occur in conjunction with broader therapeutic effects including improved scores for cell injury, inflammation and immune function. Thus anti-fibrotic effects of EVs may arise through their targeting of upstream pathways in other injury-related cell types rather than (or in addition to) myofibroblastic fibrogenesis and this question has only been addressed in a few studies, for example by delaying EV administration until inflammation has waned and fibrosis is well-established. Furthermore, demonstration of anti-fibrogenic actions in vitro does not preclude more complex EV behavior in vivo. More studies are needed to understand the mechanistic basis of anti-fibrotic EVs by establishing their full repertoire of cellular interactions and targets after injury. With these caveats in mind, a plethora of exciting and innovative strategies have been used to investigate EV-based anti-fibrotic therapy. Successful therapeutic outcomes in experimental organ fibrosis have been obtained using EVs from a strikingly broad slate of cell types including non-injured parenchymal cells, fibroblasts, stem cells, macrophages, immune cells, and endothelial cells as well as from body fluids such as serum or plasma. The anti-fibrotic actions of EVs from stem cells are of particular interest because they offer a potentially safer alternative to their producer stem cells which are themselves therapeutic in many diseases and fibrotic conditions but are associated with a potential for tumorigenesis and low rates of engraftment which reduces therapeutic efficacy [335]. Stem cell EVs have unequivocally emerged as being broadly applicable for treatment of many types of organ fibrosis irrespective of the stem cell source (Table 2) and it is quite possible that stem cell EVs will have utility as cell-free pan-organ anti-fibrotics. Since many of the studies to date have involved EV effects on a wide variety of different and sometimes disparate signaling pathways, future studies will need to focus on whether EV anti-fibrotic actions across different organs occur as the result of the regulation of shared targets by the same EV cargo components.

Table 2. Anti-fibrotic properties and actions of stem cell EVs.

\begin{tabular}{|c|c|c|c|c|c|}
\hline EV Source & $\begin{array}{c}\text { Organ } \\
\text { Targeted }\end{array}$ & Fibrosis Model & Principal EV Effects & $\begin{array}{l}\text { EV Features Associated } \\
\text { with Therapy }\end{array}$ & Reference \\
\hline \multirow{4}{*}{ Bone marrow MSC } & \multirow{4}{*}{ lung } & \multirow[t]{2}{*}{ bleomycin } & $\begin{array}{l}\text { - Reversal of septal thickening and fibrosis, } \\
\text { including late fibrotic stages lacking } \\
\text { inflammation } \\
\text { Promotion of anti-inflammatory } \\
\text { immunoregulatory monocytes or } \\
\text { macrophage phenotypes in lung and } \\
\text { bone marrow. }\end{array}$ & $\begin{array}{l}\text { Targeting of } F Z D 6 \text { by } \\
\text { miR-29b-3p }\end{array}$ & [79] \\
\hline & & & $\begin{array}{l}\text { - Decreased fibrosis, hydroxyproline in } \\
\text { lung tissue }\end{array}$ & & [83] \\
\hline & & hyperoxia-induced BPD & $\begin{array}{l}\text { - Improved lung function, decreased } \\
\text { fibrosis, vascular remodeling, reversal of } \\
\text { pulmonary hypertension } \\
\text { Stimulation of M2 macrophages and } \\
\text { corrected expression of genes involved in } \\
\text { immunity and inflammation }\end{array}$ & & [80] \\
\hline & & $\begin{array}{l}\text { LPS-induced acute lung } \\
\text { injury }\end{array}$ & $\begin{array}{ll}\text { - } & \text { Suppressed } \alpha \mathrm{SMA}, \mathrm{TGF}-\beta \text {, and } \operatorname{Col} \text { I } \mathcal{E} \\
\text { III } & \text { Suppressed p65, IKK } \beta, \mathrm{p}-\mathrm{IKB} \alpha, \mathrm{p}-\mathrm{IKB} \beta \text {, } \\
\text { Shh }\end{array}$ & $\begin{array}{l}\text { Inactivation of } N F \kappa B \\
\text { and } H h \text { pathways by EV } \\
\text { miR-182-5p and } \\
\text { miR-23a-3p }\end{array}$ & [84] \\
\hline
\end{tabular}


Table 2. Cont.

\begin{tabular}{|c|c|c|c|c|c|}
\hline EV Source & $\begin{array}{c}\text { Organ } \\
\text { Targeted }\end{array}$ & Fibrosis Model & Principal EV Effects & $\begin{array}{c}\text { EV Features Associated } \\
\text { with Therapy }\end{array}$ & Reference \\
\hline & \multirow{6}{*}{ kidney } & \multirow{3}{*}{ Stz DN } & $\begin{array}{l}\text { - Correction of interstitial fibrosis, tubular } \\
\text { expansion, TEC vacuolation, atrophy and } \\
\text { TGF- } \beta \text { expression }\end{array}$ & & [125] \\
\hline & & & $\begin{array}{l}\text { Decreased mesangial expansion, collagen } \\
\text { deposition, TGF- } \beta \text { production, } \\
\text { glomerular basement membrane } \\
\text { thickening } \\
\text { - Increased LC3, beclin-1, decreased mTOR } \\
\text { \& fibrotic markers } \\
\text { Induction of autophagy }\end{array}$ & & [126] \\
\hline & & & $\begin{array}{l}\text { Restoration of renal function, reduced } \\
\text { glomerular basement membrane } \\
\text { thickening, glomerular hypertrophy } \\
\text { Reduced tubulointerstitial fibrosis and } \\
\text { expression of fibrosis-associated genes }\end{array}$ & $\begin{array}{l}\text { EV miRs predicted to } \\
\text { target TGF- } \beta, E G F R, \\
P D G F R, A R F-6, m T O R, \\
V E G F, \text { p53-apoptosis, } \\
\text { ZTM, TNF pathways }\end{array}$ & [127] \\
\hline & & AA CKD & $\begin{array}{l}\text { - } \quad \text { Restored kidney function } \\
\text { Reduced tubular necrosis, fibrosis and } \\
\text { CD } 45+\text { cells } \\
\text { Reduced expression of collagen } 1 \alpha 1 \text {, } \\
\text { TGF } \beta 1, \alpha S M A \\
\text { Downregulated miR-21, }-34,-132,-342, \\
-212,-214 ; \text { Upregulated miR-194, }-192, \\
-378 \text { a }\end{array}$ & & [143] \\
\hline & & \multirow[t]{2}{*}{ UUO } & $\begin{array}{l}\text { Reduced tubular dilation, interstitial } \\
\text { expansion, collagen deposition, } \\
\text { inflammatory cell infiltration, expression } \\
\text { of Kim-1, collagen IV } \alpha 1, T G F-\beta 1, T G F-\beta R 1\end{array}$ & $\begin{array}{l}\text { EVs were } \\
\text { experimentally } \\
\text { augmented with } \\
\text { miR-Let7c }\end{array}$ & [130] \\
\hline & & & $\begin{array}{l}\text { Reduced fibrosis, inflammation, } \\
\text { oxidative stress, apoptosis }\end{array}$ & $\begin{array}{l}\text { Inhibition of } \\
\text { Rho/ROCK by EV } \\
\text { MFG-E8 }\end{array}$ & [128] \\
\hline & \multirow{7}{*}{ heart } & \multirow{7}{*}{ MI } & $\begin{array}{l}\text { - } \quad \text { Reduced cardiac fibrosis } \\
\text { Reduced cardiomyocyte apoptosis } \\
\text { in vitro due to suppression of Mecp } 2 \text { by } \\
\text { miR-22 }\end{array}$ & $\begin{array}{c}\text { EVs were from } \\
\text { miR-22-transfected } \\
\text { MSC since ischemic } \\
\text { conditioning of MSC } \\
\text { led to elevated miR-22 } \\
\text { in EVs. }\end{array}$ & [191] \\
\hline & & & $\begin{array}{l}\text { Improved heart function (ejection } \\
\text { fraction, fractional shortening) and } \\
\text { vascularity. } \\
\text { Decreased infarct size, fibrosis, and } \\
\text { cardiomyocyte apoptosis; increased } \\
\text { recruitment of CPC }\end{array}$ & $\begin{array}{l}\text { EVs were from ischemic } \\
\text { conditioned MSC and } \\
\text { contained elevated } \\
\text { miR-210. } \\
\text { Cardioprotective effects } \\
\text { were associated with } \\
\text { miR-210 }\end{array}$ & [192] \\
\hline & & & $\begin{array}{l}\text { Improved heart function and vascularity } \\
\text { Decreased apoptosis, inflammation, } \\
\text { inflammatory cytokines, and } \\
\text { fibrosis/infarct size } \\
\text { M1 macrophages decreased, M2 } \\
\text { macrophages increased }\end{array}$ & $\begin{array}{c}\text { EVs were } \\
\text { experimentally } \\
\text { augmented with } \\
\text { Lamp2b-IMPT to target } \\
\text { ischemic myocardium }\end{array}$ & [188] \\
\hline & & & $\begin{array}{l}\text { Decreased infarct size, fibrosis, and } \\
\text { expression of TGF- } \beta \text { or collagen I } \\
\text { Improved heart function } \\
\text { Increased M2 macrophage frequency, } \\
\text { reduced serum pro-inflammatory } \\
\text { cytokines } \\
\text { Decreased expression of } L C 3 B\end{array}$ & $\begin{array}{l}\text { EV therapy enhanced } \\
\text { by enrichment with } \\
\text { miR-101 which blocks } \\
\text { autophagy }\end{array}$ & [185] \\
\hline & & & $\begin{array}{l}\text { - Improved survival of EV-preconditioned } \\
\text { CSC } \\
\text { Improved angiogenesis and cardiac } \\
\text { function, reduced fibrosis }\end{array}$ & $\begin{array}{l}\text { EV treatment of CSC } \\
\text { before CSC therapy. } \\
\text { In CSC, EVs caused } \\
\text { increased expression of } \\
\text { genes associated with } \\
\text { angiogenesis, heart } \\
\text { development, cell } \\
\text { proliferation, migration } \\
\text { and differentiation }\end{array}$ & [193] \\
\hline & & & $\begin{array}{l}\text { Preserved cardiac function, enhanced } \\
\text { angiogenesis, reduced fibrosis }\end{array}$ & $\begin{array}{c}\text { EVs were } \\
\text { experimentally } \\
\text { augmented with } \\
\text { HIF-1 } \alpha\end{array}$ & [186] \\
\hline & & & $\begin{array}{l}\text { - Improved endothelial function and } \\
\text { cardiomyocyte survival } \\
\text { Decreased fibrosis }\end{array}$ & $\begin{array}{c}\text { EV miR-221-3p } \\
\text { inhibited PTEN leading } \\
\text { to stimulation of AKT } \\
\text { and suppression of } \\
\text { apoptosis }\end{array}$ & [187] \\
\hline
\end{tabular}


Table 2. Cont.

\begin{tabular}{|c|c|c|c|c|c|}
\hline EV Source & $\begin{array}{l}\text { Organ } \\
\text { Targeted }\end{array}$ & Fibrosis Model & Principal EV Effects & $\begin{array}{c}\text { EV Features Associated } \\
\text { with Therapy }\end{array}$ & Reference \\
\hline & & Pressure-overload & $\begin{array}{l}\text { Reduced cardiac hypertrophy, } \\
\text { myocardial apoposis, and fibrosis }\end{array}$ & $\begin{array}{l}\text { EV-mediated } \\
\text { senescence in cardiac } \\
\text { myofibroblasts }\end{array}$ & [190] \\
\hline & liver & $\mathrm{CCl}_{4}$ & $\begin{array}{l}\text { Enhanced LFTs and hepatocyte } \\
\text { regeneration } \\
\text { Reduced fibrosis, inflammation and } \\
\text { oxidative stress } \\
\text { - } \quad \text { Inhibition of Wnt / } \beta \text {-catenin pathway }\end{array}$ & & [273] \\
\hline & skin & cGVDH & $\begin{array}{ll}- & \text { Improved survival and pathology score } \\
- & \text { Reduced fibrosis in skin, lung, liver } \\
\text { - } & \text { Modulation of effector T cell populations, } \\
\text { suppressing Th17 cells and inducing Treg }\end{array}$ & & [331] \\
\hline \multirow{11}{*}{ Adipose tissue MSC } & lung & Particulate inhalation & $\begin{array}{l}\text { - } \quad \text { Reduced apoptosis and necrosis in Type } \\
\text { II alveolar cells } \\
\text { - Suppressed ROS, inflammation, fibrosis }\end{array}$ & $\begin{array}{l}\text { Suppression of TGF- } \beta R 1 \\
\text { by EV let-7d-5p }\end{array}$ & [87] \\
\hline & \multirow{4}{*}{ kidney } & \multirow{3}{*}{$\begin{array}{l}\text { Metabolic syndrome + } \\
\text { renal artery stenosis }\end{array}$} & $\begin{array}{l}\text { Attenuation of renal inflammation and } \\
\text { fibrosis, improved medullary } \\
\text { oxygenation } \\
\text { Restoration of kidney function (kidney } \\
\text { volume, RBF, GFR, serum creatinine) }\end{array}$ & $\begin{array}{l}\text { EV IL-10 mRNA } \\
\text { expressed 100x higher } \\
\text { than in producer cells. } \\
\text { EVs non-therapeutic } \\
\text { upon knockdown of } \\
\text { IL-10 in MSC. }\end{array}$ & [132] \\
\hline & & & $\begin{array}{l}\text { - Reduced peritubular capillary loss and } \\
\text { fibrosis }\end{array}$ & $\begin{array}{l}\text { EVs from } \\
\text { GDNF-transfected } \\
\text { AD-MSCs; enhanced } \\
\text { SIRT-1 and eNOS in } \\
\text { endothelial cells }\end{array}$ & [108] \\
\hline & & & $\begin{array}{l}\text { Increased M2 macrophages and } \\
\text { anti-inflammatory CD8+ T cells, } \\
\text { decreased M1 macrophages and } \\
\text { oxidative stress }\end{array}$ & $\begin{array}{l}\text { EV TGF- } \beta \text { associated } \\
\text { with anti-inflammation; } \\
\text { EV mitochondrial- } \\
\text { regulating miRs } \\
\text { associated with reduced } \\
\text { oxidative stress }\end{array}$ & [133] \\
\hline & & UUO & $\begin{array}{l}\text { - } \quad \text { Suppressed oxidative stress and } \\
\text { apoptosis and increased proliferation in } \\
\text { TEC } \\
\text { - } \quad \text { Reduced fibrosis }\end{array}$ & $\begin{array}{l}\text { EV delivery of casein } \\
\text { kinase } 1 \delta \text { and } \mathrm{E} 3 \\
\text { ubiquitin ligase } \\
\beta-\mathrm{TRCP} \text {, targeting YAP } \\
\text { and collagen }\end{array}$ & {$[136,137]$} \\
\hline & $\begin{array}{l}\text { kidney \& } \\
\text { heart }\end{array}$ & $\begin{array}{c}\text { DOCA-salt } \\
\text { hypertension }\end{array}$ & 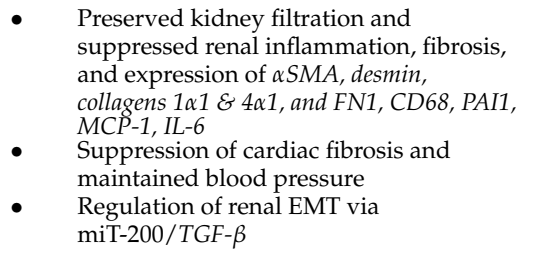 & & [135] \\
\hline & \multirow{5}{*}{ heart } & \multirow{5}{*}{ MI } & 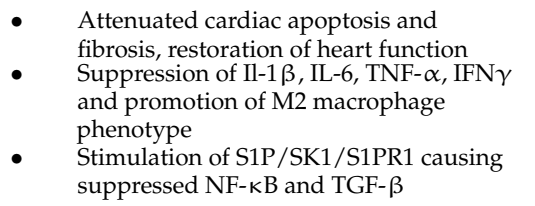 & & [199] \\
\hline & & & $\begin{array}{l}\text { - } \quad \text { Reduced cardiac infarct size, fibrosis, } \\
\text { cardiomyocyte apoptosis, and serum } \\
\text { IL-1 } \beta, \text { Il-6, TNF- } \alpha \\
\text { - } \quad \text { Improved microvascular density } \\
\text { Greater therapeutic outcomes for } \\
\text { miR-126-enrcihed versus control EVs }\end{array}$ & $\begin{array}{l}\text { EVs were } \\
\text { experimentally } \\
\text { augmented with } \\
\text { miR-126 }\end{array}$ & [200] \\
\hline & & & $\begin{array}{l}\text { - Suppression of apoptosis, inflammation, } \\
\text { fibrosis and serum IL-1 } \beta \text {, Il-6, TNF- } \alpha \\
\text { Targeting by miR-146a of early growth } \\
\text { response factor } 1 \text { and downstream } \\
T L R 4 / N F-\kappa B \text {. }\end{array}$ & $\begin{array}{c}\text { Evs were } \\
\text { experimentally } \\
\text { augmented with } \\
\text { miR-146a }\end{array}$ & [201] \\
\hline & & & $\begin{array}{ll}\text { - } & \text { Improved cardiac function and } \\
\text { vascularity } \\
\text { - } & \text { Decreased inflammation and fibrosis } \\
\text { Encapsulated EVs not advantageous }\end{array}$ & $\begin{array}{l}\text { EVs administered in } \\
\text { free form or } \\
\text { encapsulated within } \\
\text { peptide hydrogel }\end{array}$ & [189] \\
\hline & & & $\begin{array}{l}\text { Decreased infarct size, fibrosis, and } \\
\text { infiltration of CD68 inflammatory cells }\end{array}$ & $\begin{array}{l}\text { As compared to } \\
\text { producer MSC, EVs had } \\
\text { increased miR-29 or }-24 \\
\text { and decreased miR-15, } \\
-21,-34,-130, \text { or }-378\end{array}$ & [336] \\
\hline
\end{tabular}


Table 2. Cont.

\begin{tabular}{|c|c|c|c|c|c|}
\hline EV Source & $\begin{array}{c}\text { Organ } \\
\text { Targeted }\end{array}$ & Fibrosis Model & Principal EV Effects & $\begin{array}{c}\text { EV Features Associated } \\
\text { with Therapy }\end{array}$ & Reference \\
\hline & \multirow{4}{*}{ liver } & \multirow{4}{*}{$\mathrm{CCl}_{4}$} & $\begin{array}{l}\text { - Suppression of HSC activation and } \\
\text { collagen deposition } \\
\text { miR-122 targeting of IGF1R, cyclin G(1) } \\
\text { and prolyl-4-hydroxylase } \alpha 1\end{array}$ & $\begin{array}{l}\text { EVs were } \\
\text { experimentally } \\
\text { augmented with } \\
\text { miR-122 }\end{array}$ & [275] \\
\hline & & & $\begin{array}{ll}\text { - } & \text { suppression of fibrosis, collagen I, } \\
\text { - } & \text { vimentin, } \alpha \mathrm{SMA} \text { and FN } \\
\text { miR-181 targeting of Stats } 3 \text { and Bcl2 and } \\
\text { stimulation of autophagy }\end{array}$ & $\begin{array}{l}\text { EVs were } \\
\text { experimentally } \\
\text { augmented with } \\
\text { miR-181-5p }\end{array}$ & [277] \\
\hline & & & $\begin{array}{l}\text { - } \quad \text { reduced hepatic vimentin, FN, collagen, } \\
\text { and CXCL1 } \\
\text { reduced fibrosis and collagen volume } \\
\text { reduced serum TNF- } \alpha, \text { IL-6, IL-17, AST, } \\
\text { ALT and TB }\end{array}$ & $\begin{array}{l}\text { EVs were } \\
\text { experimentally } \\
\text { augmented with } \\
\text { miR-150-5p which } \\
\text { targeted CXCL1 }\end{array}$ & [276] \\
\hline & & & $\begin{array}{l}\text { - } \quad \text { reduced } \alpha \text { SMA and collagen } \\
\text { stimulated production of } \\
\text { autophagy-related proteins }\end{array}$ & $\begin{array}{c}\text { EVs were } \\
\text { experimentally } \\
\text { augmented with } \\
\text { mmu_circ_0000623 } \\
\text { which targeted miR- } \\
\text { 125/ATG4D-mediated } \\
\text { autophagy }\end{array}$ & [278] \\
\hline Tonsil-derived MSC & liver & $\mathrm{CCl}_{4}$ & $\begin{array}{l}\text { - improved liver morphology, restoration } \\
\text { of serum ALT and AST and hepatic G6pc } \\
\text { mRNA } \\
\text { reduced fibrosis } \\
\text { reduced hepatic TGF- } \beta, \alpha S M A \text {, vimentin, } \\
\text { collagen 1 1 1, hydroxyproline }\end{array}$ & $\begin{array}{l}\text { EVs enriched in } \\
\text { miR-486.5p which } \\
\text { suppressed Hh } \\
\text { signaling in HSC by } \\
\text { targeting the Smo Hh } \\
\text { receptor }\end{array}$ & [281] \\
\hline \multirow{4}{*}{ Liver stem cells } & kidney & AA CKD & $\begin{array}{l}\text { - Reduced tubular necrosis, fibrosis, and } \\
\text { CD45 cell infiltration. } \\
\text { Modulation of miRs affecting fibrosis } \\
\text { (Wnt, inflammatory cytokines, } P D G F, \\
\text { GRG, TGF- } \beta \text { ) and downregulated } \\
\text { expression of } 14 \text { pro-fibrotic genes }\end{array}$ & & [142] \\
\hline & \multirow{3}{*}{ liver } & NASH & $\begin{array}{ll}\text { - } & \text { Restored serum ALT } \\
\text { - } & \text { Reduced fibrosis and CD45 inflammatory } \\
\text { cells } & \text { Corrected expression of } 28 / 29 \text { genes } \\
\text { associated with fibrosis or inflammation }\end{array}$ & & [285] \\
\hline & & $\mathrm{CC}_{14}$ & $\begin{array}{l}\text { - Correction of serum ALT, oxidative } \\
\text { stress, and apoptosis } \\
\text { Reduced hepatic collagen and } \\
\text { hydroxyproline }\end{array}$ & $\begin{array}{l}\text { EV effects were } \\
\text { substantially improved } \\
\text { by co-administration of } \\
\text { Nilotinib }\end{array}$ & [286] \\
\hline & & $\begin{array}{l}\text { MDR2-/- primary } \\
\text { sclerosing cholangitis }\end{array}$ & $\begin{array}{ll}\text { - } & \text { Reduced ductular reaction and biliary } \\
\text { fibrosis } & \\
\text { - } & \text { Reduced chonangiocyte growth and HSC } \\
\text { - } & \text { Redivation hepatic or cholangiocyte } \\
\text { expression of let-7 targets (Lin28a/b,IL-13, } \\
\text { NR1H4, NF- } K B \text { ) }\end{array}$ & EVs enriched in let-7 & [287] \\
\hline \multirow{4}{*}{ Amnion epithelial cells } & lung & bleomycin & $\begin{array}{l}\text { - } \quad \text { Reduced inflammation, fibrosis and EMT } \\
\text { increased frequency of lung progenitor } \\
\text { cells }\end{array}$ & $\begin{array}{c}\text { EV enriched with } \\
\text { fibrosis-related miRs } \\
\text { (PI3-AKT, MAPK, Ras, } \\
\text { Hippo, TGF- } \beta, \text { FAK) } \\
\text { and proteins associated } \\
\text { with apoptosis, } \\
\text { developmental growth, } \\
\text { MAPK, inflammation, } \\
\text { EGF, PDGF, FGF. } \\
\end{array}$ & [89] \\
\hline & & Bleomycin or OVA/NA & $\begin{array}{ll}\text { - } & \text { Reduced inflammation and neutrophil or } \\
\text { macrophage infiltration } \\
\text { - } & \text { Reduced fibrosis and subepithelial ECM } \\
\text { - } & \text { Modulation of epithelial damage, TGF- } \beta \\
\text { expression and EMT } \\
\text { - } \quad \text { Increased dynamic lung compliance }\end{array}$ & $\begin{array}{l}\text { Some EV effects } \\
\text { augmented by serelaxin }\end{array}$ & [88] \\
\hline & \multirow{2}{*}{ liver } & $\mathrm{CCl}_{4}$ fibrosis & $\begin{array}{l}\text { - } \quad \text { Reduced fibrosis and number of } \\
\text { activated HSC } \\
\text { Reduced macrophage frequency with M2 } \\
\text { phenotype predominating, }\end{array}$ & $\begin{array}{l}\text { EVs contain MFGE8, } \\
\text { HSP72, SOD1 which } \\
\text { suppress TGF- } \beta \\
\text { signaling }\end{array}$ & [283] \\
\hline & & NASH & $\begin{array}{ll}\text { - } & \text { Decreased frequency of KCs and } \\
& \text { expression of TNF- } \alpha, I L-1 \beta, I L-6, T G F-\beta \\
\text { - } & \text { Suppressed fibrosis and activation of KC } \\
\text { - } & \text { and HSC } \\
\text { Suppressed TLR4 signaling }\end{array}$ & & [284] \\
\hline
\end{tabular}


Table 2. Cont.

\begin{tabular}{|c|c|c|c|c|c|}
\hline EV Source & $\begin{array}{l}\text { Organ } \\
\text { Targeted }\end{array}$ & Fibrosis Model & Principal EV Effects & $\begin{array}{c}\text { EV Features Associated } \\
\text { with Therapy }\end{array}$ & Reference \\
\hline & skin & Full thickness wounds & $\begin{array}{l}\text { - Increased rate of wound healing and } \\
\text { wound closure, reduced scar area } \\
\text { Promotion of fibroblast proliferation, } \\
\text { differentiation, migration and collagen } \\
\text { production }\end{array}$ & & [334] \\
\hline Lung spheroid cells & lung & Silicableomycin & $\begin{array}{l}\text { - Preserved lung architecture and partial } \\
\text { restoration of lung function } \\
\text { Decreased fibrosis, collagen deposition, } \\
\text { apoptosis, alveolar epithelial injury, } \\
\text { vascular injury } \\
\text { Decreased lung Smad3 expression and } \\
\text { circulating MCP-1 }\end{array}$ & $\begin{array}{l}\text { EVs enriched for } \\
\text { miR-30a, let-7, miR-99 }\end{array}$ & [90] \\
\hline \multirow{5}{*}{$\begin{array}{l}\text { Cardiosphere-derived } \\
\text { cells CDC }\end{array}$} & $\begin{array}{l}\text { kidney \& } \\
\text { heart }\end{array}$ & Ang II & $\begin{array}{l}\text { - } \quad \begin{array}{l}\text { Attenuation of cardiac hypertrophy, } \\
\text { inflammation, fibrosis } \\
\text { - } \\
\text { Attenuation of renal function, } \\
\text { inflammation, fibrosis }\end{array} \quad \text { Modulation of systemic and tissue IL-10 }\end{array}$ & $\begin{array}{l}\text { Therapeutic effects } \\
\text { mimicked by EV-FF1, } \\
\text { the most abundant } \\
\text { small RNA constituent } \\
\text { in CDC EVs }\end{array}$ & [145] \\
\hline & \multirow{4}{*}{ heart } & \multirow{2}{*}{ MI } & $\begin{array}{l}\text { Improved cardiac function, decreased } \\
\text { fibrosis and scar mass, increased infarct } \\
\text { wall thickness and microvessel density } \\
\text { Comparable therapy using CDC } \\
\text { EV-primed fibroblasts }\end{array}$ & $\begin{array}{l}\text { EVs enriched in } \\
\text { miR-146a-5p, 302b-3p, } \\
181 b-5 p, 155-5 p\end{array}$ & [207] \\
\hline & & & $\begin{array}{l}\text { - } \quad \text { Preserved cardiac function } \\
\text { Decreased scar size, ventricular collagen, } \\
\text { and cardiomyocyte hypertrophy } \\
\text { - } \quad \text { Increased microvessel density }\end{array}$ & & [208] \\
\hline & & $\begin{array}{l}\text { Pediatric dilated } \\
\text { cardiomyopathy }\end{array}$ & $\begin{array}{l}\text { Improved cardiac function, decreased } \\
\text { fibrosis }\end{array}$ & $\begin{array}{l}\text { Antifibrotic effects } \\
\text { associated with } \\
\text { suppression of } \\
\text { TRAF6/Smad4/FOS by } \\
\text { EV miR-146a-5p }\end{array}$ & [209] \\
\hline & & Doxorubicin & $\begin{array}{ll}- & \text { Improved cardiac function } \\
- & \text { Decreased fibrosis and apoptosis } \\
-\quad & \text { Increased cardiomyocyte proliferation } \\
\text { and angiogenesis }\end{array}$ & $\begin{array}{l}\text { Therapy improved by } \\
\text { conjugation of cardiac } \\
\text { homing peptide to EV }\end{array}$ & {$[209,211,212]$} \\
\hline Cardiac MSC (Sca-1+) & heart & MI & $\begin{array}{l}\text { - } \quad \text { Decreased fibrosis } \\
\text { Increased angiogenesis and microvessel } \\
\text { density in infarct area } \\
\text { Decreased apoptosis of endothelial cells, } \\
\text { and cardiomyocytes }\end{array}$ & $\begin{array}{l}\text { EVs enriched in } \\
\text { proteins associated with } \\
\text { ECM, adhesion, } \\
\text { collagens, integrins. } \\
\text { EVs from } \\
\text { Notch1-overexpressing } \\
\text { C-MSC were tested } \\
\text { therapeutically }\end{array}$ & [204] \\
\hline \multirow[b]{2}{*}{$\begin{array}{l}\text { Cardiac resident } \\
\text { progenitor cells }\end{array}$} & \multirow{2}{*}{ heart } & Doxorubicin/trastuzumab & $\begin{array}{l}\text { - Reversal of left ventricular dysfunction, } \\
\text { fibrosis, CD68 inflammatory cell } \\
\text { infiltration, and iNOS expression. } \\
\text { EV therapy blocked by silencing of EV } \\
\text { miR-146-5p which targeted Traf6 } \\
\text { (inflammation) and } M p a \text { (cell death) }\end{array}$ & $\begin{array}{l}\text { EVs were purified from } \\
\text { CRPCs derived from } \\
\text { outgrowths of primary } \\
\text { atrial tissue explants. } \\
\text { EVs enriched in } \\
\text { redox-regulating } \\
\text { proteins and } \\
\text { miR-146-5p }\end{array}$ & [205] \\
\hline & & MI & $\begin{array}{l}\text { CRPCs implanted subcutaneously were } \\
\text { therapeutic for ventricular function, } \\
\text { fibrosis, cardiomyocyte hypertrophy and } \\
\text { microvessel density } \\
\text { EVs liberated from these CRPCs } \\
\text { trafficked to heart (myocardium } \\
\text { interstitium, perivascular, } \\
\text { cardiomyocytes), skeletal muscle, liver, } \\
\text { lung, kidney }\end{array}$ & $\begin{array}{l}\text { W8B2 }{ }^{+} \text {CRPCs were } \\
\text { obtained from } \\
\text { outgrowth of primary } \\
\text { atrial tissue explants. } \\
\text { EVs contained proteins } \\
\text { associated with } \\
\text { inflammation, } \\
\text { immunoregulation, } \\
\text { tissue remodelling, } \\
\text { fibrosis. }\end{array}$ & [206] \\
\hline \multirow{3}{*}{$\begin{array}{l}\text { Umbilical cord-derived } \\
\text { MSC }\end{array}$} & \multirow{3}{*}{ lung } & $\begin{array}{l}\text { Hyperoxia-induced } \\
\text { BPD }\end{array}$ & $\begin{array}{l}\text { - Decreased inflammation, fibrosis, and } \\
\text { vascular defects } \\
\text { Stimulation of M2 macrophages, altered } \\
\text { immune/inflammation gene expression, } \\
\text { improved lung function } \\
\text { - Decreased pulmonary hypertension, } \\
\text { improved exercise capacity }\end{array}$ & $\begin{array}{l}\text { EVs isolated from } \\
\text { Wharton's jelly }\end{array}$ & [81] \\
\hline & & Monocrotaline & $\begin{array}{l}\text { - Restored cardiac function, attenuated } \\
\text { fibrosis, vascular remodeling }\end{array}$ & $\begin{array}{l}\text { Wnt5a/BMP regulated } \\
\text { by Wharton's jelly EVs }\end{array}$ & [82] \\
\hline & & silicosis & $\begin{array}{l}\text { Alleviation of respiratory resistance, } \\
\text { airway resistance, tissue dampening } \\
\text { Inhibition of fibrosis }\end{array}$ & & [85] \\
\hline
\end{tabular}


Table 2. Cont.

\begin{tabular}{|c|c|c|c|c|c|}
\hline EV Source & $\begin{array}{c}\text { Organ } \\
\text { Targeted }\end{array}$ & Fibrosis Model & Principal EV Effects & $\begin{array}{c}\text { EV Features Associated } \\
\text { with Therapy }\end{array}$ & Reference \\
\hline & \multirow[b]{2}{*}{ kidney } & \multirow[b]{2}{*}{ I/R AKI } & $\begin{array}{l}\text { Suppression of tubular necrosis, tubular } \\
\text { dilation, apoptosis and fibrosis, } \\
\text { stimulation of cell proliferation and } \\
\text { angiogenesis } \\
\text { normalization of serum creatinine \& } \\
\text { blood urea nitrogen } \\
\text { Reduced HIF-1 } \alpha \text { expression, increased } \\
\text { VEGF }\end{array}$ & $\begin{array}{l}\text { VEGF delivered directly } \\
\text { by EVs and insensitive } \\
\text { to RNase. } \\
\text { All other effects } \\
\text { abrogated by RNase } \\
\text { treatment of EVs }\end{array}$ & [139] \\
\hline & & & $\begin{array}{l}\text { - Suppression of kidney damage, fibrosis, } \\
\text { and apoptosis; stimulation of cell } \\
\text { proliferation, preserved renal function } \\
\text { Therapy enhanced by EVs from } \\
\text { Oct-4-overexpressing donor cells and } \\
\text { reduced by EVs from cells in which oct-4 } \\
\text { was inhibited } \\
\text { Reduced renal expression of Snail, an } \\
\text { EMT-inducer that is a target of oct-4 }\end{array}$ & Delivery of EV oct-4 & [138] \\
\hline & \multirow{6}{*}{ heart } & \multirow{4}{*}{ MI } & $\begin{array}{l}\text { Improved heart function, reduced } \\
\text { fibrosis, reduced cardiomyocyte } \\
\text { apoptosis }\end{array}$ & $\begin{array}{l}\text { EVs regulate } B c l-2 \\
\quad \text { expression }\end{array}$ & [195] \\
\hline & & & $\begin{array}{l}\text { Reduced inflammation (CD68 cell } \\
\text { infiltration, serum TNF- } \alpha \text { ), fibrosis, } \\
\text { collagen deposition, TGF- } \beta \text { expression, } \\
\text { apoptosis, improved angiogenesis }\end{array}$ & $\begin{array}{l}\text { EVs encapsulated in } \\
\text { functional peptide } \\
\text { hydrogel }\end{array}$ & [196] \\
\hline & & & $\begin{array}{l}\text { - } \quad \text { Restoration of cardiac function, reduced } \\
\text { fibrosis and inflammation } \\
\text { miR-24 targets pro-apoptotic Bim }\end{array}$ & $\begin{array}{l}\text { EVs more effective } \\
\text { when purified from } \\
\text { cells lacking human } \\
\text { leuckocyte antigen light } \\
\text { chain } \beta 2 \text {-microglobulin } \\
\text { (B2M) to avoid T cell } \\
\text { immunity } \\
\text { EV enriched in miR-24 }\end{array}$ & [184] \\
\hline & & & $\begin{array}{l}\text { Improved cardiac function, increased } \\
\text { cardiac vascularity, reduced fibrosis }\end{array}$ & $\begin{array}{l}\text { Targeting of apoptotic } \\
\text { peptidase activating } \\
\text { factor by EV miR-136 }\end{array}$ & [197] \\
\hline & & Type 2 diabetes stroke & $\begin{array}{l}\text { improved cardiac function, decreased } \\
\text { fibrosis, TGF- } \beta \text { expression, M1 } \\
\text { macrophages, oxidative stress, capillary } \\
\text { density } \\
\text { increased cardiac expression of miR-216 } \\
\text { and decreased expression of its targets, } \\
\text { Spred-1, MCP-1, VCAM1 }\end{array}$ & & [198] \\
\hline & & $\begin{array}{l}\text { Metabolic syndrome + } \\
\text { renal artery stenosis }\end{array}$ & $\begin{array}{l}\text { increased density of cardiomyocytes and } \\
\text { capillaries } \\
\text { reduced inflammatory cytokine } \\
\text { expression, reduced fibrosis }\end{array}$ & & [202] \\
\hline & \multirow[t]{2}{*}{ liver } & \multirow[t]{2}{*}{$\mathrm{CCl}_{4}$} & $\begin{array}{l}\text { - } \quad \begin{array}{l}\text { Reduced fibrosis, surface fibrous nodules, } \\
\text { inflammation } \\
\text { - }\end{array} \\
\text { Suppression of serum AST, HA, and } \\
\text { TGF- } \beta \\
\text { Suppression of TGF- } \beta \text { and myofibroblast } \\
\text { production }\end{array}$ & & [280] \\
\hline & & & 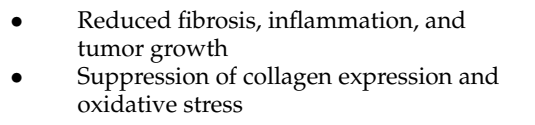 & & [279] \\
\hline & \multirow{2}{*}{ skin } & Full thickness wound & $\begin{array}{l}\text { - } \quad \text { Reduced scar formation and } \\
\text { myofibrblast frequency } \\
\text { EV miR-mediated suppression of } \\
\text { TGF- } \beta \text { /Smad2 }\end{array}$ & $\begin{array}{l}\text { EVs enriched in miR-21, } \\
23 a, 100,125 b, 145\end{array}$ & [332] \\
\hline & & cGVHD & $\begin{array}{l}\text { - Reduced cGVHD score and fibrosis, } \\
\text { macrophage accumulation, and } \\
\text { TGF- } \beta \text { /Smad2 in the skin } \\
\text { - } \quad \text { Regulation of B cell immunity }\end{array}$ & & [333] \\
\hline \multirow{2}{*}{ Placental MSC } & lung & radiation & $\begin{array}{l}\text { Decreased vascular damage, } \\
\text { inflammation and fibrosis } \\
\text { - } \quad \text { Decreased DNA damage }\end{array}$ & $\begin{array}{l}\text { EVs enriched in } \\
\text { miR-214-3p which } \\
\text { targeted } A T M / \text { p53/p21 }\end{array}$ & [86] \\
\hline & kidney & UUO & $\begin{array}{l}-\quad \text { Decreased } \alpha \mathrm{SMA} \text { and collagen I } \\
\text { Increased infiltration of Foxp3+/IL-17+ } \\
\text { CD4+ T cells }\end{array}$ & & [144] \\
\hline
\end{tabular}


Table 2. Cont.

\begin{tabular}{|c|c|c|c|c|c|}
\hline EV Source & $\begin{array}{c}\text { Organ } \\
\text { Targeted }\end{array}$ & Fibrosis Model & Principal EV Effects & $\begin{array}{l}\text { EV Features Associated } \\
\text { with Therapy }\end{array}$ & Reference \\
\hline $\begin{array}{c}\text { Menstrual } \\
\text { blood-derived stem } \\
\text { cells }\end{array}$ & lung & bleomycin & $\begin{array}{l}\text { Reversal of alveolar cell damage and } \\
\text { fibrosis } \\
\text { Correction of hydroxyproline, } \\
\text { malondialdehyde, glutathione } \\
\text { peroxidase } \\
\text { - Suppression of ROS, mitochondrial } \\
\text { damage, apoptosis }\end{array}$ & $\begin{array}{l}\text { Targeting of } L O X 1 \text { and } \\
\text { NLRP3 apoptosis by EV } \\
\text { let-7 }\end{array}$ & [91] \\
\hline \multirow{4}{*}{ Embryonic stem cells } & \multirow[t]{3}{*}{ heart } & \multirow[t]{2}{*}{ MI } & $\begin{array}{l}\text { - } \\
\text { neduced fibrosis, increased } \\
\text { neovascularization, cardiomyocyte } \\
\text { survival } \\
\text { Stimulation of survival, proliferation and } \\
\text { cardiac commitment of CPC by EV } \\
\text { miR-294 }\end{array}$ & $\begin{array}{l}\text { EVs enriched in } \\
\text { miR290-295 cluster }\end{array}$ & [221] \\
\hline & & & $\begin{array}{l}\text { Improved cardiac function, reduced } \\
\text { fibrosis, increased capillary density }\end{array}$ & $\begin{array}{l}\text { EVs purified from } \\
\text { human embryonic stem } \\
\text { cell-derived CPCs }\end{array}$ & [222] \\
\hline & & & $\begin{array}{l}\text { - Improved but sub-optimal heart function } \\
\text { - } \quad \text { Fibrosis more pronounced, not lessened }\end{array}$ & & [223] \\
\hline & liver & TAA & 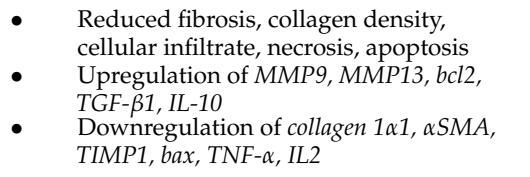 & & [289] \\
\hline Telocytes & heart & MI & $\begin{array}{l}\text { - Reduced fibrosis, collagen deposition, } \\
\text { increased angiogenesis }\end{array}$ & & [217] \\
\hline \multirow{3}{*}{$\begin{array}{l}\text { Induced pluripotent } \\
\text { stem cells (iPSC) }\end{array}$} & \multirow[b]{2}{*}{ heart } & \multirow[b]{2}{*}{ MI } & $\begin{array}{l}\text { - Improved cardiac function, reduced } \\
\text { fibrosis and apoptosis } \\
\text { - } \quad \text { Increased expression of pro-survival } b c l-x \\
\text { and } b c l-2 \\
\text { - Stimulation of mTOR signaling }\end{array}$ & $\begin{array}{l}\text { EVs from iPSC-derived } \\
\text { cardiomyocytes }\end{array}$ & [219] \\
\hline & & & $\begin{array}{l}\text { - Improved cardiac function, increased } \\
\text { cardiomyocyte proliferation, and } \\
\text { reduced scar size } \\
\text { EV therapeutic effects mimicked by } \\
\text { miR-373 in vivo } \\
\text { In fibroblasts in vitro, miR-373 } \\
\text { downregulated TGF- } \beta \text {-mediated fibrotic } \\
\text { gene expression by targeting GDF and } \\
\text { ROCK-2 }\end{array}$ & $\begin{array}{l}\text { EVs from CPCs induced } \\
\text { from iPSCs with ISX-9. } \\
\text { EVs enriched in } \\
\text { miR-373/-520 family } \\
\text { members }\end{array}$ & [220] \\
\hline & liver & $\mathrm{CCL}_{4}, \mathrm{BDL}$ & $\begin{array}{l}\text { - } \quad \text { Suppression of fibrosis and expression of } \\
\alpha S M A \text {, collagen } 1 \alpha 1 \text {, and TIMP-1 } \\
\text { EV-mediated regulation of } \\
\text { TGF- } \beta \text {-induced genes in cultured HSC }\end{array}$ & $\begin{array}{l}\text { EVs from iPSC that } \\
\text { were reprogrammed } \\
\text { from primary } \\
\text { fibroblasts } \\
\text { EVs enriched in } \\
\text { anti-fibrotic miRs } \\
\text { (miR-92a-5p, }-10 b-5 p \\
-302-3 p,-92 b-3 p)\end{array}$ & [288] \\
\hline
\end{tabular}

Additionally, evidence has accumulated demonstrating an intimate association between fibrosis-associated changes in autophagy and the production or action of pro-fibrotic EVs, consistent with the recognition that these vesicular transport systems pathways are functionally linked [337-339]. Autophagy involves the lysosomal degradation of stress-induced defective proteins and organelles after they have been encapsulated in autophagosomes, a process that contributes to tissue homeostasis and which is altered during fibrosing injury. When autophagy is compromised, exosome release may become an alternative mechanism of removing stress-induced components from the cell that may have pro-pathogenic effects in other cells For example, in fibrotic liver, the levels of the stress protein TRIB3 were increased in hepatocytes causing impaired autophagy and obstruction of autophagic flux of SQSTM1/p62 as well as triggering the production of inhibin/activin A-enriched exosomes that stimulated HSC activation [252]. Similarly, in a model of PDGFmediated HSC activation, autophagy was decreased with a concomitant increase in the release of pro-fibrogenic exosomes and microvesicles due to, respectively, reduced MVB degradation and stimulation of ROCK1 activation [262]. On the other hand, anti-fibrotic effects of EVs in several organ systems have been attributed to, or are coincident with, alter- 
ations in autophagic pathways in parenchymal and/or fibrogenic cells. For example in the liver, AD-MSC EVs enriched in either miR-181-5p or mmu_circ_0000623 were anti-fibrotic and also stimulated autophagy, with the latter involving activation of a miR-125-ATG4D axis in hepatocytes [277,278]. In contrast, autophagy was reported to be increased during HSC activation [340] but the targeting of ATG7 by miR-223 delivered in NK cell exosomes resulted in reduced HSC autophagy, thereby suppressing HSC activation [298]. In stz DN, EVs from BM-MSC were anti-fibrotic in the kidney but concomitantly induced autophagy and increased the expression of autophagy markers $L C 3$ and beclin-1 while decreasing the expression of $m$ TOR [126]. In cardiac MI models, EVs from iPSC-derived cardiomyocytes were anti-fibrotic and promoted myocardial repair and autophagy [219] but the reparative and anti-fibrotic affects EVs from BM-MSC were associated with decreased expression of $L C 3 B$, and EV therapy was enhanced by enrichment with miR-101 which blocks autophagy [185]. Although current data are not fully consistent as to the nature and direction of dynamic alterations of autophagy during fibrosing injury (which may reflect injury severity/type or cell-specific or temporal differences between the experimental systems), it is nonetheless evident that changes in autophagosome function and autophagic flux influence the production of EVs and their pathogenic payloads as well as providing a target for EV therapy.

While miRs and, to a lesser extent, proteins have generally been implicated in the proor anti-fibrotic actions of EVs, there is uncertainty as to the relative contribution of these components in eliciting meaningful biological responses. A role for a specific EV miR is often inferred when its ablation or enrichment in EVs by experimental manipulation of the producer cells results in altered expression of its presumed target in recipient cells, but such manipulation likely results in additional downstream miR-dependent changes in gene expression in the producer cells that are also manifested in the EVs, such that altered outcomes in the recipient cells may be due to other altered EV cargo molecules. Co-culture of EV producer cells with recipient cells that harbor untranslated region (UTR) reporters has also been used to demonstrate that miR circuitry in EVs is biologically effective at intrinsic levels of EV production but the high sensitivity of UTR reporter assays may not recapitulate the conditions needed for biologically relevant altered gene expression. Moreover, it has been argued both that the intra-vesicular concentration of many miRs may be too low to result in delivery of an effective dose to target cells and that the structural conformation of mature miRs in EVs may not ensure their functional activity in recipient cells [341,342]. Although these aspects are unresolved and contrary to many studies that have implicated miR-based mechanisms of EV action, more detailed consideration needs to be given to the role of other EV constituents in regulating fibrosis. With respect to functional EV proteins, therapeutic actions of MSC EVs in reducing myocardial infarct after I/R injury have been attributed to combinatorial actions of EV enzymes [341], while the proteome of EVs from activated HSC is consistent with their ability to promote fibrogenesis and matrigenesis in the liver [267]. While more data will undoubtedly be obtained in the future using reductionist approaches to establish the functional role of individual EV components, a molecular systems strategy that integrates the entire vesicle payload (miR, RNA, protein, lipid) [343] will likely be needed to comprehensively account for the pro- or anti-fibrotic actions of a specific EV population.

Although the biomarker potential for EVs in certain stages of chronic diseases is high, more data are needed to determine if EV components are present at sufficient sensitivity and specificity to allow them to be used diagnostically or prognostically for accurate detection and staging of fibrotic pathology against a background of other pathological sequalae. Emerging evidence does however suggest that body fluids (serum, plasma, lung fluid, urine) harbor EV populations that undergo dynamic changes in frequency or compositions of their molecular payloads that are associated with fibrotic changes. The principal cargo components identified to date as promising biomarker candidates are various miRs which undergo alterations in expression that are "pro-fibrogenic" and are often reflective of their known function or expression in fibrotic tissues. Although the 
EV miRs so far characterized are often distinct between different fibrotic organ systems, they are frequently associated with inflammation, production of myofibroblasts, and collagen production. On the other hand, miR-21 and several members of the let- 7 family have been identified as potential biomarkers for fibrosis of the lung, kidney, heart, and liver $[95,96,162,173,231,301,344]$ indicating that these miRs may have shared pan-organ functions or mechanisms of production during fibrosis. Although other EV components are less well studied, evidence from renal fibrosis suggests that some EV mRNAs (e.g., $C D 2 A P$ ) and proteins (E-cadherin, vimentin) may also be useful fibrotic markers. While data so far support the use of EV components of as fibrosis biomarkers, this aspect is in its infancy and more rigorous analysis is needed to clarify this aspect of EV biology. In the long run, EV biomarkers will most likely be impactful clinically by complementing other patient tests (serum chemistry, imaging, etc.) rather than being used as a stand-alone tool for fibrosis assessment.

Funding: This work was funded by NIH grant R01AA027502.

Acknowledgments: Lisa Feurer is thanked for assisting with the artwork.

Conflicts of Interest: The author declares no conflict of interest.

\section{Abbreviations}

AAN: aristolochic acid nephropathy; AD-MSC, adipose-derived MSC; AEC, amnion epithelial cells; AKI, acute kidney injury; ALD, alcoholic liver disease; AKT, protein kinase B; ALT, alanine transaminase; Ang II, angiotensin II; ARDS, acute respiratory distress syndrome; ARF, ADPribosylation factor; $\alpha \mathrm{SMA}$, alpha smooth muscle cell actin; $\mathrm{ATM}$, ataxia telangiectasia mutated; BALF, bronchoalveolar lavage fluid; BDL, bile duct ligation; BPD, bronchopulmonary dysplasia; BM-MSC, bone marrow MSC; BMP, bone morphogenic protein; $\mathrm{CCl}_{4}$, carbon tetrachloride; $\mathrm{CCN} 2$, cell communication network factor 2 /connective tissue growth factor; $\mathrm{CDC}$, cardiosphere-derived cells; cGVHD, chronic graft versus host disease; $\mathrm{CHB}$, chronic hepatitis $\mathrm{B}$; $\mathrm{CHC}$, chronic hepatitis C; CKD, chronic kidney disease; CMSC, cardiac MSC; COPD, chronic obstructive pulmonary disease; CPC, cardiac-resident mesenchymal progenitor cells; CYP2E1, cytochrome P450 2E1; DN, diabetic nephropathy; DOCA, deoxycorticosterone acetate; DR5, death receptor 5; ECFC, endothelial colony-forming cell; ECM, extracellular matrix; EMT, epithelial-to-mesenchymal transition; ERK, extracellular signal-regulated kinase; ESC, embryonic stem cell; ESCRT, endosomal sorting complex required for transport; EV, extracellular vesicle; FN, fibronectin; FZD6, Frizzled Class Receptor 6; GDF-11, growth differentiation factor-1; GEC, glomerular endothelial cell; GLUT1, glucose transporter 1; GMC, glomerular mesangial cell; GTPase, guanosine triphosphate hydrolase; HBV, hepatitis B; HCV, hepatitis C; Hh, hedgehog; HIF, hypoxia inducible factor; HNF-4 $\alpha$, hepatocyte nuclear factor- $4 \alpha$; HSC, hepatic stellate cell; HSP, heat shock protein; HTF-C, trans-fatty acids, fructose, and cholesterol; huR, human antigen R; iCM, iPSC-derived cardiomyocytes; IGF-1, insulin-like growth factor; IGF-1R, IGF-1 receptor; IL, interleukin; ILV, intraluminal vesicle; iNOS, inducible nitric oxide synthase; IPF, idiopathic pulmonary fibrosis; iPSC, induced pluripotent stem cells; I/R, ischemia/reperfusion; KC, Kupffer cell; lnc, long noncoding; LOX-1, lectin-like oxidized low-density lipoprotein scavenger receptor-1; LPS, lipopolysaccharide; LSEC, luminal sinusoidal endothelial cell; MALAT, metastasis-associated lung adenocarcinoma transcript; MAPK, mitogen-activated protein kinase; MenSC, menstrual blood-derived stems cells; MFG-E8, milk fat globule-epidermal growth factor-factor 8; MI, myocardial infarction; miR, microRNA; MMP, matrix metalloprotease; MSC, mesenchymal stem cell; mTOR, mechanistic target of rapamycin; MVB, multivesicular body; NAFLD, non-alcoholic fatty liver disease; NASH, non-alcoholic steatohepatitis; NF- $\mathrm{B}$, nuclear factor kappalight-chain-enhancer of activated B cells; NLRP3, NLR family pyrin domain containing 3; Nrf, nuclear factor erythroid 2-related factor; nSMase2, neutral sphingomyelinase 2; PDAC, pancreatic ductal adenocarcinoma; PDGF, platelet-derived growth factor; PDGFR, PDGF receptor; PD-L1, programmed death-ligand 1; PKM2, pyruvate kinase M2; PMN, polymorphonuclear; PMSC, placental MSC; PPAR, peroxisome proliferator-activated receptor; PSC, pancreatic stellate cell; PTEN, phosphatase and tensin homolog; Rictor, rapamycin-insensitive companion of mTOR; RISC, RNA-induced silencing complex; ROCK, rho-associated protein kinase; ROS, reactive oxygen species; S1P, sphingosine 
1-phosphate; Shh, sonic hedgehog; SHP2, Src homology region 2 domain-containing phosphatase-2; SIRT, sirtuin; SK1, sphingosine kinase 1; SM, systemic mastocytosis; Smad, small mothers against decapentaplegic; SOCS, suppressor of cytokine signaling; SOD1, superoxide dismutase 1; Sparc, secreted protein acidic and rich in cysteine; SSc, systemic sclerosis; STAT, signal transducer and activator of transcription; stz, streptozotocin; TAA, thioacetamide; TEC, tubular epithelial cells; TGF- $\beta$, transforming growth factor beta; TGF- $\beta$ R1, Type 1 TGF- $\beta$ receptor; TIMP, tissue inhibitor of MMP; TLR, Toll-like receptor; TNF- $\alpha$, tumor necrosis factor- $\alpha$; TSG101, tumor susceptibility gene 101; UMSC, umbilical cord MSC; UTR, untranslated region UUO, unilateral ureteral obstruction; VEGF, vascular endothelial growth factor; WJ-MSC, Wharton's jelly MSC; Wnt, wingless/integrated; YAP, yes associated protein.

\section{References}

1. Rockey, D.C.; Bell, P.D.; Hill, J.A. Fibrosis-A common pathway to organ injury and failure. N. Engl. J. Med. 2015, 372, 1138-1149. [CrossRef]

2. Wynn, T.A. Common and unique mechanisms regulate fibrosis in various fibroproliferative diseases. J. Clin. Investig. 2007, 117, 524-529. [CrossRef]

3. Wynn, T.A. Cellular and molecular mechanisms of fibrosis. J. Pathol. 2008, 214, 199-210. [CrossRef]

4. Wynn, T.A.; Barron, L. Macrophages: Master regulators of inflammation and fibrosis. Semin. Liver Dis. 2010, 30, $245-257$. [CrossRef]

5. Biernacka, A.; Dobaczewski, M.; Frangogiannis, N.G. TGF-beta signaling in fibrosis. Growth Factors 2011, 29, 196-202. [CrossRef]

6. Gressner, A.M.; Weiskirchen, R.; Breitkopf, K.; Dooley, S. Roles of TGF-beta in hepatic fibrosis. Front. Biosci. 2002, 7, d793-d807. [CrossRef]

7. Ismaeel, A.; Kim, J.S.; Kirk, J.S.; Smith, R.S.; Bohannon, W.T.; Koutakis, P. Role of Transforming Growth Factor-beta in Skeletal Muscle Fibrosis: A Review. Int. J. Mol. Sci. 2019, 20, 2446. [CrossRef] [PubMed]

8. Leask, A. Signaling in fibrosis: Targeting the TGF beta, endothelin-1 and CCN2 axis in scleroderma. Front. Biosci. 2009, 1, 115-122.

9. Leask, A.; Abraham, D.J. TGF-beta signaling and the fibrotic response. FASEB J. 2004, 18, 816-827. [CrossRef] [PubMed]

10. Meng, X.M.; Nikolic-Paterson, D.J.; Lan, H.Y. TGF-beta: The master regulator of fibrosis. Nat. Rev. Nephrol. 2016, 12, 325-338. [CrossRef] [PubMed]

11. Saito, A.; Horie, M.; Nagase, T. TGF-beta Signaling in Lung Health and Disease. Int. J. Mol. Sci. 2018, 19, 2460. [CrossRef]

12. Sureshbabu, A.; Muhsin, S.A.; Choi, M.E. TGF-beta signaling in the kidney: Profibrotic and protective effects. Am. J. Physiol. Ren. Physiol. 2016, 310, F596-F606. [CrossRef] [PubMed]

13. Verrecchia, F.; Mauviel, A. Transforming growth factor-beta and fibrosis. World J. Gastroenterol. 2007, 13, 3056-3062. [CrossRef]

14. Border, W.A.; Noble, N.A. Transforming growth factor beta in tissue fibrosis. N. Engl. J. Med. 1994, 331, 1286-1292. [CrossRef] [PubMed]

15. Burgy, O.; Konigshoff, M. The WNT signaling pathways in wound healing and fibrosis. Matrix Biol. 2018, 68-69, 67-80. [CrossRef] [PubMed]

16. Chanda, D.; Otoupalova, E.; Smith, S.R.; Volckaert, T.; De Langhe, S.P.; Thannickal, V.J. Developmental pathways in the pathogenesis of lung fibrosis. Mol. Asp. Med. 2019, 65, 56-69. [CrossRef]

17. Guo, Y.; Xiao, L.; Sun, L.; Liu, F. Wnt/beta-catenin signaling: A promising new target for fibrosis diseases. Physiol. Res. 2012, 61, 337-346. [CrossRef]

18. Miao, C.G.; Yang, Y.Y.; He, X.; Huang, C.; Huang, Y.; Zhang, L.; Lv, X.W.; Jin, Y.; Li, J. Wnt signaling in liver fibrosis: Progress, challenges and potential directions. Biochimie 2013, 95, 2326-2335. [CrossRef] [PubMed]

19. Tao, H.; Yang, J.J.; Shi, K.H.; Li, J. Wnt signaling pathway in cardiac fibrosis: New insights and directions. Metabolism 2016, 65, 30-40. [CrossRef] [PubMed]

20. Zuo, Y.; Liu, Y. New insights into the role and mechanism of Wnt/beta-catenin signalling in kidney fibrosis. Nephrology 2018, 23 (Suppl. 4), 38-43. [CrossRef]

21. Piersma, B.; Bank, R.A.; Boersema, M. Signaling in Fibrosis: TGF-beta, WNT, and YAP/TAZ Converge. Front. Med. 2015, 2, 59. [CrossRef]

22. Edeling, M.; Ragi, G.; Huang, S.; Pavenstadt, H.; Susztak, K. Developmental signalling pathways in renal fibrosis: The roles of Notch, Wnt and Hedgehog. Nat. Rev. Nephrol. 2016, 12, 426-439. [CrossRef]

23. Weiskirchen, R.; Weiskirchen, S.; Tacke, F. Organ and tissue fibrosis: Molecular signals, cellular mechanisms and translational implications. Mol. Asp. Med. 2019, 65, 2-15. [CrossRef] [PubMed]

24. Friedman, S.L.; Sheppard, D.; Duffield, J.S.; Violette, S. Therapy for fibrotic diseases: Nearing the starting line. Sci. Transl. Med. 2013, 5, 167sr1. [CrossRef] [PubMed]

25. Schuppan, D.; Ashfaq-Khan, M.; Yang, A.T.; Kim, Y.O. Liver fibrosis: Direct antifibrotic agents and targeted therapies. Matrix Biol. 2018, 68-69, 435-451. [CrossRef] [PubMed] 
26. Lemoinne, S.; Friedman, S.L. New and emerging anti-fibrotic therapeutics entering or already in clinical trials in chronic liver diseases. Curr. Opin. Pharmacol. 2019, 49, 60-70. [CrossRef] [PubMed]

27. Henne, W.M.; Buchkovich, N.J.; Emr, S.D. The ESCRT pathway. Dev. Cell 2011, 21, 77-91. [CrossRef]

28. Juan, T.; Furthauer, M. Biogenesis and function of ESCRT-dependent extracellular vesicles. Semin. Cell Dev. Biol. $2018,74,66-77$. [CrossRef] [PubMed]

29. Pegtel, D.M.; Gould, S.J. Exosomes. Annu. Rev. Biochem. 2019, 88, 487-514. [CrossRef]

30. Van Niel, G.; D'Angelo, G.; Raposo, G. Shedding light on the cell biology of extracellular vesicles. Nat. Rev. Mol. Cell Biol. 2018, 19, 213-228. [CrossRef]

31. Thery, C.; Witwer, K.W.; Aikawa, E.; Alcaraz, M.J.; Anderson, J.D.; Andriantsitohaina, R.; Antoniou, A.; Arab, T.; Archer, F.; Atkin-Smith, G.K.; et al. Minimal information for studies of extracellular vesicles 2018 (MISEV2018): A position statement of the International Society for Extracellular Vesicles and update of the MISEV2014 guidelines. J. Extracell. Vesicles 2018, 7, 1535750. [CrossRef] [PubMed]

32. Trajkovic, K.; Hsu, C.; Chiantia, S.; Rajendran, L.; Wenzel, D.; Wieland, F.; Schwille, P.; Brugger, B.; Simons, M. Ceramide triggers budding of exosome vesicles into multivesicular endosomes. Science 2008, 319, 1244-1247. [CrossRef] [PubMed]

33. Chairoungdua, A.; Smith, D.L.; Pochard, P.; Hull, M.; Caplan, M.J. Exosome release of beta-catenin: A novel mechanism that antagonizes Wnt signaling. J. Cell Biol. 2010, 190, 1079-1091. [CrossRef] [PubMed]

34. Kosaka, N.; Iguchi, H.; Yoshioka, Y.; Takeshita, F.; Matsuki, Y.; Ochiya, T. Secretory mechanisms and intercellular transfer of microRNAs in living cells. J. Biol. Chem. 2010, 285, 17442-17452. [CrossRef]

35. Li, J.; Liu, K.; Liu, Y.; Xu, Y.; Zhang, F.; Yang, H.; Liu, J.; Pan, T.; Chen, J.; Wu, M.; et al. Exosomes mediate the cell-to-cell transmission of IFN-alpha-induced antiviral activity. Nat. Immunol. 2013, 14, 793-803. [CrossRef]

36. Charrier, A.; Chen, R.; Chen, L.; Kemper, S.; Hattori, T.; Takigawa, M.; Brigstock, D.R. Exosomes mediate intercellular transfer of pro-fibrogenic connective tissue growth factor (CCN2) between hepatic stellate cells, the principal fibrotic cells in the liver. Surgery 2014, 156, 548-555. [CrossRef]

37. Chen, L.; Charrier, A.; Zhou, Y.; Chen, R.; Yu, B.; Agarwal, K.; Tsukamoto, H.; Lee, L.J.; Paulaitis, M.E.; Brigstock, D.R. Epigenetic regulation of connective tissue growth factor by MicroRNA-214 delivery in exosomes from mouse or human hepatic stellate cells. Hepatology 2014, 59, 1118-1129. [CrossRef]

38. Lang, J.K.; Young, R.F.; Ashraf, H.; Canty, J.M., Jr. Inhibiting Extracellular Vesicle Release from Human Cardiosphere Derived Cells with Lentiviral Knockdown of nSMase2 Differentially Effects Proliferation and Apoptosis in Cardiomyocytes, Fibroblasts and Endothelial Cells In Vitro. PLoS ONE 2016, 11, e0165926. [CrossRef]

39. Blanc, L.; Vidal, M. New insights into the function of Rab GTPases in the context of exosomal secretion. Small GTPases 2018, 9 , 95-106. [CrossRef]

40. Hessvik, N.P.; Llorente, A. Current knowledge on exosome biogenesis and release. Cell. Mol. Life Sci. 2018, 75, 193-208. [CrossRef] [PubMed]

41. Bonifacino, J.S.; Glick, B.S. The mechanisms of vesicle budding and fusion. Cell 2004, 116, 153-166. [CrossRef]

42. Muralidharan-Chari, V.; Clancy, J.W.; Sedgwick, A.; D'Souza-Schorey, C. Microvesicles: Mediators of extracellular communication during cancer progression. J. Cell Sci. 2010, 123, 1603-1611. [CrossRef] [PubMed]

43. Li, B.; Antonyak, M.A.; Zhang, J.; Cerione, R.A. RhoA triggers a specific signaling pathway that generates transforming microvesicles in cancer cells. Oncogene 2012, 31, 4740-4749. [CrossRef] [PubMed]

44. D'Souza-Schorey, C.; Chavrier, P. ARF proteins: Roles in membrane traffic and beyond. Nat. Rev. Mol. Cell Biol. 2006, 7, 347-358. [CrossRef]

45. McMahon, H.T.; Boucrot, E. Membrane curvature at a glance. J. Cell Sci. 2015, 128, 1065-1070. [CrossRef]

46. Tkach, M.; Kowal, J.; Thery, C. Why the need and how to approach the functional diversity of extracellular vesicles. Philos. Trans. R. Soc. Lond. B Biol. Sci. 2018, 373, 20160479. [CrossRef] [PubMed]

47. Kowal, J.; Arras, G.; Colombo, M.; Jouve, M.; Morath, J.P.; Primdal-Bengtson, B.; Dingli, F.; Loew, D.; Tkach, M.; Thery, C. Proteomic comparison defines novel markers to characterize heterogeneous populations of extracellular vesicle subtypes. Proc. Natl. Acad. Sci. USA 2016, 113, E968-E977. [CrossRef]

48. Rilla, K.; Mustonen, A.M.; Arasu, U.T.; Harkonen, K.; Matilainen, J.; Nieminen, P. Extracellular vesicles are integral and functional components of the extracellular matrix. Matrix Biol. 2019, 75-76, 201-219. [CrossRef]

49. Lenzini, S.; Bargi, R.; Chung, G.; Shin, J.W. Matrix mechanics and water permeation regulate extracellular vesicle transport. Nat. Nanotechnol. 2020, 15, 217-223. [CrossRef] [PubMed]

50. Garcia-Romero, N.; Esteban-Rubio, S.; Rackov, G.; Carrion-Navarro, J.; Belda-Iniesta, C.; Ayuso-Sacido, A. Extracellular vesicles compartment in liquid biopsies: Clinical application. Mol. Asp. Med. 2018, 60, 27-37. [CrossRef]

51. Meyer, K.C. Pulmonary fibrosis, part I: Epidemiology, pathogenesis, and diagnosis. Expert Rev. Respir. Med. 2017, 11, 343-359. [CrossRef]

52. Wijsenbeek, M.; Cottin, V. Spectrum of Fibrotic Lung Diseases. N. Engl. J. Med. 2020, 383, 958-968. [CrossRef] [PubMed]

53. Gross, T.J.; Hunninghake, G.W. Idiopathic pulmonary fibrosis. N. Engl. J. Med. 2001, 345, 517-525. [CrossRef]

54. Lederer, D.J.; Martinez, F.J. Idiopathic Pulmonary Fibrosis. N. Engl. J. Med. 2018, 378, 1811-1823. [CrossRef]

55. Wolters, P.J.; Collard, H.R.; Jones, K.D. Pathogenesis of idiopathic pulmonary fibrosis. Annu. Rev. Pathol. 2014, 9, 157-179. [CrossRef] 
56. Hughes, G.; Toellner, H.; Morris, H.; Leonard, C.; Chaudhuri, N. Real World Experiences: Pirfenidone and Nintedanib are Effective and Well Tolerated Treatments for Idiopathic Pulmonary Fibrosis. J. Clin. Med. 2016, 5, 78. [CrossRef]

57. Pollard, K.M. Silica, Silicosis, and Autoimmunity. Front. Immunol. 2016, 7, 97. [CrossRef]

58. Fujimura, N. Pathology and pathophysiology of pneumoconiosis. Curr. Opin. Pulm. Med. 2000, 6, 140-144. [CrossRef]

59. Bhandari, J.; Thada, P.K.; Sedhai, Y.R. Asbestosis; StatPearls: Treasure Island, FL, USA, 2020.

60. Lareau, S.C.; Fahy, B.; Meek, P.; Wang, A. Chronic Obstructive Pulmonary Disease (COPD). Am. J. Respir. Crit. Care Med. 2019, 199, P1-P2. [CrossRef] [PubMed]

61. Rabe, K.F.; Watz, H. Chronic obstructive pulmonary disease. Lancet 2017, 389, 1931-1940. [CrossRef]

62. Hwang, J.S.; Rehan, V.K. Recent Advances in Bronchopulmonary Dysplasia: Pathophysiology, Prevention, and Treatment. Lung 2018, 196, 129-138. [CrossRef]

63. Savani, R.C. Modulators of inflammation in Bronchopulmonary Dysplasia. Semin. Perinatol. 2018, 42, 459-470. [CrossRef] [PubMed]

64. Moore, B.B.; Hogaboam, C.M. Murine models of pulmonary fibrosis. Am. J. Physiol. Lung Cell. Mol. Physiol. 2008, 294, L152-L160. [CrossRef] [PubMed]

65. O'Dwyer, D.N.; Moore, B.B. Animal Models of Pulmonary Fibrosis. Methods Mol. Biol. 2018, 1809, 363-378. [CrossRef]

66. Martin-Medina, A.; Lehmann, M.; Burgy, O.; Hermann, S.; Baarsma, H.A.; Wagner, D.E.; De Santis, M.M.; Ciolek, F.; Hofer, T.P.; Frankenberger, M.; et al. Increased Extracellular Vesicles Mediate WNT-5A Signaling in Idiopathic Pulmonary Fibrosis. Am. J. Respir. Crit. Care Med. 2018, 198, 1527-1538. [CrossRef]

67. Xie, H.; Gao, Y.M.; Zhang, Y.C.; Jia, M.W.; Peng, F.; Meng, Q.H.; Wang, Y.C. Low let-7d exosomes from pulmonary vascular endothelial cells drive lung pericyte fibrosis through the TGFbetaRI/FoxM1/Smad/beta-catenin pathway. J. Cell. Mol. Med. 2020, 24, 13913-13926. [CrossRef]

68. Parimon, T.; Yao, C.; Habiel, D.M.; Ge, L.; Bora, S.A.; Brauer, R.; Evans, C.M.; Xie, T.; Alonso-Valenteen, F.; Medina-Kauwe, L.K.; et al. Syndecan-1 promotes lung fibrosis by regulating epithelial reprogramming through extracellular vesicles. JCI Insight 2019, 5, e129359. [CrossRef]

69. Kadota, T.; Fujita, Y.; Yoshioka, Y.; Araya, J.; Kuwano, K.; Ochiya, T. Emerging role of extracellular vesicles as a senescenceassociated secretory phenotype: Insights into the pathophysiology of lung diseases. Mol. Asp. Med. 2018, 60, 92-103. [CrossRef]

70. Kadota, T.; Yoshioka, Y.; Fujita, Y.; Araya, J.; Minagawa, S.; Hara, H.; Miyamoto, A.; Suzuki, S.; Fujimori, S.; Kohno, T.; et al. Extracellular Vesicles from Fibroblasts Induce Epithelial-Cell Senescence in Pulmonary Fibrosis. Am. J. Respir. Cell Mol. Biol. 2020, 63, 623-636. [CrossRef]

71. Kang, J.H.; Jung, M.Y.; Choudhury, M.; Leof, E.B. Transforming growth factor beta induces fibroblasts to express and release the immunomodulatory protein PD-L1 into extracellular vesicles. FASEB J. 2020, 34, 2213-2226. [CrossRef]

72. Yao, M.Y.; Zhang, W.H.; Ma, W.T.; Liu, Q.H.; Xing, L.H.; Zhao, G.F. microRNA-328 in exosomes derived from M2 macrophages exerts a promotive effect on the progression of pulmonary fibrosis via FAM13A in a rat model. Exp. Mol. Med. 2019, 51, 1-16. [CrossRef]

73. Ye, C.; Li, H.; Bao, M.; Zhuo, R.; Jiang, G.; Wang, W. Alveolar macrophage-derived exosomes modulate severity and outcome of acute lung injury. Aging 2020, 12, 6120-6128. [CrossRef]

74. Munson, P.; Lam, Y.W.; Dragon, J.; MacPherson, M.; Shukla, A. Exosomes from asbestos-exposed cells modulate gene expression in mesothelial cells. FASEB J. 2018, 32, 4328-4342. [CrossRef] [PubMed]

75. Munson, P.; Lam, Y.W.; MacPherson, M.; Beuschel, S.; Shukla, A. Mouse serum exosomal proteomic signature in response to asbestos exposure. J. Cell. Biochem. 2018, 119, 6266-6273. [CrossRef]

76. Wang, D.; Hao, C.; Zhang, L.; Zhang, J.; Liu, S.; Li, Y.; Qu, Y.; Zhao, Y.; Huang, R.; Wei, J.; et al. Exosomal miR-125a-5p derived from silica-exposed macrophages induces fibroblast transdifferentiation. Ecotoxicol. Environ. Saf. 2020, 192, 110253. [CrossRef] [PubMed]

77. Kuse, N.; Kamio, K.; Azuma, A.; Matsuda, K.; Inomata, M.; Usuki, J.; Morinaga, A.; Tanaka, T.; Kashiwada, T.; Atsumi, K.; et al. Exosome-Derived microRNA-22 Ameliorates Pulmonary Fibrosis by Regulating Fibroblast-to-Myofibroblast Differentiation in Vitro and in Vivo. J. Nippon. Med. Sch. 2020, 87, 118-128. [CrossRef]

78. Wang, Y.C.; Xie, H.; Zhang, Y.C.; Meng, Q.H.; Xiong, M.M.; Jia, M.W.; Peng, F.; Tang, D.L. Exosomal miR-107 antagonizes profibrotic phenotypes of pericytes by targeting a pathway involving HIF-1alpha/Notch1/PDGFRbeta/YAP1/Twist1 axis in vitro. Am. J. Physiol. Heart Circ. Physiol. 2021, 320, H520-H534. [CrossRef] [PubMed]

79. Mansouri, N.; Willis, G.R.; Fernandez-Gonzalez, A.; Reis, M.; Nassiri, S.; Mitsialis, S.A.; Kourembanas, S. Mesenchymal stromal cell exosomes prevent and revert experimental pulmonary fibrosis through modulation of monocyte phenotypes. JCI Insight 2019, 4, e128060. [CrossRef]

80. Willis, G.R.; Fernandez-Gonzalez, A.; Anastas, J.; Vitali, S.H.; Liu, X.; Ericsson, M.; Kwong, A.; Mitsialis, S.A.; Kourembanas, S. Mesenchymal Stromal Cell Exosomes Ameliorate Experimental Bronchopulmonary Dysplasia and Restore Lung Function through Macrophage Immunomodulation. Am. J. Respir. Crit. Care Med. 2018, 197, 104-116. [CrossRef]

81. Willis, G.R.; Fernandez-Gonzalez, A.; Reis, M.; Yeung, V.; Liu, X.; Ericsson, M.; Andrews, N.A.; Mitsialis, S.A.; Kourembanas, S. Mesenchymal stromal cell-derived small extracellular vesicles restore lung architecture and improve exercise capacity in a model of neonatal hyperoxia-induced lung injury. J. Extracell. Vesicles 2020, 9, 1790874. [CrossRef] 
82. Zhang, Z.; Ge, L.; Zhang, S.; Wang, J.; Jiang, W.; Xin, Q.; Luan, Y. The protective effects of MSC-EXO against pulmonary hypertension through regulating Wnt5a/BMP signalling pathway. J. Cell. Mol. Med. 2020, 24, 13938-13948. [CrossRef]

83. Wan, X.; Chen, S.; Fang, Y.; Zuo, W.; Cui, J.; Xie, S. Mesenchymal stem cell-derived extracellular vesicles suppress the fibroblast proliferation by downregulating FZD6 expression in fibroblasts via micrRNA-29b-3p in idiopathic pulmonary fibrosis. J. Cell. Physiol. 2020, 235, 8613-8625. [CrossRef]

84. Xiao, K.; He, W.; Guan, W.; Hou, F.; Yan, P.; Xu, J.; Zhou, T.; Liu, Y.; Xie, L. Mesenchymal stem cells reverse EMT process through blocking the activation of NF-kappaB and Hedgehog pathways in LPS-induced acute lung injury. Cell Death Dis. 2020, 11, 863. [CrossRef]

85. Xu, C.; Zhao, J.; Li, Q.; Hou, L.; Wang, Y.; Li, S.; Jiang, F.; Zhu, Z.; Tian, L. Exosomes derived from three-dimensional cultured human umbilical cord mesenchymal stem cells ameliorate pulmonary fibrosis in a mouse silicosis model. Stem Cell Res. Ther. 2020, 11, 503. [CrossRef]

86. Lei, X.; He, N.; Zhu, L.; Zhou, M.; Zhang, K.; Wang, C.; Huang, H.; Chen, S.; Li, Y.; Liu, Q.; et al. Mesenchymal Stem Cell-Derived Extracellular Vesicles Attenuate Radiation-Induced Lung Injury via miRNA-214-3p. Antioxid. Redox Signal. 2020. [CrossRef]

87. Gao, Y.; Sun, J.; Dong, C.; Zhao, M.; Hu, Y.; Jin, F. Extracellular Vesicles Derived from Adipose Mesenchymal Stem Cells Alleviate PM2.5-Induced Lung Injury and Pulmonary Fibrosis. Med. Sci. Monit. 2020, 26, e922782. [CrossRef] [PubMed]

88. Royce, S.G.; Patel, K.P.; Mao, W.; Zhu, D.; Lim, R.; Samuel, C.S. Serelaxin enhances the therapeutic effects of human amnion epithelial cell-derived exosomes in experimental models of lung disease. Br. J. Pharmacol. 2019, 176, 2195-2208. [CrossRef] [PubMed]

89. Tan, J.L.; Lau, S.N.; Leaw, B.; Nguyen, H.P.T.; Salamonsen, L.A.; Saad, M.I.; Chan, S.T.; Zhu, D.; Krause, M.; Kim, C.; et al. Amnion Epithelial Cell-Derived Exosomes Restrict Lung Injury and Enhance Endogenous Lung Repair. Stem Cells Transl. Med. 2018, 7, 180-196. [CrossRef]

90. Dinh, P.C.; Paudel, D.; Brochu, H.; Popowski, K.D.; Gracieux, M.C.; Cores, J.; Huang, K.; Hensley, M.T.; Harrell, E.; Vandergriff, A.C.; et al. Inhalation of lung spheroid cell secretome and exosomes promotes lung repair in pulmonary fibrosis. Nat. Commun. 2020, 11, 1064. [CrossRef] [PubMed]

91. Sun, L.; Zhu, M.; Feng, W.; Lin, Y.; Yin, J.; Jin, J.; Wang, Y. Exosomal miRNA Let-7 from Menstrual Blood-Derived Endometrial Stem Cells Alleviates Pulmonary Fibrosis through Regulating Mitochondrial DNA Damage. Oxidative Med. Cell. Longev. 2019, 2019, 4506303. [CrossRef]

92. Guiot, J.; Cambier, M.; Boeckx, A.; Henket, M.; Nivelles, O.; Gester, F.; Louis, E.; Malaise, M.; Dequiedt, F.; Louis, R.; et al. Macrophage-derived exosomes attenuate fibrosis in airway epithelial cells through delivery of antifibrotic miR-142-3p. Thorax 2020, 75, 870-881. [CrossRef]

93. Wang, L.; Liu, J.; Xie, W.; Li, G.; Yao, L.; Zhang, R.; Xu, B. miR-425 reduction causes aberrant proliferation and collagen synthesis through modulating TGF-beta/Smad signaling in acute respiratory distress syndrome. Int. J. Clin. Exp. Pathol. 2019, 12, 2604-2612.

94. Inomata, M.; Kamio, K.; Azuma, A.; Matsuda, K.; Usuki, J.; Morinaga, A.; Tanaka, T.; Kashiwada, T.; Atsumi, K.; Hayashi, H.; et al. Rictor-targeting exosomal microRNA-16 ameliorates lung fibrosis by inhibiting the mTORC2-SPARC axis. Exp. Cell Res. 2021, 398, 112416. [CrossRef]

95. Makiguchi, T.; Yamada, M.; Yoshioka, Y.; Sugiura, H.; Koarai, A.; Chiba, S.; Fujino, N.; Tojo, Y.; Ota, C.; Kubo, H.; et al. Serum extracellular vesicular miR-21-5p is a predictor of the prognosis in idiopathic pulmonary fibrosis. Respir. Res. 2016, 17, 110. [CrossRef]

96. Njock, M.S.; Guiot, J.; Henket, M.A.; Nivelles, O.; Thiry, M.; Dequiedt, F.; Corhay, J.L.; Louis, R.E.; Struman, I. Sputum exosomes: Promising biomarkers for idiopathic pulmonary fibrosis. Thorax 2019, 74, 309-312. [CrossRef]

97. Webster, A.C.; Nagler, E.V.; Morton, R.L.; Masson, P. Chronic Kidney Disease. Lancet 2017, 389, 1238-1252. [CrossRef]

98. Lopez-Novoa, J.M.; Martinez-Salgado, C.; Rodriguez-Pena, A.B.; Lopez-Hernandez, F.J. Common pathophysiological mechanisms of chronic kidney disease: Therapeutic perspectives. Pharmacol. Ther. 2010, 128, 61-81. [CrossRef] [PubMed]

99. Liu, Y. Cellular and molecular mechanisms of renal fibrosis. Nat. Rev. Nephrol. 2011, 7, 684-696. [CrossRef] [PubMed]

100. Nogueira, A.; Pires, M.J.; Oliveira, P.A. Pathophysiological Mechanisms of Renal Fibrosis: A Review of Animal Models and Therapeutic Strategies. In Vivo 2017, 31, 1-22. [CrossRef] [PubMed]

101. Humphreys, B.D. Mechanisms of Renal Fibrosis. Annu. Rev. Physiol. 2018, 80, 309-326. [CrossRef]

102. Zeisberg, M.; Neilson, E.G. Mechanisms of tubulointerstitial fibrosis. J. Am. Soc. Nephrol. 2010, 21, 1819-1834. [CrossRef]

103. Forbes, J.M.; Coughlan, M.T.; Cooper, M.E. Oxidative stress as a major culprit in kidney disease in diabetes. Diabetes 2008, 57, 1446-1454. [CrossRef]

104. Molitch, M.E. Diabetic Kidney Disease: Much Progress, But Still More to Do. Diabetes Spectr. 2015, 28, 154-156. [CrossRef]

105. Rao, V.R.A.L.B.V.; Tan, S.H.; Candasamy, M.; Bhattamisra, S.K. Diabetic nephropathy: An update on pathogenesis and drug development. Diabetes Metab. Syndr. 2019, 13, 754-762. [CrossRef]

106. Tanaka, S.; Tanaka, T.; Nangaku, M. Hypoxia as a key player in the AKI-to-CKD transition. Am. J. Physiol. Ren. Physiol. 2014, 307, F1187-F1195. [CrossRef]

107. Coca, S.G.; Yusuf, B.; Shlipak, M.G.; Garg, A.X.; Parikh, C.R. Long-term risk of mortality and other adverse outcomes after acute kidney injury: A systematic review and meta-analysis. Am. J. Kidney Dis. 2009, 53, 961-973. [CrossRef] 
108. Chen, L.; Wang, Y.; Li, S.; Zuo, B.; Zhang, X.; Wang, F.; Sun, D. Exosomes derived from GDNF-modified human adipose mesenchymal stem cells ameliorate peritubular capillary loss in tubulointerstitial fibrosis by activating the SIRT1/eNOS signaling pathway. Theranostics 2020, 10, 9425-9442. [CrossRef]

109. Liu, X.; Miao, J.; Wang, C.; Zhou, S.; Chen, S.; Ren, Q.; Hong, X.; Wang, Y.; Hou, F.F.; Zhou, L.; et al. Tubule-derived exosomes play a central role in fibroblast activation and kidney fibrosis. Kidney Int. 2020, 97, 1181-1195. [CrossRef] [PubMed]

110. Zhou, Y.; Xiong, M.; Fang, L.; Jiang, L.; Wen, P.; Dai, C.; Zhang, C.Y.; Yang, J. miR-21-containing microvesicles from injured tubular epithelial cells promote tubular phenotype transition by targeting PTEN protein. Am. J. Pathol. 2013, 183, 1183-1196. [CrossRef] [PubMed]

111. Wen, J.; Ma, Z.; Livingston, M.J.; Zhang, W.; Yuan, Y.; Guo, C.; Liu, Y.; Fu, P.; Dong, Z. Decreased secretion and profibrotic activity of tubular exosomes in diabetic kidney disease. Am. J. Physiol. Ren. Physiol. 2020, 319, F664-F673. [CrossRef]

112. Liu, J.R.; Cai, G.Y.; Ning, Y.C.; Wang, J.C.; Lv, Y.; Guo, Y.N.; Fu, B.; Hong, Q.; Sun, X.F.; Chen, X.M. Caloric restriction alleviates aging-related fibrosis of kidney through downregulation of miR-21 in extracellular vesicles. Aging 2020, 12, 18052-18072. [CrossRef]

113. Borges, F.T.; Melo, S.A.; Ozdemir, B.C.; Kato, N.; Revuelta, I.; Miller, C.A.; Gattone, V.H., 2nd; LeBleu, V.S.; Kalluri, R. TGF-beta1containing exosomes from injured epithelial cells activate fibroblasts to initiate tissue regenerative responses and fibrosis. J. Am. Soc. Nephrol. 2013, 24, 385-392. [CrossRef] [PubMed]

114. Furini, G.; Schroeder, N.; Huang, L.; Boocock, D.; Scarpellini, A.; Coveney, C.; Tonoli, E.; Ramaswamy, R.; Ball, G.; Verderio, C.; et al. Proteomic Profiling Reveals the Transglutaminase-2 Externalization Pathway in Kidneys after Unilateral Ureteric Obstruction. J. Am. Soc. Nephrol. 2018, 29, 880-905. [CrossRef] [PubMed]

115. Hu, R.; Li, X.; Peng, C.; Gao, R.; Ma, L.; Hu, J.; Luo, T.; Qing, H.; Wang, Y.; Ge, Q.; et al. miR-196b-5p-enriched extracellular vesicles from tubular epithelial cells mediated aldosterone-induced renal fibrosis in mice with diabetes. BMJ Open Diabetes Res. Care 2020, 8, e001101. [CrossRef] [PubMed]

116. Prunotto, M.; Farina, A.; Lane, L.; Pernin, A.; Schifferli, J.; Hochstrasser, D.F.; Lescuyer, P.; Moll, S. Proteomic analysis of podocyte exosome-enriched fraction from normal human urine. J. Proteom. 2013, 82, 193-229. [CrossRef] [PubMed]

117. Munkonda, M.N.; Akbari, S.; Landry, C.; Sun, S.; Xiao, F.; Turner, M.; Holterman, C.E.; Nasrallah, R.; Hebert, R.L.; Kennedy, C.R.J.; et al. Podocyte-derived microparticles promote proximal tubule fibrotic signaling via p38 MAPK and CD36. J. Extracell. Vesicles 2018, 7, 1432206. [CrossRef] [PubMed]

118. Wu, X.; Gao, Y.; Xu, L.; Dang, W.; Yan, H.; Zou, D.; Zhu, Z.; Luo, L.; Tian, N.; Wang, X.; et al. Exosomes from high glucose-treated glomerular endothelial cells trigger the epithelial-mesenchymal transition and dysfunction of podocytes. Sci. Rep. 2017, 7, 9371. [CrossRef]

119. Wu, X.M.; Gao, Y.B.; Xu, L.P.; Zou, D.W.; Zhu, Z.Y.; Wang, X.L.; Yao, W.J.; Luo, L.T.; Tong, Y.; Tian, N.X.; et al. Tongxinluo Inhibits Renal Fibrosis in Diabetic Nephropathy: Involvement of the Suppression of Intercellular Transfer of TGF- $\beta 1-C o n t a i n i n g$ Exosomes from GECs to GMCs. Am. J. Chin. Med. 2017, 45, 1075-1092. [CrossRef]

120. Ling, L.; Tan, Z.; Zhang, C.; Gui, S.; Cui, Y.; Hu, Y.; Chen, L. CircRNAs in exosomes from high glucose-treated glomerular endothelial cells activate mesangial cells. Am. J. Transl. Res. 2019, 11, 4667-4682. [PubMed]

121. Wang, Y.Y.; Tang, L.Q.; Wei, W. Berberine attenuates podocytes injury caused by exosomes derived from high glucose-induced mesangial cells through TGFbeta1-PI3K/AKT pathway. Eur. J. Pharmacol. 2018, 824, 185-192. [CrossRef]

122. Da Silva Novaes, A.; Borges, F.T.; Maquigussa, E.; Varela, V.A.; Dias, M.V.S.; Boim, M.A. Influence of high glucose on mesangial cell-derived exosome composition, secretion and cell communication. Sci. Rep. 2019, 9, 6270. [CrossRef]

123. Zhu, Q.J.; Zhu, M.; Xu, X.X.; Meng, X.M.; Wu, Y.G. Exosomes from high glucose-treated macrophages activate glomerular mesangial cells via TGF-beta1/Smad3 pathway in vivo and in vitro. FASEB J. 2019, 33, 9279-9290. [CrossRef] [PubMed]

124. Zhu, M.; Sun, X.; Qi, X.; Xia, L.; Wu, Y. Exosomes from high glucose-treated macrophages activate macrophages andinduce inflammatory responses via NF-kappaB signaling pathway in vitro and in vivo. Int. Immunopharmacol. 2020, $84,106551$. [CrossRef] [PubMed]

125. Nagaishi, K.; Mizue, Y.; Chikenji, T.; Otani, M.; Nakano, M.; Konari, N.; Fujimiya, M. Mesenchymal stem cell therapy ameliorates diabetic nephropathy via the paracrine effect of renal trophic factors including exosomes. Sci. Rep. 2016, 6, 34842. [CrossRef]

126. Ebrahim, N.; Ahmed, I.A.; Hussien, N.I.; Dessouky, A.A.; Farid, A.S.; Elshazly, A.M.; Mostafa, O.; Gazzar, W.B.E.; Sorour, S.M.; Seleem, Y.; et al. Mesenchymal Stem Cell-Derived Exosomes Ameliorated Diabetic Nephropathy by Autophagy Induction through the mTOR Signaling Pathway. Cells 2018, 7, 226. [CrossRef]

127. Grange, C.; Tritta, S.; Tapparo, M.; Cedrino, M.; Tetta, C.; Camussi, G.; Brizzi, M.F. Stem cell-derived extracellular vesicles inhibit and revert fibrosis progression in a mouse model of diabetic nephropathy. Sci. Rep. 2019, 9, 4468. [CrossRef] [PubMed]

128. Shi, Z.; Wang, Q.; Zhang, Y.; Jiang, D. Extracellular vesicles produced by bone marrow mesenchymal stem cells attenuate renal fibrosis, in part by inhibiting the RhoA/ROCK pathway, in a UUO rat model. Stem Cell Res. Ther. 2020, 11, 253. [CrossRef]

129. Wang, Y.; Guo, Y.F.; Fu, G.P.; Guan, C.; Zhang, X.; Yang, D.G.; Shi, Y.C. Protective effect of miRNA-containing extracellular vesicles derived from mesenchymal stromal cells of old rats on renal function in chronic kidney disease. Stem Cell Res. Ther. 2020, 11, 274. [CrossRef]

130. Wang, B.; Yao, K.; Huuskes, B.M.; Shen, H.H.; Zhuang, J.; Godson, C.; Brennan, E.P.; Wilkinson-Berka, J.L.; Wise, A.F.; Ricardo, S.D. Mesenchymal Stem Cells Deliver Exogenous MicroRNA-let7c via Exosomes to Attenuate Renal Fibrosis. Mol. Ther. 2016, 24, 1290-1301. [CrossRef] 
131. He, J.; Jiang, Y.L.; Wang, Y.; Tian, X.J.; Sun, S.R. Micro-vesicles from mesenchymal stem cells over-expressing miR-34a inhibit transforming growth factor-beta1-induced epithelial-mesenchymal transition in renal tubular epithelial cells in vitro. Chin. Med. J. (Engl.) 2020, 133, 800-807. [CrossRef]

132. Eirin, A.; Zhu, X.Y.; Puranik, A.S.; Tang, H.; McGurren, K.A.; van Wijnen, A.J.; Lerman, A.; Lerman, L.O. Mesenchymal stem cell-derived extracellular vesicles attenuate kidney inflammation. Kidney Int. 2017, 92, 114-124. [CrossRef] [PubMed]

133. Song, T.; Eirin, A.; Zhu, X.; Zhao, Y.; Krier, J.D.; Tang, H.; Jordan, K.L.; Woollard, J.R.; Taner, T.; Lerman, A.; et al. Mesenchymal Stem Cell-Derived Extracellular Vesicles Induce Regulatory T Cells to Ameliorate Chronic Kidney Injury. Hypertension 2020, 75, 1223-1232. [CrossRef] [PubMed]

134. Farahani, R.A.; Zhu, X.Y.; Tang, H.; Jordan, K.L.; Lerman, A.; Lerman, L.O.; Eirin, A. Metabolic Syndrome Alters the Cargo of Mitochondria-Related microRNAs in Swine Mesenchymal Stem Cell-Derived Extracellular Vesicles, Impairing Their Capacity to Repair the Stenotic Kidney. Stem Cells Int. 2020, 2020, 8845635. [CrossRef] [PubMed]

135. Lindoso, R.S.; Lopes, J.A.; Binato, R.; Abdelhay, E.; Takiya, C.M.; Miranda, K.R.; Lara, L.S.; Viola, A.; Bussolati, B.; Vieyra, A.; et al. Adipose Mesenchymal Cells-Derived EVs Alleviate DOCA-Salt-Induced Hypertension by Promoting Cardio-Renal Protection. Mol. Ther. Methods Clin. Dev. 2020, 16, 63-77. [CrossRef] [PubMed]

136. Liu, B.; Hu, D.; Zhou, Y.; Yu, Y.; Shen, L.; Long, C.; Butnaru, D.; Timashev, P.; He, D.; Lin, T.; et al. Exosomes released by human umbilical cord mesenchymal stem cells protect against renal interstitial fibrosis through ROS-mediated P38MAPK/ERK signaling pathway. Am. J. Transl. Res. 2020, 12, 4998-5014.

137. Ji, C.; Zhang, J.; Zhu, Y.; Shi, H.; Yin, S.; Sun, F.; Wang, Q.; Zhang, L.; Yan, Y.; Zhang, X.; et al. Exosomes derived from hucMSC attenuate renal fibrosis through CK1delta/beta-TRCP-mediated YAP degradation. Cell Death Dis. 2020, 11, 327. [CrossRef] [PubMed]

138. Zhang, Z.Y.; Hou, Y.P.; Zou, X.Y.; Xing, X.Y.; Ju, G.Q.; Zhong, L.; Sun, J. Oct-4 Enhanced the Therapeutic Effects of Mesenchymal Stem Cell-Derived Extracellular Vesicles in Acute Kidney Injury. Kidney Blood Press. Res. 2020, 45, 95-108. [CrossRef] [PubMed]

139. Zou, X.; Gu, D.; Xing, X.; Cheng, Z.; Gong, D.; Zhang, G.; Zhu, Y. Human mesenchymal stromal cell-derived extracellular vesicles alleviate renal ischemic reperfusion injury and enhance angiogenesis in rats. Am. J. Transl. Res. 2016, 8, 4289-4299.

140. Xiang, E.; Han, B.; Zhang, Q.; Rao, W.; Wang, Z.; Chang, C.; Zhang, Y.; Tu, C.; Li, C.; Wu, D. Human umbilical cord-derived mesenchymal stem cells prevent the progression of early diabetic nephropathy through inhibiting inflammation and fibrosis. Stem Cell Res. Ther. 2020, 11, 336. [CrossRef]

141. Li, H.; Rong, P.; Ma, X.; Nie, W.; Chen, Y.; Zhang, J.; Dong, Q.; Yang, M.; Wang, W. Mouse Umbilical Cord Mesenchymal Stem Cell Paracrine Alleviates Renal Fibrosis in Diabetic Nephropathy by Reducing Myofibroblast Transdifferentiation and Cell Proliferation and Upregulating MMPs in Mesangial Cells. J. Diabetes Res. 2020, 2020, 3847171. [CrossRef]

142. Kholia, S.; Herrera Sanchez, M.B.; Cedrino, M.; Papadimitriou, E.; Tapparo, M.; Deregibus, M.C.; Brizzi, M.F.; Tetta, C.; Camussi, G. Human Liver Stem Cell-Derived Extracellular Vesicles Prevent Aristolochic Acid-Induced Kidney Fibrosis. Front. Immunol. 2018, 9, 1639. [CrossRef] [PubMed]

143. Kholia, S.; Herrera Sanchez, M.B.; Cedrino, M.; Papadimitriou, E.; Tapparo, M.; Deregibus, M.C.; Bruno, S.; Antico, F.; Brizzi, M.F.; Quesenberry, P.J.; et al. Mesenchymal Stem Cell Derived Extracellular Vesicles Ameliorate Kidney Injury in Aristolochic Acid Nephropathy. Front. Cell Dev. Biol. 2020, 8, 188. [CrossRef] [PubMed]

144. Zhu, Z.; Han, C.; Xian, S.; Zhuang, F.; Ding, F.; Zhang, W.; Liu, Y. Placental Mesenchymal Stromal Cells (PMSCs) and PMSCDerived Extracellular Vesicles (PMSC-EVs) Attenuated Renal Fibrosis in Rats with Unilateral Ureteral Obstruction (UUO) by Regulating CD4(+) T Cell Polarization. Stem Cells Int. 2020, 2020, 2685820. [CrossRef]

145. Cambier, L.; Giani, J.F.; Liu, W.; Ijichi, T.; Echavez, A.K.; Valle, J.; Marban, E. Angiotensin II-Induced End-Organ Damage in Mice Is Attenuated by Human Exosomes and by an Exosomal Y RNA Fragment. Hypertension 2018, 72, 370-380. [CrossRef] [PubMed]

146. Dominguez, J.H.; Liu, Y.; Gao, H.; Dominguez, J.M., 2nd; Xie, D.; Kelly, K.J. Renal Tubular Cell-Derived Extracellular Vesicles Accelerate the Recovery of Established Renal Ischemia Reperfusion Injury. J. Am. Soc. Nephrol. 2017, 28, 3533-3544. [CrossRef]

147. Dominguez, J.M., 2nd; Dominguez, J.H.; Xie, D.; Kelly, K.J. Human extracellular microvesicles from renal tubules reverse kidney ischemia-reperfusion injury in rats. PLoS ONE 2018, 13, e0202550. [CrossRef]

148. Kim, S.; Jeong, C.H.; Song, S.H.; Um, J.E.; Kim, H.S.; Yun, J.S.; Han, D.; Cho, E.S.; Nam, B.Y.; Yook, J.I.; et al. Micellized Protein Transduction Domain-Bone Morphogenetic Protein-7 Efficiently Blocks Renal Fibrosis Via Inhibition of Transforming Growth Factor-Beta-Mediated Epithelial-Mesenchymal Transition. Front. Pharmacol. 2020, 11, 591275. [CrossRef]

149. Qin, W.; Chung, A.C.; Huang, X.R.; Meng, X.M.; Hui, D.S.; Yu, C.M.; Sung, J.J.; Lan, H.Y. TGF-beta/Smad3 signaling promotes renal fibrosis by inhibiting miR-29. J. Am. Soc. Nephrol. 2011, 22, 1462-1474. [CrossRef]

150. Chun-Yan, L.; Zi-Yi, Z.; Tian-Lin, Y.; Yi-Li, W.; Bao, L.; Jiao, L.; Wei-Jun, D. Liquid biopsy biomarkers of renal interstitial fibrosis based on urinary exosome. Exp. Mol. Pathol. 2018, 105, 223-228. [CrossRef]

151. Lv, C.Y.; Ding, W.J.; Wang, Y.L.; Zhao, Z.Y.; Li, J.H.; Chen, Y.; Lv, J. A PEG-based method for the isolation of urinary exosomes and its application in renal fibrosis diagnostics using cargo miR-29c and miR-21 analysis. Int. Urol. Nephrol. 2018, 50, 973-982. [CrossRef]

152. Lv, L.L.; Cao, Y.H.; Ni, H.F.; Xu, M.; Liu, D.; Liu, H.; Chen, P.S.; Liu, B.C. MicroRNA-29c in urinary exosome/microvesicle as a biomarker of renal fibrosis. Am. J. Physiol. Ren. Physiol. 2013, 305, F1220-F1227. [CrossRef] [PubMed] 
153. Wang, B.; Wang, J.; He, W.; Zhao, Y.; Zhang, A.; Liu, Y.; Hassounah, F.; Ma, F.; Klein, J.D.; Wang, X.H.; et al. Exogenous miR-29a Attenuates Muscle Atrophy and Kidney Fibrosis in Unilateral Ureteral Obstruction Mice. Hum. Gene Ther. 2020, 31, 367-375. [CrossRef]

154. Wang, H.; Wang, B.; Zhang, A.; Hassounah, F.; Seow, Y.; Wood, M.; Ma, F.; Klein, J.D.; Price, S.R.; Wang, X.H. Exosome-Mediated miR-29 Transfer Reduces Muscle Atrophy and Kidney Fibrosis in Mice. Mol. Ther. 2019, 27, 571-583. [CrossRef]

155. Zhang, A.; Wang, H.; Wang, B.; Yuan, Y.; Klein, J.D.; Wang, X.H. Exogenous miR-26a suppresses muscle wasting and renal fibrosis in obstructive kidney disease. FASEB J. 2019, 33, 13590-13601. [CrossRef] [PubMed]

156. Sole, C.; Cortes-Hernandez, J.; Felip, M.L.; Vidal, M.; Ordi-Ros, J. miR-29c in urinary exosomes as predictor of early renal fibrosis in lupus nephritis. Nephrol. Dial. Transplant. 2015, 30, 1488-1496. [CrossRef] [PubMed]

157. Perez-Hernandez, J.; Martinez-Arroyo, O.; Ortega, A.; Galera, M.; Solis-Salguero, M.A.; Chaves, F.J.; Redon, J.; Forner, M.J.; Cortes, R. Urinary exosomal miR-146a as a marker of albuminuria, activity changes and disease flares in lupus nephritis. J. Nephrol. 2020. [CrossRef]

158. Garcia-Vives, E.; Sole, C.; Moline, T.; Vidal, M.; Agraz, I.; Ordi-Ros, J.; Cortes-Hernandez, J. The Urinary Exosomal miRNA Expression Profile is Predictive of Clinical Response in Lupus Nephritis. Int. J. Mol. Sci. 2020, 21, 1372. [CrossRef]

159. Khurana, R.; Ranches, G.; Schafferer, S.; Lukasser, M.; Rudnicki, M.; Mayer, G.; Huttenhofer, A. Identification of urinary exosomal noncoding RNAs as novel biomarkers in chronic kidney disease. RNA 2017, 23, 142-152. [CrossRef]

160. Lv, L.L.; Cao, Y.H.; Pan, M.M.; Liu, H.; Tang, R.N.; Ma, K.L.; Chen, P.S.; Liu, B.C. CD2AP mRNA in urinary exosome as biomarker of kidney disease. Clin. Chim. Acta 2014, 428, 26-31. [CrossRef]

161. Carreras-Planella, L.; Cucchiari, D.; Canas, L.; Juega, J.; Franquesa, M.; Bonet, J.; Revuelta, I.; Diekmann, F.; Taco, O.; Lauzurica, R.; et al. Urinary vitronectin identifies patients with high levels of fibrosis in kidney grafts. J. Nephrol. 2020, 34, 861-874. [CrossRef]

162. Saejong, S.; Townamchai, N.; Somparn, P.; Tangtanatakul, P.; Ondee, T.; Hirankarn, N.; Leelahavanichkul, A. MicroRNA-21 in plasma exosome, but not from whole plasma, as a biomarker for the severe interstitial fibrosis and tubular atrophy (IF/TA) in post-renal transplantation. Asian Pac. J. Allergy Immunol. 2020. [CrossRef]

163. Xie, J.X.; Fan, X.; Drummond, C.A.; Majumder, R.; Xie, Y.; Chen, T.; Liu, L.; Haller, S.T.; Brewster, P.S.; Dworkin, L.D.; et al. MicroRNA profiling in kidney disease: Plasma versus plasma-derived exosomes. Gene 2017, 627, 1-8. [CrossRef]

164. Kong, P.; Christia, P.; Frangogiannis, N.G. The pathogenesis of cardiac fibrosis. Cell. Mol. Life Sci. 2014, 71, 549-574. [CrossRef]

165. Gonzalez, A.; Schelbert, E.B.; Diez, J.; Butler, J. Myocardial Interstitial Fibrosis in Heart Failure: Biological and Translational Perspectives. J. Am. Coll. Cardiol. 2018, 71, 1696-1706. [CrossRef] [PubMed]

166. Talman, V.; Ruskoaho, H. Cardiac fibrosis in myocardial infarction-from repair and remodeling to regeneration. Cell Tissue Res. 2016, 365, 563-581. [CrossRef] [PubMed]

167. Murtha, L.A.; Schuliga, M.J.; Mabotuwana, N.S.; Hardy, S.A.; Waters, D.W.; Burgess, J.K.; Knight, D.A.; Boyle, A.J. The Processes and Mechanisms of Cardiac and Pulmonary Fibrosis. Front. Physiol. 2017, 8, 777. [CrossRef] [PubMed]

168. Bacmeister, L.; Schwarzl, M.; Warnke, S.; Stoffers, B.; Blankenberg, S.; Westermann, D.; Lindner, D. Inflammation and fibrosis in murine models of heart failure. Basic Res. Cardiol. 2019, 114, 19. [CrossRef] [PubMed]

169. Rai, V.; Sharma, P.; Agrawal, S.; Agrawal, D.K. Relevance of mouse models of cardiac fibrosis and hypertrophy in cardiac research. Mol. Cell. Biochem. 2017, 424, 123-145. [CrossRef] [PubMed]

170. Yang, J.; Yu, X.; Xue, F.; Li, Y.; Liu, W.; Zhang, S. Exosomes derived from cardiomyocytes promote cardiac fibrosis via myocytefibroblast cross-talk. Am. J. Transl. Res. 2018, 10, 4350-4366.

171. Kenneweg, F.; Bang, C.; Xiao, K.; Boulanger, C.M.; Loyer, X.; Mazlan, S.; Schroen, B.; Hermans-Beijnsberger, S.; Foinquinos, A.; Hirt, M.N.; et al. Long Noncoding RNA-Enriched Vesicles Secreted by Hypoxic Cardiomyocytes Drive Cardiac Fibrosis. Mol. Ther. Nucleic Acids 2019, 18, 363-374. [CrossRef]

172. Danielson, K.M.; Shah, R.; Yeri, A.; Liu, X.; Camacho Garcia, F.; Silverman, M.; Tanriverdi, K.; Das, A.; Xiao, C.; Jerosch-Herold, M.; et al. Plasma Circulating Extracellular RNAs in Left Ventricular Remodeling Post-Myocardial Infarction. EBioMedicine 2018, 32, 172-181. [CrossRef] [PubMed]

173. Xia, Y.W.; Wang, S.B. Microvesicles containing microRNA-21 induce myocardial fibrosis via AKT pathway. Eur. Rev. Med. Pharmacol. Sci. 2018, 22, 4634-4641. [CrossRef]

174. Kuo, H.F.; Hsieh, C.C.; Wang, S.C.; Chang, C.Y.; Hung, C.H.; Kuo, P.L.; Liu, Y.R.; Li, C.Y.; Liu, P.L. Simvastatin Attenuates Cardiac Fibrosis via Regulation of Cardiomyocyte-Derived Exosome Secretion. J. Clin. Med. 2019, 8, 794. [CrossRef] [PubMed]

175. Vaskova, E.; Ikeda, G.; Tada, Y.; Wahlquist, C.; Mercola, M.; Yang, P.C. Sacubitril/Valsartan Improves Cardiac Function and Decreases Myocardial Fibrosis Via Downregulation of Exosomal miR-181a in a Rodent Chronic Myocardial Infarction Model. J. Am. Heart Assoc. 2020, 9, e015640. [CrossRef]

176. Tian, C.; Gao, L.; Zimmerman, M.C.; Zucker, I.H. Myocardial infarction-induced microRNA-enriched exosomes contribute to cardiac Nrf2 dysregulation in chronic heart failure. Am. J. Physiol. Heart Circ. Physiol. 2018, 314, H928-H939. [CrossRef] [PubMed]

177. Dzialo, E.; Rudnik, M.; Koning, R.I.; Czepiel, M.; Tkacz, K.; Baj-Krzyworzeka, M.; Distler, O.; Siedlar, M.; Kania, G.; Blyszczuk, P. WNT3a and WNT5a Transported by Exosomes Activate WNT Signaling Pathways in Human Cardiac Fibroblasts. Int. J. Mol. Sci. 2019, 20, 1436. [CrossRef]

178. Frieler, R.A.; Mortensen, R.M. Immune cell and other noncardiomyocyte regulation of cardiac hypertrophy and remodeling. Circulation 2015, 131, 1019-1030. [CrossRef] 
179. Cai, L.; Chao, G.; Li, W.; Zhu, J.; Li, F.; Qi, B.; Wei, Y.; Chen, S.; Zhou, G.; Lu, X.; et al. Activated CD4(+) T cells-derived exosomal miR-142-3p boosts post-ischemic ventricular remodeling by activating myofibroblast. Aging 2020, 12, 7380-7396. [CrossRef]

180. Govindappa, P.K.; Patil, M.; Garikipati, V.N.S.; Verma, S.K.; Saheera, S.; Narasimhan, G.; Zhu, W.; Kishore, R.; Zhang, J.; Krishnamurthy, P. Targeting exosome-associated human antigen $\mathrm{R}$ attenuates fibrosis and inflammation in diabetic heart. FASEB J. 2020, 34, 2238-2251. [CrossRef]

181. Wang, C.; Zhang, C.; Liu, L.; Xi, A.; Chen, B.; Li, Y.; Du, J. Macrophage-Derived mir-155-Containing Exosomes Suppress Fibroblast Proliferation and Promote Fibroblast Inflammation during Cardiac Injury. Mol. Ther. 2017, 25, 192-204. [CrossRef]

182. Wang, B.; Wang, Z.M.; Ji, J.L.; Gan, W.; Zhang, A.; Shi, H.J.; Wang, H.; Lv, L.; Li, Z.; Tang, T.; et al. Macrophage-Derived Exosomal Mir-155 Regulating Cardiomyocyte Pyroptosis and Hypertrophy in Uremic Cardiomyopathy. JACC Basic Transl. Sci. 2020, 5 , 148-166. [CrossRef]

183. Yang, J.; Yu, X.F.; Li, Y.Y.; Xue, F.T.; Zhang, S. Decreased HSP70 expression on serum exosomes contributes to cardiac fibrosis during senescence. Eur. Rev. Med. Pharmacol. Sci. 2019, 23, 3993-4001. [CrossRef]

184. Shao, L.; Zhang, Y.; Pan, X.; Liu, B.; Liang, C.; Zhang, Y.; Wang, Y.; Yan, B.; Xie, W.; Sun, Y.; et al. Knockout of beta-2 microglobulin enhances cardiac repair by modulating exosome imprinting and inhibiting stem cell-induced immune rejection. Cell. Mol. Life Sci. 2020, 77, 937-952. [CrossRef]

185. Wang, J.; Lee, C.J.; Deci, M.B.; Jasiewicz, N.; Verma, A.; Canty, J.M.; Nguyen, J. MiR-101a loaded extracellular nanovesicles as bioactive carriers for cardiac repair. Nanomedicine 2020, 27, 102201. [CrossRef] [PubMed]

186. Sun, J.; Shen, H.; Shao, L.; Teng, X.; Chen, Y.; Liu, X.; Yang, Z.; Shen, Z. HIF-1alpha overexpression in mesenchymal stem cell-derived exosomes mediates cardioprotection in myocardial infarction by enhanced angiogenesis. Stem Cell Res. Ther. 2020, 11, 373. [CrossRef]

187. Sun, L.; Zhu, W.; Zhao, P.; Zhang, J.; Lu, Y.; Zhu, Y.; Zhao, W.; Liu, Y.; Chen, Q.; Zhang, F. Down-Regulated Exosomal MicroRNA-221-3p Derived from Senescent Mesenchymal Stem Cells Impairs Heart Repair. Front. Cell Dev. Biol. $2020,8,263$. [CrossRef]

188. Wang, X.; Chen, Y.; Zhao, Z.; Meng, Q.; Yu, Y.; Sun, J.; Yang, Z.; Chen, Y.; Li, J.; Ma, T.; et al. Engineered Exosomes with Ischemic Myocardium-Targeting Peptide for Targeted Therapy in Myocardial Infarction. J. Am. Heart Assoc. 2018, 7, e008737. [CrossRef]

189. Firoozi, S.; Pahlavan, S.; Ghanian, M.H.; Rabbani, S.; Barekat, M.; Nazari, A.; Pakzad, M.; Shekari, F.; Hassani, S.N.; Moslem, F.; et al. Mesenchymal stem cell-derived extracellular vesicles alone or in conjunction with a SDKP-conjugated self-assembling peptide improve a rat model of myocardial infarction. Biochem. Biophys. Res. Commun. 2020, 524, 903-909. [CrossRef]

190. Chen, F.; Li, X.; Zhao, J.; Geng, J.; Xie, J.; Xu, B. Bone marrow mesenchymal stem cell-derived exosomes attenuate cardiac hypertrophy and fibrosis in pressure overload induced remodeling. In Vitro Cell. Dev. Biol. Anim. 2020, 56, 567-576. [CrossRef] [PubMed]

191. Feng, Y.; Huang, W.; Wani, M.; Yu, X.; Ashraf, M. Ischemic preconditioning potentiates the protective effect of stem cells through secretion of exosomes by targeting Mecp2 via miR-22. PLoS ONE 2014, 9, e88685. [CrossRef]

192. Zhu, J.; Lu, K.; Zhang, N.; Zhao, Y.; Ma, Q.; Shen, J.; Lin, Y.; Xiang, P.; Tang, Y.; Hu, X.; et al. Myocardial reparative functions of exosomes from mesenchymal stem cells are enhanced by hypoxia treatment of the cells via transferring microRNA-210 in an nSMase2-dependent way. Artif. Cells Nanomed. Biotechnol. 2018, 46, 1659-1670. [CrossRef]

193. Zhang, Z.; Yang, J.; Yan, W.; Li, Y.; Shen, Z.; Asahara, T. Pretreatment of Cardiac Stem Cells with Exosomes Derived from Mesenchymal Stem Cells Enhances Myocardial Repair. J. Am. Heart Assoc. 2016, 5, e002856. [CrossRef]

194. Wang, B.; Zhang, A.; Wang, H.; Klein, J.D.; Tan, L.; Wang, Z.M.; Du, J.; Naqvi, N.; Liu, B.C.; Wang, X.H. miR-26a Limits Muscle Wasting and Cardiac Fibrosis through Exosome-Mediated microRNA Transfer in Chronic Kidney Disease. Theranostics 2019, 9 , 1864-1877. [CrossRef]

195. Zhao, Y.; Sun, X.; Cao, W.; Ma, J.; Sun, L.; Qian, H.; Zhu, W.; Xu, W. Exosomes Derived from Human Umbilical Cord Mesenchymal Stem Cells Relieve Acute Myocardial Ischemic Injury. Stem Cells Int. 2015, 2015, 761643. [CrossRef]

196. Han, C.; Zhou, J.; Liang, C.; Liu, B.; Pan, X.; Zhang, Y.; Wang, Y.; Yan, B.; Xie, W.; Liu, F.; et al. Human umbilical cord mesenchymal stem cell derived exosomes encapsulated in functional peptide hydrogels promote cardiac repair. Biomater. Sci. 2019, 7, $2920-2933$. [CrossRef]

197. Zhang, N.; Zhu, J.; Ma, Q.; Zhao, Y.; Wang, Y.; Hu, X.; Chen, J.; Zhu, W.; Han, Z.; Yu, H. Exosomes derived from human umbilical cord MSCs rejuvenate aged MSCs and enhance their functions for myocardial repair. Stem Cell Res. Ther. 2020, 11, 273. [CrossRef]

198. Venkat, P.; Cui, C.; Chen, Z.; Chopp, M.; Zacharek, A.; Landschoot-Ward, J.; Culmone, L.; Yang, X.P.; Xu, J.; Chen, J. CD133+Exosome Treatment Improves Cardiac Function after Stroke in Type 2 Diabetic Mice. Transl. Stroke Res. 2020, 12, 112-124. [CrossRef]

199. Deng, S.; Zhou, X.; Ge, Z.; Song, Y.; Wang, H.; Liu, X.; Zhang, D. Exosomes from adipose-derived mesenchymal stem cells ameliorate cardiac damage after myocardial infarction by activating S1P/SK1/S1PR1 signaling and promoting macrophage M2 polarization. Int. J. Biochem. Cell Biol. 2019, 114, 105564. [CrossRef]

200. Luo, Q.; Guo, D.; Liu, G.; Chen, G.; Hang, M.; Jin, M. Exosomes from MiR-126-Overexpressing Adscs Are Therapeutic in Relieving Acute Myocardial Ischaemic Injury. Cell Physiol. Biochem. 2017, 44, 2105-2116. [CrossRef]

201. Pan, J.; Alimujiang, M.; Chen, Q.; Shi, H.; Luo, X. Exosomes derived from miR-146a-modified adipose-derived stem cells attenuate acute myocardial infarction-induced myocardial damage via downregulation of early growth response factor 1. J. Cell. Biochem. 2019, 120, 4433-4443. [CrossRef] 
202. Zhang, L.; Zhu, X.Y.; Zhao, Y.; Eirin, A.; Liu, L.; Ferguson, C.M.; Tang, H.; Lerman, A.; Lerman, L.O. Selective intrarenal delivery of mesenchymal stem cell-derived extracellular vesicles attenuates myocardial injury in experimental metabolic renovascular disease. Basic Res. Cardiol. 2020, 115, 16. [CrossRef]

203. Feng, Y.; Huang, W.; Meng, W.; Jegga, A.G.; Wang, Y.; Cai, W.; Kim, H.W.; Pasha, Z.; Wen, Z.; Rao, F.; et al. Heat shock improves Sca-1+ stem cell survival and directs ischemic cardiomyocytes toward a prosurvival phenotype via exosomal transfer: A critical role for HSF1/miR-34a/HSP70 pathway. Stem Cells 2014, 32, 462-472. [CrossRef]

204. Xuan, W.; Khan, M.; Ashraf, M. Extracellular Vesicles from Notch Activated Cardiac Mesenchymal Stem Cells Promote Myocyte Proliferation and Neovasculogenesis. Front. Cell Dev. Biol. 2020, 8, 11. [CrossRef]

205. Milano, G.; Biemmi, V.; Lazzarini, E.; Balbi, C.; Ciullo, A.; Bolis, S.; Ameri, P.; Di Silvestre, D.; Mauri, P.; Barile, L.; et al. Intravenous administration of cardiac progenitor cell-derived exosomes protects against doxorubicin/trastuzumab-induced cardiac toxicity. Cardiovasc. Res. 2020, 116, 383-392. [CrossRef]

206. Kompa, A.R.; Greening, D.W.; Kong, A.M.; McMillan, P.J.; Fang, H.; Saxena, R.; Wong, R.C.B.; Lees, J.G.; Sivakumaran, P.; Newcomb, A.E.; et al. Sustained subcutaneous delivery of secretome of human cardiac stem cells promotes cardiac repair following myocardial infarction. Cardiovasc. Res. 2020. [CrossRef]

207. Tseliou, E.; Fouad, J.; Reich, H.; Slipczuk, L.; de Couto, G.; Aminzadeh, M.; Middleton, R.; Valle, J.; Weixin, L.; Marban, E. Fibroblasts Rendered Antifibrotic, Antiapoptotic, and Angiogenic by Priming with Cardiosphere-Derived Extracellular Membrane Vesicles. J. Am. Coll. Cardiol. 2015, 66, 599-611. [CrossRef]

208. Gallet, R.; Dawkins, J.; Valle, J.; Simsolo, E.; de Couto, G.; Middleton, R.; Tseliou, E.; Luthringer, D.; Kreke, M.; Smith, R.R.; et al. Exosomes secreted by cardiosphere-derived cells reduce scarring, attenuate adverse remodelling, and improve function in acute and chronic porcine myocardial infarction. Eur. Heart J. 2017, 38, 201-211. [CrossRef]

209. Hirai, K.; Ousaka, D.; Fukushima, Y.; Kondo, M.; Eitoku, T.; Shigemitsu, Y.; Hara, M.; Baba, K.; Iwasaki, T.; Kasahara, S.; et al. Cardiosphere-derived exosomal microRNAs for myocardial repair in pediatric dilated cardiomyopathy. Sci. Transl. Med. 2020, 12. [CrossRef]

210. Ibrahim, A.G.E.; Li, C.; Rogers, R.; Fournier, M.; Li, L.; Vaturi, S.D.; Antes, T.; Sanchez, L.; Akhmerov, A.; Moseley, J.J.; et al. Augmenting canonical Wnt signalling in therapeutically inert cells converts them into therapeutically potent exosome factories. Nat. Biomed. Eng. 2019, 3, 695-705. [CrossRef]

211. Vandergriff, A.C.; de Andrade, J.B.; Tang, J.; Hensley, M.T.; Piedrahita, J.A.; Caranasos, T.G.; Cheng, K. Intravenous Cardiac Stem Cell-Derived Exosomes Ameliorate Cardiac Dysfunction in Doxorubicin Induced Dilated Cardiomyopathy. Stem Cells Int. 2015, 2015, 960926. [CrossRef]

212. Vandergriff, A.; Huang, K.; Shen, D.; Hu, S.; Hensley, M.T.; Caranasos, T.G.; Qian, L.; Cheng, K. Targeting regenerative exosomes to myocardial infarction using cardiac homing peptide. Theranostics 2018, 8, 1869-1878. [CrossRef]

213. Ni, J.; Liu, Y.; Kang, L.; Wang, L.; Han, Z.; Wang, K.; Xu, B.; Gu, R. Human trophoblast-derived exosomes attenuate doxorubicininduced cardiac injury by regulating miR-200b and downstream Zeb1. J. Nanobiotechnol. 2020, 18, 171. [CrossRef]

214. Ke, X.; Yang, D.; Liang, J.; Wang, X.; Wu, S.; Wang, X.; Hu, C. Human Endothelial Progenitor Cell-Derived Exosomes Increase Proliferation and Angiogenesis in Cardiac Fibroblasts by Promoting the Mesenchymal-Endothelial Transition and Reducing High Mobility Group Box 1 Protein B1 Expression. DNA Cell Biol. 2017, 36, 1018-1028. [CrossRef]

215. Lin, F.; Zeng, Z.; Song, Y.; Li, L.; Wu, Z.; Zhang, X.; Li, Z.; Ke, X.; Hu, X. YBX-1 mediated sorting of miR-133 into hypoxia/reoxygenation-induced EPC-derived exosomes to increase fibroblast angiogenesis and MEndoT. Stem Cell Res. Ther. 2019, 10, 263. [CrossRef]

216. Liu, W.; Zhang, H.; Mai, J.; Chen, Z.; Huang, T.; Wang, S.; Chen, Y.; Wang, J. Distinct Anti-Fibrotic Effects of Exosomes Derived from Endothelial Colony-Forming Cells Cultured Under Normoxia and Hypoxia. Med. Sci. Monit. 2018, 24, 6187-6199. [CrossRef]

217. Yang, J.; Li, Y.; Xue, F.; Liu, W.; Zhang, S. Exosomes derived from cardiac telocytes exert positive effects on endothelial cells. Am. J. Transl. Res. 2017, 9, 5375-5387.

218. Su, X.; Jin, Y.; Shen, Y.; Ju, C.; Cai, J.; Liu, Y.; Kim, I.M.; Wang, Y.; Yu, H.; Weintraub, N.L.; et al. Exosome-Derived Dystrophin from Allograft Myogenic Progenitors Improves Cardiac Function in Duchenne Muscular Dystrophic Mice. J. Cardiovasc. Transl. Res. 2018, 11, 412-419. [CrossRef]

219. Santoso, M.R.; Ikeda, G.; Tada, Y.; Jung, J.H.; Vaskova, E.; Sierra, R.G.; Gati, C.; Goldstone, A.B.; von Bornstaedt, D.; Shukla, P.; et al. Exosomes from Induced Pluripotent Stem Cell-Derived Cardiomyocytes Promote Autophagy for Myocardial Repair. J. Am. Heart Assoc. 2020, 9, e014345. [CrossRef]

220. Xuan, W.; Wang, L.; Xu, M.; Weintraub, N.L.; Ashraf, M. miRNAs in Extracellular Vesicles from iPS-Derived Cardiac Progenitor Cells Effectively Reduce Fibrosis and Promote Angiogenesis in Infarcted Heart. Stem Cells Int. 2019, 2019, 3726392. [CrossRef]

221. Khan, M.; Nickoloff, E.; Abramova, T.; Johnson, J.; Verma, S.K.; Krishnamurthy, P.; Mackie, A.R.; Vaughan, E.; Garikipati, V.N.; Benedict, C.; et al. Embryonic stem cell-derived exosomes promote endogenous repair mechanisms and enhance cardiac function following myocardial infarction. Circ. Res. 2015, 117, 52-64. [CrossRef]

222. Kervadec, A.; Bellamy, V.; El Harane, N.; Arakelian, L.; Vanneaux, V.; Cacciapuoti, I.; Nemetalla, H.; Perier, M.C.; Toeg, H.D.; Richart, A.; et al. Cardiovascular progenitor-derived extracellular vesicles recapitulate the beneficial effects of their parent cells in the treatment of chronic heart failure. J. Heart Lung Transplant. 2016, 35, 795-807. [CrossRef] [PubMed] 
223. Charles, C.J.; Li, R.R.; Yeung, T.; Mazlan, S.M.I.; Lai, R.C.; de Kleijn, D.P.V.; Lim, S.K.; Richards, A.M. Systemic Mesenchymal Stem Cell-Derived Exosomes Reduce Myocardial Infarct Size: Characterization with MRI in a Porcine Model. Front. Cardiovasc. Med. 2020, 7, 601990. [CrossRef] [PubMed]

224. Chaturvedi, P.; Kalani, A.; Medina, I.; Familtseva, A.; Tyagi, S.C. Cardiosome mediated regulation of MMP9 in diabetic heart: Role of mir29b and mir455 in exercise. J. Cell. Mol. Med. 2015, 19, 2153-2161. [CrossRef] [PubMed]

225. Yuan, J.; Liu, H.; Gao, W.; Zhang, L.; Ye, Y.; Yuan, L.; Ding, Z.; Wu, J.; Kang, L.; Zhang, X.; et al. MicroRNA-378 suppresses myocardial fibrosis through a paracrine mechanism at the early stage of cardiac hypertrophy following mechanical stress. Theranostics 2018, 8, 2565-2582. [CrossRef] [PubMed]

226. Yamaguchi, T.; Izumi, Y.; Nakamura, Y.; Yamazaki, T.; Shiota, M.; Sano, S.; Tanaka, M.; Osada-Oka, M.; Shimada, K.; Miura, K.; et al. Repeated remote ischemic conditioning attenuates left ventricular remodeling via exosome-mediated intercellular communication on chronic heart failure after myocardial infarction. Int. J. Cardiol. 2015, 178, 239-246. [CrossRef] [PubMed]

227. Gollmann-Tepekoylu, C.; Polzl, L.; Graber, M.; Hirsch, J.; Nagele, F.; Lobenwein, D.; Hess, M.W.; Blumer, M.J.; Kirchmair, E.; Zipperle, J.; et al. miR-19a-3p containing exosomes improve function of ischemic myocardium upon shock wave therapy. Cardiovasc. Res. 2020, 116, 1226-1236. [CrossRef]

228. Paudel, K.R.; Kim, D.W. Microparticles-Mediated Vascular Inflammation and its Amelioration by Antioxidant Activity of Baicalin. Antioxidants 2020, 9, 890. [CrossRef] [PubMed]

229. Otani, K.; Yokoya, M.; Kodama, T.; Hori, K.; Matsumoto, K.; Okada, M.; Yamawaki, H. Plasma exosomes regulate systemic blood pressure in rats. Biochem. Biophys. Res. Commun. 2018, 503, 776-783. [CrossRef]

230. Kang, J.Y.; Park, H.; Kim, H.; Mun, D.; Park, H.; Yun, N.; Joung, B. Human peripheral bloodderived exosomes for microRNA delivery. Int. J. Mol. Med. 2019, 43, 2319-2328. [CrossRef]

231. Mun, D.; Kim, H.; Kang, J.Y.; Park, H.; Park, H.; Lee, S.H.; Yun, N.; Joung, B. Expression of miRNAs in circulating exosomes derived from patients with persistent atrial fibrillation. FASEB J. 2019, 33, 5979-5989. [CrossRef]

232. Liu, L.; Chen, Y.; Shu, J.; Tang, C.E.; Jiang, Y.; Luo, F. Identification of microRNAs enriched in exosomes in human pericardial fluid of patients with atrial fibrillation based on bioinformatic analysis. J. Thorac. Dis. 2020, 12, 5617-5627. [CrossRef]

233. Wang, L.; Liu, J.; Xu, B.; Liu, Y.L.; Liu, Z. Reduced exosome miR-425 and miR-744 in the plasma represents the progression of fibrosis and heart failure. Kaohsiung J. Med. Sci. 2018, 34, 626-633. [CrossRef] [PubMed]

234. Tsochatzis, E.A.; Bosch, J.; Burroughs, A.K. Liver cirrhosis. Lancet 2014, 383, 1749-1761. [CrossRef]

235. Higashi, T.; Friedman, S.L.; Hoshida, Y. Hepatic stellate cells as key target in liver fibrosis. Adv. Drug Deliv. Rev. 2017, 121, 27-42. [CrossRef] [PubMed]

236. Nishio, T.; Hu, R.; Koyama, Y.; Liang, S.; Rosenthal, S.B.; Yamamoto, G.; Karin, D.; Baglieri, J.; Ma, H.Y.; Xu, J.; et al. Activated hepatic stellate cells and portal fibroblasts contribute to cholestatic liver fibrosis in MDR2 knockout mice. J. Hepatol. 2019, 71, 573-585. [CrossRef] [PubMed]

237. Seitz, H.K.; Bataller, R.; Cortez-Pinto, H.; Gao, B.; Gual, A.; Lackner, C.; Mathurin, P.; Mueller, S.; Szabo, G.; Tsukamoto, H. Alcoholic liver disease. Nat. Rev. Dis. Primers 2018, 4, 16. [CrossRef] [PubMed]

238. Younossi, Z.M.; Koenig, A.B.; Abdelatif, D.; Fazel, Y.; Henry, L.; Wymer, M. Global epidemiology of nonalcoholic fatty liver disease-Meta-analytic assessment of prevalence, incidence, and outcomes. Hepatology 2016, 64, 73-84. [CrossRef]

239. Kabbany, M.N.; Conjeevaram Selvakumar, P.K.; Watt, K.; Lopez, R.; Akras, Z.; Zein, N.; Carey, W.; Alkhouri, N. Prevalence of Nonalcoholic Steatohepatitis-Associated Cirrhosis in the United States: An Analysis of National Health and Nutrition Examination Survey Data. Am. J. Gastroenterol. 2017, 112, 581-587. [CrossRef]

240. Mendez-Sanchez, N.; Valencia-Rodriguez, A.; Coronel-Castillo, C.; Vera-Barajas, A.; Contreras-Carmona, J.; Ponciano-Rodriguez, G.; Zamora-Valdes, D. The cellular pathways of liver fibrosis in non-alcoholic steatohepatitis. Ann. Transl. Med. 2020, 8, 400. [CrossRef] [PubMed]

241. Magee, N.; Zou, A.; Zhang, Y. Pathogenesis of Nonalcoholic Steatohepatitis: Interactions between Liver Parenchymal and Nonparenchymal Cells. Biomed. Res. Int. 2016, 2016, 5170402. [CrossRef]

242. Yanguas, S.C.; Cogliati, B.; Willebrords, J.; Maes, M.; Colle, I.; van den Bossche, B.; de Oliveira, C.; Andraus, W.; Alves, V.A.F.; Leclercq, I.; et al. Experimental models of liver fibrosis. Arch. Toxicol. 2016, 90, 1025-1048. [CrossRef] [PubMed]

243. Guo, Q.; Furuta, K.; Lucien, F.; Gutierrez Sanchez, L.H.; Hirsova, P.; Krishnan, A.; Kabashima, A.; Pavelko, K.D.; Madden, B.; Alhuwaish, H.; et al. Integrin beta1-enriched extracellular vesicles mediate monocyte adhesion and promote liver inflammation in murine NASH. J. Hepatol. 2019, 71, 1193-1205. [CrossRef] [PubMed]

244. Hirsova, P.; Ibrahim, S.H.; Krishnan, A.; Verma, V.K.; Bronk, S.F.; Werneburg, N.W.; Charlton, M.R.; Shah, V.H.; Malhi, H.; Gores, G.J. Lipid-Induced Signaling Causes Release of Inflammatory Extracellular Vesicles from Hepatocytes. Gastroenterology 2016, 150, 956-967. [CrossRef]

245. Lee, Y.S.; Kim, S.Y.; Ko, E.; Lee, J.H.; Yi, H.S.; Yoo, Y.J.; Je, J.; Suh, S.J.; Jung, Y.K.; Kim, J.H.; et al. Exosomes derived from palmitic acid-treated hepatocytes induce fibrotic activation of hepatic stellate cells. Sci. Rep. 2017, 7, 3710. [CrossRef] [PubMed]

246. Povero, D.; Panera, N.; Eguchi, A.; Johnson, C.D.; Papouchado, B.G.; de Araujo Horcel, L.; Pinatel, E.M.; Alisi, A.; Nobili, V.; Feldstein, A.E. Lipid-induced hepatocyte-derived extracellular vesicles regulate hepatic stellate cell via microRNAs targeting PPAR-gamma. Cell. Mol. Gastroenterol. Hepatol. 2015, 1, 646-663.e4. [CrossRef] [PubMed] 
247. Cannito, S.; Morello, E.; Bocca, C.; Foglia, B.; Benetti, E.; Novo, E.; Chiazza, F.; Rogazzo, M.; Fantozzi, R.; Povero, D.; et al. Microvesicles released from fat-laden cells promote activation of hepatocellular NLRP3 inflammasome: A pro-inflammatory link between lipotoxicity and non-alcoholic steatohepatitis. PLoS ONE 2017, 12, e0172575. [CrossRef]

248. Povero, D.; Eguchi, A.; Li, H.; Johnson, C.D.; Papouchado, B.G.; Wree, A.; Messer, K.; Feldstein, A.E. Circulating extracellular vesicles with specific proteome and liver microRNAs are potential biomarkers for liver injury in experimental fatty liver disease. PLoS ONE 2014, 9, e113651. [CrossRef]

249. McCommis, K.S.; Hodges, W.T.; Brunt, E.M.; Nalbantoglu, I.; McDonald, W.G.; Holley, C.; Fujiwara, H.; Schaffer, J.E.; Colca, J.R.; Finck, B.N. Targeting the mitochondrial pyruvate carrier attenuates fibrosis in a mouse model of nonalcoholic steatohepatitis. Hepatology 2017, 65, 1543-1556. [CrossRef]

250. Eguchi, A.; Yan, R.; Pan, S.Q.; Wu, R.; Kim, J.; Chen, Y.; Ansong, C.; Smith, R.D.; Tempaku, M.; Ohno-Machado, L.; et al. Comprehensive characterization of hepatocyte-derived extracellular vesicles identifies direct miRNA-based regulation of hepatic stellate cells and DAMP-based hepatic macrophage IL-1beta and IL-17 upregulation in alcoholic hepatitis mice. J. Mol. Med. 2020, 98, 1021-1034. [CrossRef]

251. Seo, W.; Eun, H.S.; Kim, S.Y.; Yi, H.S.; Lee, Y.S.; Park, S.H.; Jang, M.J.; Jo, E.; Kim, S.C.; Han, Y.M.; et al. Exosome-mediated activation of toll-like receptor 3 in stellate cells stimulates interleukin-17 production by gammadelta $\mathrm{T}$ cells in liver fibrosis. Hepatology 2016, 64, 616-631. [CrossRef]

252. Zhang, X.W.; Zhou, J.C.; Peng, D.; Hua, F.; Li, K.; Yu, J.J.; Lv, X.X.; Cui, B.; Liu, S.S.; Yu, J.M.; et al. Disrupting the TRIB3-SQSTM1 interaction reduces liver fibrosis by restoring autophagy and suppressing exosome-mediated HSC activation. Autophagy 2020, 16, 782-796. [CrossRef] [PubMed]

253. Dai, X.; Chen, C.; Xue, J.; Xiao, T.; Mostofa, G.; Wang, D.; Chen, X.; Xu, H.; Sun, Q.; Li, J.; et al. Exosomal MALAT1 derived from hepatic cells is involved in the activation of hepatic stellate cells via miRNA-26b in fibrosis induced by arsenite. Toxicol. Lett. 2019, 316, 73-84. [CrossRef]

254. Dhanraj, P.; Venter, C.; Bester, M.J.; Oberholzer, H.M. Induction of hepatic portal fibrosis, mitochondria damage, and extracellular vesicle formation in Sprague-Dawley rats exposed to copper, manganese, and mercury, alone and in combination. Ultrastruct. Pathol. 2020, 44, 182-192. [CrossRef]

255. Devhare, P.B.; Sasaki, R.; Shrivastava, S.; Di Bisceglie, A.M.; Ray, R.; Ray, R.B. Exosome-Mediated Intercellular Communication between Hepatitis C Virus-Infected Hepatocytes and Hepatic Stellate Cells. J. Virol. 2017, 91, e02225-16. [CrossRef] [PubMed]

256. Kim, J.H.; Lee, C.H.; Lee, S.W. Exosomal Transmission of MicroRNA from HCV Replicating Cells Stimulates Transdifferentiation in Hepatic Stellate Cells. Mol. Ther. Nucleic Acids 2019, 14, 483-497. [CrossRef]

257. Li, X.; Liu, R.; Huang, Z.; Gurley, E.C.; Wang, X.; Wang, J.; He, H.; Yang, H.; Lai, G.; Zhang, L.; et al. Cholangiocyte-derived exosomal long noncoding RNA H19 promotes cholestatic liver injury in mouse and humans. Hepatology 2018, 68, 599-615. [CrossRef] [PubMed]

258. Li, X.; Liu, R.; Wang, Y.; Zhu, W.; Zhao, D.; Wang, X.; Yang, H.; Gurley, E.C.; Chen, W.; Hylemon, P.B.; et al. Cholangiocyte-Derived Exosomal lncRNA H19 Promotes Macrophage Activation and Hepatic Inflammation under Cholestatic Conditions. Cells 2020, 9 , 190. [CrossRef]

259. Liu, R.; Li, X.; Zhu, W.; Wang, Y.; Zhao, D.; Wang, X.; Gurley, E.C.; Liang, G.; Chen, W.; Lai, G.; et al. Cholangiocyte-Derived Exosomal Long Noncoding RNA H19 Promotes Hepatic Stellate Cell Activation and Cholestatic Liver Fibrosis. Hepatology 2019, 70, 1317-1335. [CrossRef]

260. Al Suraih, M.S.; Trussoni, C.E.; Splinter, P.L.; LaRusso, N.F.; O’Hara, S.P. Senescent cholangiocytes release extracellular vesicles that alter target cell phenotype via the epidermal growth factor receptor. Liver Int. 2020, 40, 2455-2468. [CrossRef]

261. Kostallari, E.; Hirsova, P.; Prasnicka, A.; Verma, V.K.; Yaqoob, U.; Wongjarupong, N.; Roberts, L.R.; Shah, V.H. Hepatic stellate cell-derived platelet-derived growth factor receptor-alpha-enriched extracellular vesicles promote liver fibrosis in mice through SHP2. Hepatology 2018, 68, 333-348. [CrossRef]

262. Gao, J.; Wei, B.; de Assuncao, T.M.; Liu, Z.; Hu, X.; Ibrahim, S.; Cooper, S.A.; Cao, S.; Shah, V.H.; Kostallari, E. Hepatic stellate cell autophagy inhibits extracellular vesicle release to attenuate liver fibrosis. J. Hepatol. 2020, 73, 1144-1154. [CrossRef] [PubMed]

263. Chen, J.; Yu, Y.; Li, S.; Liu, Y.; Zhou, S.; Cao, S.; Yin, J.; Li, G. MicroRNA-30a ameliorates hepatic fibrosis by inhibiting Beclin1mediated autophagy. J. Cell. Mol. Med. 2017, 21, 3679-3692. [CrossRef]

264. Wan, L.; Xia, T.; Du, Y.; Liu, J.; Xie, Y.; Zhang, Y.; Guan, F.; Wu, J.; Wang, X.; Shi, C. Exosomes from activated hepatic stellate cells contain GLUT1 and PKM2: A role for exosomes in metabolic switch of liver nonparenchymal cells. FASEB J. 2019, 33, 8530-8542. [CrossRef] [PubMed]

265. Chen, L.; Brigstock, D.R. Integrins and heparan sulfate proteoglycans on hepatic stellate cells (HSC) are novel receptors for HSC-derived exosomes. FEBS Lett. 2016, 590, 4263-4274. [CrossRef]

266. Fang, P.P.; Pan, C.W.; Lin, W.; Li, J.; Huang, S.S.; Zhou, G.Y.; Du, W.J.; Li, Q. ASK1 Enhances Angiotensin II-Induced Liver Fibrosis In Vitro by Mediating Endoplasmic Reticulum Stress-Dependent Exosomes. Mediat. Inflamm. 2020, 2020, 8183713. [CrossRef] [PubMed]

267. Li, X.; Chen, R.; Kemper, S.; Brigstock, D.R. Dynamic Changes in Function and Proteomic Composition of Extracellular Vesicles from Hepatic Stellate Cells during Cellular Activation. Cells 2020, 9, 290. [CrossRef] [PubMed] 
268. Lemoinne, S.; Cadoret, A.; Rautou, P.E.; El Mourabit, H.; Ratziu, V.; Corpechot, C.; Rey, C.; Bosselut, N.; Barbu, V.; Wendum, D.; et al. Portal myofibroblasts promote vascular remodeling underlying cirrhosis formation through the release of microparticles. Hepatology 2015, 61, 1041-1055. [CrossRef] [PubMed]

269. Wang, R.; Ding, Q.; Yaqoob, U.; de Assuncao, T.M.; Verma, V.K.; Hirsova, P.; Cao, S.; Mukhopadhyay, D.; Huebert, R.C.; Shah, V.H. Exosome Adherence and Internalization by Hepatic Stellate Cells Triggers Sphingosine 1-Phosphate-dependent Migration. J. Biol. Chem. 2015, 290, 30684-30696. [CrossRef]

270. Chen, L.; Yao, X.; Yao, H.; Ji, Q.; Ding, G.; Liu, X. Exosomal miR-103-3p from LPS-activated THP-1 macrophage contributes to the activation of hepatic stellate cells. FASEB J. 2020, 34, 5178-5192. [CrossRef]

271. Khodayari, N.; Oshins, R.; Holliday, L.S.; Clark, V.; Xiao, Q.; Marek, G.; Mehrad, B.; Brantly, M. Alpha-1 antitrypsin deficient individuals have circulating extracellular vesicles with profibrogenic cargo. Cell Commun. Signal. 2020, 18, 140. [CrossRef]

272. Kim, D.K.; Cho, Y.E.; Komarow, H.D.; Bandara, G.; Song, B.J.; Olivera, A.; Metcalfe, D.D. Mastocytosis-derived extracellular vesicles exhibit a mast cell signature, transfer KIT to stellate cells, and promote their activation. Proc. Natl. Acad. Sci. USA 2018, 115, E10692-E10701. [CrossRef] [PubMed]

273. Rong, X.; Liu, J.; Yao, X.; Jiang, T.; Wang, Y.; Xie, F. Human bone marrow mesenchymal stem cells-derived exosomes alleviate liver fibrosis through the Wnt/beta-catenin pathway. Stem Cell Res. Ther. 2019, 10, 98. [CrossRef]

274. Nishi, M.; Matsumoto, T.; Fujisawa, K.; Suehiro, Y.; Takami, T.; Yamamoto, N.; Yamasaki, T.; Sakaida, I. Mesenchymal Stem Cells Induce a Fibrolytic Phenotype by Regulating mmu-miR-6769b-5p Expression in Macrophages. Stem Cells Dev. 2020, 29, 1457-1466. [CrossRef]

275. Lou, G.; Yang, Y.; Liu, F.; Ye, B.; Chen, Z.; Zheng, M.; Liu, Y. MiR-122 modification enhances the therapeutic efficacy of adipose tissue-derived mesenchymal stem cells against liver fibrosis. J. Cell. Mol. Med. 2017, 21, 2963-2973. [CrossRef]

276. Du, Z.; Wu, T.; Liu, L.; Luo, B.; Wei, C. Extracellular vesicles-derived miR-150-5p secreted by adipose-derived mesenchymal stem cells inhibits CXCL1 expression to attenuate hepatic fibrosis. J. Cell. Mol. Med. 2020. [CrossRef]

277. Qu, Y.; Zhang, Q.; Cai, X.; Li, F.; Ma, Z.; Xu, M.; Lu, L. Exosomes derived from miR-181-5p-modified adipose-derived mesenchymal stem cells prevent liver fibrosis via autophagy activation. J. Cell. Mol. Med. 2017, 21, 2491-2502. [CrossRef] [PubMed]

278. Zhu, M.; Liu, X.; Li, W.; Wang, L. Exosomes derived from mmu_circ_0000623-modified ADSCs prevent liver fibrosis via activating autophagy. Hum. Exp. Toxicol. 2020, 39, 1619-1627. [CrossRef] [PubMed]

279. Jiang, W.; Tan, Y.; Cai, M.; Zhao, T.; Mao, F.; Zhang, X.; Xu, W.; Yan, Z.; Qian, H.; Yan, Y. Human Umbilical Cord MSC-Derived Exosomes Suppress the Development of CCl4-Induced Liver Injury through Antioxidant Effect. Stem Cells Int. 2018, 2018, 6079642. [CrossRef]

280. Li, T.; Yan, Y.; Wang, B.; Qian, H.; Zhang, X.; Shen, L.; Wang, M.; Zhou, Y.; Zhu, W.; Li, W.; et al. Exosomes derived from human umbilical cord mesenchymal stem cells alleviate liver fibrosis. Stem Cells Dev. 2013, 22, 845-854. [CrossRef]

281. Kim, J.; Lee, C.; Shin, Y.; Wang, S.; Han, J.; Kim, M.; Kim, J.M.; Shin, S.C.; Lee, B.J.; Kim, T.J.; et al. sEVs from tonsil-derived mesenchymal stromal cells alleviate activation of hepatic stellate cells and liver fibrosis through miR-486-5p. Mol. Ther. 2020, 29, 1471-1486. [CrossRef]

282. Fiore, E.; Dominguez, L.M.; Bayo, J.; Malvicini, M.; Atorrasagasti, C.; Rodriguez, M.; Cantero, M.J.; Garcia, M.; Yannarelli, G.; Mazzolini, G. Human umbilical cord perivascular cells-derived extracellular vesicles mediate the transfer of IGF-I to the liver and ameliorate hepatic fibrogenesis in mice. Gene Ther. 2020, 27, 62-73. [CrossRef]

283. Alhomrani, M.; Correia, J.; Zavou, M.; Leaw, B.; Kuk, N.; Xu, R.; Saad, M.I.; Hodge, A.; Greening, D.W.; Lim, R.; et al. The Human Amnion Epithelial Cell Secretome Decreases Hepatic Fibrosis in Mice with Chronic Liver Fibrosis. Front. Pharmacol. 2017, 8, 748. [CrossRef]

284. Ohara, M.; Ohnishi, S.; Hosono, H.; Yamamoto, K.; Yuyama, K.; Nakamura, H.; Fu, Q.; Maehara, O.; Suda, G.; Sakamoto, N. Extracellular Vesicles from Amnion-Derived Mesenchymal Stem Cells Ameliorate Hepatic Inflammation and Fibrosis in Rats. Stem Cells Int. 2018, 2018, 3212643. [CrossRef] [PubMed]

285. Bruno, S.; Pasquino, C.; Herrera Sanchez, M.B.; Tapparo, M.; Figliolini, F.; Grange, C.; Chiabotto, G.; Cedrino, M.; Deregibus, M.C.; Tetta, C.; et al. HLSC-Derived Extracellular Vesicles Attenuate Liver Fibrosis and Inflammation in a Murine Model of Non-alcoholic Steatohepatitis. Mol. Ther. 2020, 28, 479-489. [CrossRef] [PubMed]

286. Shiha, G.; Nabil, A.; Lotfy, A.; Soliman, R.; Hassan, A.A.; Ali, I.S.; Gad, D.F.; Zahran, F. Antifibrotic Effect of Combination of Nilotinib and Stem Cell-Conditioned Media on CCl4-Induced Liver Fibrosis. Stem Cells Int. 2020, 2020, 6574010. [CrossRef]

287. McDaniel, K.; Wu, N.; Zhou, T.; Huang, L.; Sato, K.; Venter, J.; Ceci, L.; Chen, D.; Ramos-Lorenzo, S.; Invernizzi, P.; et al. Amelioration of Ductular Reaction by Stem Cell Derived Extracellular Vesicles in MDR2 Knockout Mice via Lethal-7 microRNA. Hepatology 2019, 69, 2562-2578. [CrossRef] [PubMed]

288. Povero, D.; Pinatel, E.M.; Leszczynska, A.; Goyal, N.P.; Nishio, T.; Kim, J.; Kneiber, D.; de Araujo Horcel, L.; Eguchi, A.; Ordonez, P.M.; et al. Human induced pluripotent stem cell-derived extracellular vesicles reduce hepatic stellate cell activation and liver fibrosis. JCI Insight 2019, 5, e125652. [CrossRef] [PubMed]

289. Mardpour, S.; Hassani, S.N.; Mardpour, S.; Sayahpour, F.; Vosough, M.; Ai, J.; Aghdami, N.; Hamidieh, A.A.; Baharvand, H. Extracellular vesicles derived from human embryonic stem cell-MSCs ameliorate cirrhosis in thioacetamide-induced chronic liver injury. J. Cell Physiol. 2018, 233, 9330-9344. [CrossRef]

290. Chen, L.; Chen, R.; Kemper, S.; Brigstock, D.R. Pathways of production and delivery of hepatocyte exosomes. J. Cell Commun. Signal. 2018, 12, 343-357. [CrossRef] 
291. Li, X.; Chen, R.; Kemper, S.; Brigstock, D.R. Extracellular Vesicles from Hepatocytes Are Therapeutic for Toxin-Mediated Fibrosis and Gene Expression in the Liver. Front. Cell Dev. Biol. 2019, 7, 368. [CrossRef] [PubMed]

292. Luo, N.; Li, J.; Chen, Y.; Xu, Y.; Wei, Y.; Lu, J.; Dong, R. Hepatic stellate cell reprogramming via exosome-mediated CRISPR/dCas9VP64 delivery. Drug Deliv. 2021, 28, 10-18. [CrossRef] [PubMed]

293. Chen, L.; Chen, R.; Kemper, S.; Charrier, A.; Brigstock, D.R. Suppression of fibrogenic signaling in hepatic stellate cells by Twist1-dependent microRNA-214 expression: Role of exosomes in horizontal transfer of Twist1. Am. J. Physiol. Gastrointest. Liver Physiol. 2015, 309, G491-G499. [CrossRef] [PubMed]

294. Chen, L.; Chen, R.; Velazquez, V.M.; Brigstock, D.R. Fibrogenic Signaling Is Suppressed in Hepatic Stellate Cells through Targeting of Connective Tissue Growth Factor (CCN2) by Cellular or Exosomal MicroRNA-199a-5p. Am. J. Pathol. 2016, 186, 2921-2933. [CrossRef] [PubMed]

295. Kornek, M.; Popov, Y.; Libermann, T.A.; Afdhal, N.H.; Schuppan, D. Human T cell microparticles circulate in blood of hepatitis patients and induce fibrolytic activation of hepatic stellate cells. Hepatology 2011, 53, 230-242. [CrossRef]

296. Hou, X.; Yin, S.; Ren, R.; Liu, S.; Yong, L.; Liu, Y.; Li, Y.; Zheng, M.H.; Kunos, G.; Gao, B.; et al. Myeloid cell-specific IL-6 signaling promotes miR-223-enriched exosome production to attenuate NAFLD-associated fibrosis. Hepatology 2020. [CrossRef]

297. Wang, L.; Wang, Y.; Quan, J. Exosomes derived from natural killer cells inhibit hepatic stellate cell activation and liver fibrosis. Hum. Cell 2020, 33, 582-589. [CrossRef]

298. Wang, L.; Wang, Y.; Quan, J. Exosomal miR-223 derived from natural killer cells inhibits hepatic stellate cell activation by suppressing autophagy. Mol. Med. 2020, 26, 81. [CrossRef]

299. Chen, L.; Chen, R.; Kemper, S.; Cong, M.; You, H.; Brigstock, D.R. Therapeutic effects of serum extracellular vesicles in liver fibrosis. J. Extracell. Vesicles 2018, 7, 1461505. [CrossRef]

300. Welsh, J.A.; Scorletti, E.; Clough, G.F.; Englyst, N.A.; Byrne, C.D. Leukocyte extracellular vesicle concentration is inversely associated with liver fibrosis severity in NAFLD. J. Leukoc. Biol. 2018, 104, 631-639. [CrossRef]

301. Murakami, Y.; Toyoda, H.; Tanahashi, T.; Tanaka, J.; Kumada, T.; Yoshioka, Y.; Kosaka, N.; Ochiya, T.; Taguchi, Y.H. Comprehensive miRNA expression analysis in peripheral blood can diagnose liver disease. PLoS ONE 2012, 7, e48366. [CrossRef]

302. Lambrecht, J.; Jan Poortmans, P.; Verhulst, S.; Reynaert, H.; Mannaerts, I.; van Grunsven, L.A. Circulating ECV-Associated miRNAs as Potential Clinical Biomarkers in Early Stage HBV and HCV Induced Liver Fibrosis. Front. Pharmacol. 2017, 8, 56. [CrossRef] [PubMed]

303. Matsuura, K.; Aizawa, N.; Enomoto, H.; Nishiguchi, S.; Toyoda, H.; Kumada, T.; Iio, E.; Ito, K.; Ogawa, S.; Isogawa, M.; et al. Circulating let-7 Levels in Serum Correlate with the Severity of Hepatic Fibrosis in Chronic Hepatitis C. Open Forum Infect. Dis. 2018, 5, ofy268. [CrossRef]

304. Broermann, A.; Schmid, R.; Gabrielyan, O.; Sakowski, M.; Eisele, C.; Keller, S.; Wolff, M.; Baum, P.; Stierstorfer, B.; Huber, J.; et al. Exosomal miRNAs as Potential Biomarkers to Monitor Phosphodiesterase 5 Inhibitor Induced Anti-Fibrotic Effects on CCl4 Treated Rats. Int. J. Mol. Sci. 2020, 22, 382. [CrossRef]

305. Cai, P.; Mu, Y.; Olveda, R.M.; Ross, A.G.; Olveda, D.U.; McManus, D.P. Serum Exosomal miRNAs for Grading Hepatic Fibrosis Due to Schistosomiasis. Int. J. Mol. Sci. 2020, 21, 3560. [CrossRef]

306. Lunardi, S.; Muschel, R.J.; Brunner, T.B. The stromal compartments in pancreatic cancer: Are there any therapeutic targets? Cancer Lett. 2014, 343, 147-155. [CrossRef] [PubMed]

307. Lew, D.; Afghani, E.; Pandol, S. Chronic Pancreatitis: Current Status and Challenges for Prevention and Treatment. Dig. Dis. Sci. 2017, 62, 1702-1712. [CrossRef] [PubMed]

308. Apte, M.; Pirola, R.C.; Wilson, J.S. Pancreatic stellate cell: Physiologic role, role in fibrosis and cancer. Curr. Opin. Gastroenterol. 2015, 31, 416-423. [CrossRef]

309. Xue, R.; Jia, K.; Wang, J.; Yang, L.; Wang, Y.; Gao, L.; Hao, J. A Rising Star in Pancreatic Diseases: Pancreatic Stellate Cells. Front. Physiol. 2018, 9, 754. [CrossRef]

310. Korc, M. Pancreatic cancer-associated stroma production. Am. J. Surg. 2007, 194, S84-S86. [CrossRef]

311. Farran, B.; Nagaraju, G.P. The dynamic interactions between the stroma, pancreatic stellate cells and pancreatic tumor development: Novel therapeutic targets. Cytokine Growth Factor Rev. 2019, 48, 11-23. [CrossRef]

312. Ali, S.; Suresh, R.; Banerjee, S.; Bao, B.; Xu, Z.; Wilson, J.; Philip, P.A.; Apte, M.; Sarkar, F.H. Contribution of microRNAs in understanding the pancreatic tumor microenvironment involving cancer associated stellate and fibroblast cells. Am. J. Cancer Res. 2015, 5, 1251-1264.

313. Takikawa, T.; Masamune, A.; Yoshida, N.; Hamada, S.; Kogure, T.; Shimosegawa, T. Exosomes Derived from Pancreatic Stellate Cells: MicroRNA Signature and Effects on Pancreatic Cancer Cells. Pancreas 2017, 46, 19-27. [CrossRef] [PubMed]

314. Li, M.; Guo, H.; Wang, Q.; Chen, K.; Marko, K.; Tian, X.; Yang, Y. Pancreatic stellate cells derived exosomal miR-5703 promotes pancreatic cancer by downregulating CMTM4 and activating PI3K/Akt pathway. Cancer Lett. 2020, 490, 20-30. [CrossRef]

315. Ma, Q.; Wu, H.; Xiao, Y.; Liang, Z.; Liu, T. Upregulation of exosomal microRNA21 in pancreatic stellate cells promotes pancreatic cancer cell migration and enhances Ras/ERK pathway activity. Int. J. Oncol. 2020, 56, 1025-1033. [CrossRef] [PubMed]

316. Zhang, Y.F.; Zhou, Y.Z.; Zhang, B.; Huang, S.F.; Li, P.P.; He, X.M.; Cao, G.D.; Kang, M.X.; Dong, X.; Wu, Y.L. Pancreatic cancer-derived exosomes promoted pancreatic stellate cells recruitment by pancreatic cancer. J. Cancer 2019, 10, 4397-4407. [CrossRef] 
317. Masamune, A.; Yoshida, N.; Hamada, S.; Takikawa, T.; Nabeshima, T.; Shimosegawa, T. Exosomes derived from pancreatic cancer cells induce activation and profibrogenic activities in pancreatic stellate cells. Biochem. Biophys. Res. Commun. 2018, 495, 71-77. [CrossRef] [PubMed]

318. Rodrigues, M.; Kosaric, N.; Bonham, C.A.; Gurtner, G.C. Wound Healing: A Cellular Perspective. Physiol. Rev. 2019, 99, 665-706. [CrossRef]

319. Martin, P.; Nunan, R. Cellular and molecular mechanisms of repair in acute and chronic wound healing. Br. J. Dermatol. 2015, 173, 370-378. [CrossRef]

320. Lingzhi, Z.; Meirong, L.; Xiaobing, F. Biological approaches for hypertrophic scars. Int. Wound J. 2020, 17, 405-418. [CrossRef]

321. Berman, B.; Maderal, A.; Raphael, B. Keloids and Hypertrophic Scars: Pathophysiology, Classification, and Treatment. Dermatol. Surg. 2017, 43 (Suppl. 1), S3-S18. [CrossRef]

322. Mari, W.; Alsabri, S.G.; Tabal, N.; Younes, S.; Sherif, A.; Simman, R. Novel Insights on Understanding of Keloid Scar: Article Review. J. Am. Coll. Clin. Wound Spec. 2015, 7, 1-7. [CrossRef] [PubMed]

323. Denton, C.P.; Khanna, D. Systemic sclerosis. Lancet 2017, 390, 1685-1699. [CrossRef]

324. Zeiser, R.; Blazar, B.R. Pathophysiology of Chronic Graft-versus-Host Disease and Therapeutic Targets. N. Engl. J. Med. 2017, 377, 2565-2579. [CrossRef]

325. Iversen, L.V.; Ullman, S.; Ostergaard, O.; Nielsen, C.T.; Halberg, P.; Karlsmark, T.; Heegaard, N.H.; Jacobsen, S. Cross-sectional study of soluble selectins, fractions of circulating microparticles and their relationship to lung and skin involvement in systemic sclerosis. BMC Musculoskelet. Disord. 2015, 16, 191. [CrossRef] [PubMed]

326. Nakamura, K.; Jinnin, M.; Harada, M.; Kudo, H.; Nakayama, W.; Inoue, K.; Ogata, A.; Kajihara, I.; Fukushima, S.; Ihn, H. Altered expression of CD63 and exosomes in scleroderma dermal fibroblasts. J. Dermatol. Sci. 2016, 84, 30-39. [CrossRef]

327. Li, L.; Zuo, X.; Xiao, Y.; Liu, D.; Luo, H.; Zhu, H. Neutrophil-derived exosome from systemic sclerosis inhibits the proliferation and migration of endothelial cells. Biochem. Biophys. Res. Commun. 2020, 526, 334-340. [CrossRef]

328. Wermuth, P.J.; Piera-Velazquez, S.; Jimenez, S.A. Exosomes isolated from serum of systemic sclerosis patients display alterations in their content of profibrotic and antifibrotic microRNA and induce a profibrotic phenotype in cultured normal dermal fibroblasts. Clin. Exp. Rheumatol. 2017, 35 (Suppl. 106), 21-30.

329. Li, L.; Zuo, X.; Liu, D.; Luo, H.; Zhu, H. The profiles of miRNAs and lncRNAs in peripheral blood neutrophils exosomes of diffuse cutaneous systemic sclerosis. J. Dermatol. Sci. 2020, 98, 88-97. [CrossRef]

330. Moulin, V.J.; Mayrand, D.; Messier, H.; Martinez, M.C.; Lopez-Valle, C.A.; Genest, H. Shedding of microparticles by myofibroblasts as mediator of cellular cross-talk during normal wound healing. J. Cell. Physiol. 2010, 225, 734-740. [CrossRef]

331. Lai, P.; Chen, X.; Guo, L.; Wang, Y.; Liu, X.; Liu, Y.; Zhou, T.; Huang, T.; Geng, S.; Luo, C.; et al. A potent immunomodulatory role of exosomes derived from mesenchymal stromal cells in preventing cGVHD. J. Hematol. Oncol. 2018, 11, 135. [CrossRef]

332. Fang, S.; Xu, C.; Zhang, Y.; Xue, C.; Yang, C.; Bi, H.; Qian, X.; Wu, M.; Ji, K.; Zhao, Y.; et al. Umbilical Cord-Derived Mesenchymal Stem Cell-Derived Exosomal MicroRNAs Suppress Myofibroblast Differentiation by Inhibiting the Transforming Growth Factorbeta/SMAD2 Pathway During Wound Healing. Stem Cells Transl. Med. 2016, 5, 1425-1439. [CrossRef] [PubMed]

333. Guo, L.; Lai, P.; Wang, Y.; Huang, T.; Chen, X.; Geng, S.; Huang, X.; Luo, C.; Wu, S.; Ling, W.; et al. Extracellular vesicles derived from mesenchymal stem cells prevent skin fibrosis in the cGVHD mouse model by suppressing the activation of macrophages and B cells immune response. Int. Immunopharmacol. 2020, 84, 106541. [CrossRef]

334. Zhao, B.; Zhang, Y.; Han, S.; Zhang, W.; Zhou, Q.; Guan, H.; Liu, J.; Shi, J.; Su, L.; Hu, D. Exosomes derived from human amniotic epithelial cells accelerate wound healing and inhibit scar formation. J. Mol. Histol. 2017, 48, 121-132. [CrossRef] [PubMed]

335. Bruno, S.; Kholia, S.; Deregibus, M.C.; Camussi, G. The Role of Extracellular Vesicles as Paracrine Effectors in Stem Cell-Based Therapies. Adv. Exp. Med. Biol. 2019, 1201, 175-193. [CrossRef]

336. Shao, L.; Zhang, Y.; Lan, B.; Wang, J.; Zhang, Z.; Zhang, L.; Xiao, P.; Meng, Q.; Geng, Y.J.; Yu, X.Y.; et al. MiRNA-Sequence Indicates That Mesenchymal Stem Cells and Exosomes Have Similar Mechanism to Enhance Cardiac Repair. Biomed. Res. Int. 2017, 2017, 4150705. [CrossRef]

337. Baixauli, F.; Lopez-Otin, C.; Mittelbrunn, M. Exosomes and autophagy: Coordinated mechanisms for the maintenance of cellular fitness. Front. Immunol. 2014, 5, 403. [CrossRef]

338. Xu, J.; Camfield, R.; Gorski, S.M. The interplay between exosomes and autophagy-Partners in crime. J. Cell Sci. 2018, 131, jcs215210. [CrossRef] [PubMed]

339. Xing, H.; Tan, J.; Miao, Y.; Lv, Y.; Zhang, Q. Crosstalk between exosomes and autophagy: A review of molecular mechanisms and therapies. J. Cell. Mol. Med. 2021, 25, 2297-2308. [CrossRef]

340. Ye, H.L.; Zhang, J.W.; Chen, X.Z.; Wu, P.B.; Chen, L.; Zhang, G. Ursodeoxycholic acid alleviates experimental liver fibrosis involving inhibition of autophagy. Life Sci. 2020, 242, 117175. [CrossRef]

341. Toh, W.S.; Lai, R.C.; Zhang, B.; Lim, S.K. MSC exosome works through a protein-based mechanism of action. Biochem. Soc. Trans. 2018, 46, 843-853. [CrossRef]

342. Chevillet, J.R.; Kang, Q.; Ruf, I.K.; Briggs, H.A.; Vojtech, L.N.; Hughes, S.M.; Cheng, H.H.; Arroyo, J.D.; Meredith, E.K.; Gallichotte, E.N.; et al. Quantitative and stoichiometric analysis of the microRNA content of exosomes. Proc. Natl. Acad. Sci. USA 2014, 111, 14888-14893. [CrossRef] [PubMed] 
343. Gho, Y.S.; Lee, C. Emergent properties of extracellular vesicles: A holistic approach to decode the complexity of intercellular communication networks. Mol. Biosyst. 2017, 13, 1291-1296. [CrossRef] [PubMed]

344. Matsuura, K.; De Giorgi, V.; Schechterly, C.; Wang, R.Y.; Farci, P.; Tanaka, Y.; Alter, H.J. Circulating let-7 levels in plasma and extracellular vesicles correlate with hepatic fibrosis progression in chronic hepatitis C. Hepatology 2016, 64, 732-745. [CrossRef] [PubMed] 